Universidade de São Paulo

Faculdade de Medicina de Ribeirão Preto

\title{
2018
}

Influência socioeconômica no desempenho da marcha de idosos residentes em regiões com diferentes índices de

Desenvolvimento Humano
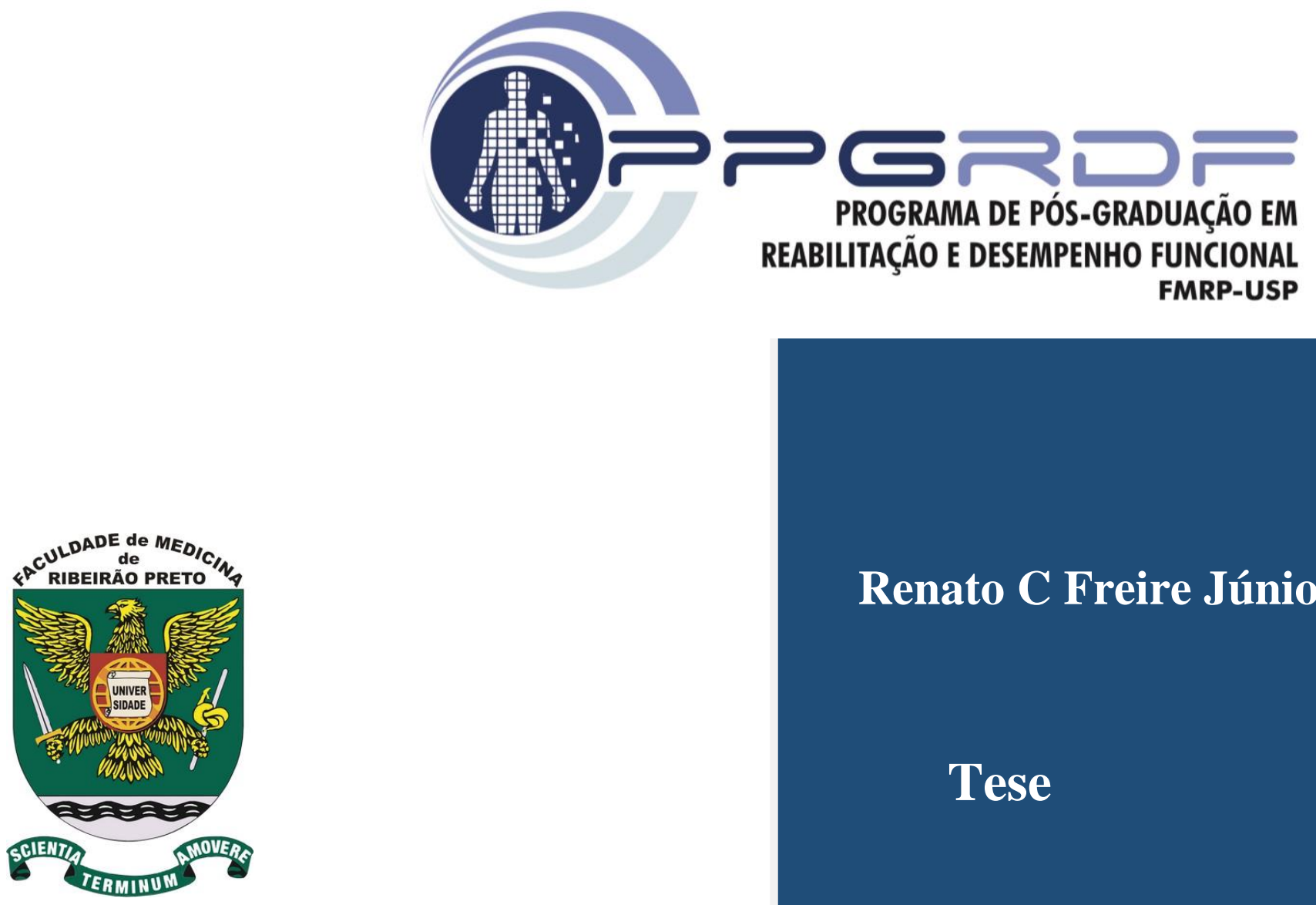

Renato C Freire Júnior

Tese 
UNIVERSIDADE DE SÃO PAULO

Faculdade de Medicina de Ribeirão Preto

Departamento de Ciências da Saúde

RENATO CAMPOS FREIRE JÚNIOR

Influência socioeconômica no desempenho da marcha de idosos residentes em regiões com diferentes índices de Desenvolvimento Humano

Ribeirão Preto 


\section{Influência socioeconômica no desempenho da marcha de idosos residentes em regiões com diferentes índices de Desenvolvimento Humano}

Tese apresentada a Faculdade de Medicina de Ribeirão Preto, Universidade de São Paulo, para obtenção do título de Doutor em Reabilitação e Ciência da Saúde.

Programa de Pós-graduação em Reabilitação e Desempenho Funcional

Área de concentração: Fisioterapia

Orientadora: Profa. Dra. Daniela Cristina Carvalho de Abreu

Colaboradores: Prof Dr. Manuel Montero-Odasso

Jaqueline Mello Porto

Larissa Bocarde

Júlia Adorno Fernandes

Ribeirão Preto - SP 
Autorizo a reprodução e divulgação total ou parcial deste trabalho, por qualquer meio convencional ou eletrônico, para fins de estudo e pesquisa, desde que citada à fonte.

\section{FICHA CATALOGRÁFICA}

Faculdade de Medicina da Universidade de São Paulo

Freire Júnior, Renato Campos.

Influência socioeconômica no desempenho da marcha de idosos residentes em regiões com diferentes índices de Desenvolvimento Humano / Renato Campos Freire Júnior; orientadora Daniela Cristina Carvalho de Abreu - Ribeirão Preto, 2018. f.:119.

Tese de Doutorado. Universidade de São Paulo, 2018.

1. Fisioterapia. 2. Idosos. 3. Marcha. 4. Fatores socioeconômicos. 5. Educação. 6. Índice de Desenvolvimento Humano. de Abreu, Daniela Cristina Carvalho. 


\section{Dedicatória}


Por tudo que representam e por serem minhas maiores inspirações e exemplo, dedico este trabalho aos meus amados pais, Renato e Gildete Freire 
Agradecimentos 


\section{Agradeço:}

A Deus, por guiar meus passos e permitir vivenciar essa caminhada de crescimento pessoal e profissional.

Um agradecimento muito especial à Prof. Dra. Daniela Cristina Carvalho de Abreu, por ser, além de uma orientadora admirável, uma grande amiga e inspiração de conduta profissional e pessoal. Agradeço do fundo do meu coração sua amizade e todo o seu apoio ao longo deste trabalho. Seus ensinamentos foram fundamentais para o meu crescimento $e$ amadurecimento profissional nesse processo de doutoramento. Obrigado por acreditar em mim. Me sinto muito honrado pela oportunidade de aprender com você. Que a minha vida profissional me permita seguir teus passos, pisando exatamente sobre as suas pegadas!

Ao Prof, Dr. Manuel Montero-Odasso e toda a equipe do "Gait and Brain Lab" por me receberem com tanto carinho no meu estágio sanduíche na University Western of Ontario, fazendo com que eu me sentisse em casa. Agradeço toda a ajuda oferecida neste período especial do meu doutorado.

Ao Dr. Frederico Pieruccini-Faria pela amizade e ensinamentos valiosos durante o meu estágio sanduíche. Sua ajuda e conselhos foram fundamentais. 
Aos amigos do Laboratório de Avaliação e Reabilitação do Equilíbrio, por toda ajuda, pela amizade, e pelas agradáveis conversas e risadas durante o “cafezinho do LARE”.

Ao querido trio, Jaqueline Mello Porto, Júlia Adorno Fernandes e Larissa Bocarde pela parceria e ajuda fundamental na condução deste trabalho em Ribeirão Preto.

Aos alunos de iniciação científica da UFAM e ao grupo de trabalho do “Estudo da Saúde e Fragilidade do Idoso da Amazônia” - ESFRIA pela ajuda nas coletas e avaliações dos idosos em Coari-AM.

Aos amigos de Ribeirão Preto, por me acolherem carinhosamente, por todos os momentos de ajuda e distração. Vocês fizeram desse processo um período muito feliz.

Ao meu pai, minha mãe e meu grande irmão Roberto, pelo suporte e apoio incondicional. Vocês são meu porto seguro!

À minha companheira de vida, Tatiane. Obrigado por estar sempre ao meu lado e por escolher trilhar comigo esse caminho. Sua presença, sua força e alegria foram decisivos para a conclusão desse ciclo. Esse trabalho também é seu. Muito obrigado pela parceria e companheirismo meu amor! 
Ao grande amigo Fernando Abreu, na qual estendo esse agradecimento a toda família Carvalho pelo acolhimento e amizade. Vocês nos receberam, eu e Tati, com muito carinho e seremos eternamente gratos. Obrigado pelo apoio e por se tornarem nossa família do coração.

À UFAM - Universidade Federal do Amazonas pelo apoio e incentivo através de minha liberação para que eu pudesse cursar o doutorado.

À FAPEAM - Fundação de Amparo a pesquisa do Estado do Amazonas, pelo respaldo científico e financeiro concedendo a bolsa de doutorado (edital 003/2014).

À CAPES - Coordenação de Aperfeiçoamento de Pessoal de Nível Superior pelo respaldo científico e financeiro concedendo a bolsa de estágio sanduíche (processo 88881.134675/2016-01).

Á Faculdade de Medicina de Ribeirão Preto pela oportunidade de realização deste doutorado e ao secretário do programa da pós-graduação, Samuel Ribeiro Filipini por sua disponibilidade em ajudar sempre que era necessário.

E aos idosos voluntários da pesquisa. Sem vocês a realização deste trabalho não seria possível. 


\section{Epígrafe}


"O cientista não é o homem que fornece as verdadeiras respostas; é quem faz as verdadeiras perguntas" 
Resumo 


\section{RESUMO}

FREIRE JÚNIOR, R. C. Influência socioeconômica no desempenho da marcha de idosos residentes em regiões com diferentes índices de desenvolvimento humano. 2018. 116 f. Tese (Doutorado) - Faculdade de Medicina de Ribeirão Preto, Universidade de São Paulo, Ribeirão Preto, 2018

Fatores socioeconômicos tem sido associado com problemas relacionados à saúde, entretanto nenhum estudo investigou especificamente o impacto a longo prazo das diferenças socioeconômicas no desempenho da marcha. O objetivo deste estudo foi avaliar o desempenho da marcha de idosos nascidos, criados e vivendo atualmente em regiões com diferentes Índices de Desenvolvimento Humano (IDH) sob a marcha habitual e em condições de dupla-tarefa. Métodos: Estudo transversal multi-país conduzido com uma amostra de 373 idosos divididos em três regiões com diferentes IDH's: Coari, estado do Amazonas, Brasil ( $\mathrm{n}=124$, IDH-baixo = 0,586); Ribeirão Preto, estado de São Paulo, Brasil ( $\mathrm{n}=109$, IDH-alto = 0,800); e London, Província de Ontario, Canadá $(\mathrm{n}=140$, IDH-muito alto = 0,905). Informações sobre dados socioeconômicos, demográficos, condições de saúde e histórico de quedas nos últimos seis meses foram registrados, e a função física dos membros inferiores foi avaliada pelo Short Physical Perfomance Battery (SPPB). O desempenho da marcha foi avaliado utilizando GAITRite Platinum 26' Portable Walkway System em duas situações diferentes: marcha habitual e marcha associada a dupla-tarefa (nomear animais enquanto caminha). As variáveis de interesse foram: velocidade $(\mathrm{cm} / \mathrm{s})$, cadência (passos $/ \mathrm{min})$, tempo da passada (milissegundos), comprimento do passo $(\mathrm{cm})$ e largura da passada $(\mathrm{cm})$, além da variabilidade da marcha e o custo da dupla-tarefa para cada variável. A análise de comparação entre os grupos no desempenho da marcha, foi realizada usando um modelo linear geral multivariado, e a variabilidade da marcha, bem como o custo da dupla-tarefa analisados pela ANOVA one-way. O teste post-hoc de Bonferroni foi usado para determinar as diferenças entre os grupos quando apropriado. Os modelos estatísticos foram ajustados por várias covariáveis, incluindo anos de estudo. Resultados: idosos do grupo IDH-baixo apresentaram menor velocidade, menor cadência, maior tempo da passada, comprimento do passo mais curto comparado com os idosos dos outros dois grupos, IDH-alto e IDH-muito alto, e menor largura da passada comparado ao grupo 
IDH-alto. Maior variabilidade do comprimento do passo foi encontrada no grupo IDHmuito alto comparado aos dois grupos brasileiros, IDH-baixo e IDH-alto. O custo da dupla-tarefa na marcha para velocidade, comprimento do passo e variabilidade do comprimento do passo foi maior entre os idosos do grupo IDH-baixo quando comparados aos outros dois grupos. As diferenças estatísticas foram atenuadas, mas não desapareceram após o ajuste por anos de educação. Conclusões: Idosos vivendo em regiões com baixo IDH apresentam pior desempenho da marcha durante a tarefa simples (habitual) e em condições de dupla-tarefa comparados com idosos que vivem em regiões com alto ou muito alto IDH. Menos anos de escolaridade pode limitar a capacidade de processamento central dos idosos, afetando potencialmente o desempenho da marcha.

Palavras-chaves: Caminhada, Marcha, Fatores socioeconômicos, educação, Índice de Desenvolvimento Humano 
Abstract 


\begin{abstract}
FREIRE JÚNIOR, R. C. Socioeconomic influence on gait performance of older adults living in regions with different Human Development indexes. 2018. $116 \mathrm{f}$. Tese (Doutorado) - Faculdade de Medicina de Ribeirão Preto, Universidade de São Paulo, Ribeirão Preto, 2018
\end{abstract}

Socioeconomic factors have been associated with health-related problems, however no study has specifically investigated the long-term impact of socioeconomic differences on gait performance. The aim of this study was to assess gait patterns of older adults born, raised and currently living in regions with different Human Development Indexes (HDI), under single and dual-task conditions. Methods: This is a cross-sectional multi-country design study conducted with a sample of 373 older adults divided into three regions with different HDIs: Coari, Amazonas state, Brazil $(n=124$, Low-HDI = 0.586); Ribeirão Preto, São Paulo state, Brazil $(n=109$, High-HDI = 0.800); and London, Ontario, Canada $(n=140$, Very high-HDI $=0.905)$. Socioeconomic, demographics, health conditions and history of falls in the last six months information were recorded, and the physical function of the lower limbs was assessed by the Short Physical Performance Battery (SPPB). Gait performance was assessed using GAITRite Platinum 26 'Portable Walkway System under two conditions: single task (usual pace) and dual-task (walking while naming animals). The interest variables were: gait speed $(\mathrm{cm} / \mathrm{s})$, cadence (steps / $\mathrm{min})$, stride time (milliseconds), step length $(\mathrm{cm})$, step width $(\mathrm{cm})$, gait variability, as well as, dual-task cost for each variable. Gait performance comparison analysis between groups was performed using a general linear model multivariate, and gait variability as well as dual-task cost were analyzed by one-way ANOVA. Bonferroni post-hoc test was used to determine differences between groups when appropriate. The statistical models were adjusted for several covariates, including years of study. Results: Older adults from lowHDI group presented slower gait speed, slower cadence, higher stride time, shorter step length, compared with individuals from both High-HDI and Very high-HDI groups, and shorter stride width compared to High-HDI. Higher step length variability was found in Very High-HDI group compared to both Brazilian groups, Low-HDI, and High-HDI. Dual-task gait cost for gait speed, step length, and step length variability was higher among older adults living in low HDI when compared with high, and very high HDI 
group. The statistical differences between groups were deeply attenuated, but not vanished, after adjusting for years of education. Conclusion: Individuals living in regions with Low-HDI present worse gait performance during single and dual-task conditions compared with individuals living in High- and Very-High HDIs. Fewer years of education may limit central processing capacity of older potentially affecting gait performance.

Key words: walking, gait, socioeconomic factors, education, human development index 


\section{Listas}




\section{LISTA DE FIGURAS}

Figura 1- Fluxograma do processo de seleção dos estudos.

Figura 2- Distribuição dos artigos selecionados para revisão por dimensões do IDH.....42

Figura 3 - Mapa do Brasil destacando o estado do Amazonas - com a delimitação em vermelho do município de Coari, e o estado de São Paulo - com delimitação em vermelho do município de Ribeirão Preto..................................................................60

Figura 4 - Mapa do Canadá destacando uma parte da Província de Ontario e a cidade de London. 62

Figura 5 - Representação gráfica do desempenho da marcha dos grupos na caminhada habitual (tarefa única) e em condição de dupla-tarefa. A, comprimento do passo; B, velocidade da marcha; e C, variabilidade do comprimento do passo.............................74 


\section{LISTA DE TABELAS}

Tabela 1 - Características dos 35 estudos selecionados..............................................35

Tabela 2 - Quadro comparativo das características socioeconômicas entre os dois

municípios brasileiros - Coari - AM e Ribeirão Preto - SP .........................................60

Tabela 3 - Características sociodemográficas e antropométricas dos três grupos...........68

Tabela 4 - Características de saúde e função física dos três grupos................................70

Tabela 5 - Desempenho da marcha habitual dos grupos por IDH...............................72

Tabela 6 - Variabilidade da marcha dos grupos por IDH.........................................73

Tabela 7 - Dados do desempenho da marcha na condição de dupla-tarefa e o custo da

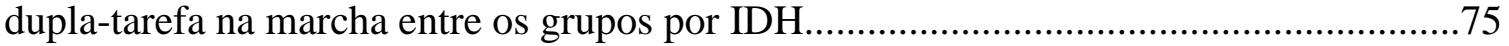




\section{LISTA DE ABREVIATURAS E SIGLAS}

IDH

Índice de Desenvolvimento Humano

PRISMA

Preferred Reporting Items for Systematic Reviews and Meta-

Analyses

NIH

National Institutes of Health

UNDP

United Nations Development Programme

TUG

Time Up and Go

NSE

Nível Socioeconômico

I.E.,

Isto é

EX

Exemplo

IDH's

Índices de Desenvolvimento Humano

TCLE

Termo de Consentimento Livre e Esclarecido

MEEM

Mini Exame do Estado Mental

AM

Amazonas

ISB

Instituto de Saúde e Biotecnologia

UFAM

Universidade Federal do Amazonas

LARE

Laboratório de Avaliação e Reabilitação do Equilíbrio

FMRP

Faculdade de Medicina de Ribeirão Preto

USP

Universidade de São Paulo

$\mathrm{ON}$

Ontário

IBGE

Instituto Brasileiro de Geografia e Estatística

LICO

Low Income Cut Off

IMC

Índice de Massa Corporal

SPPB

Short Physical Performance Battery 
Sumário 


\section{Sumário}

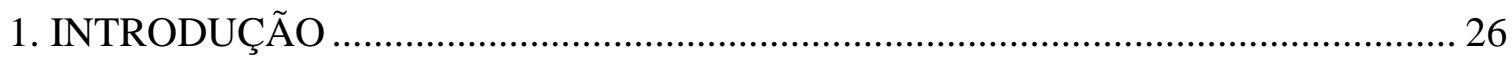

2. DIMENSÕES DO IDH E O DESEMPENHO DA MARCHA EM IDOSOS: UMA

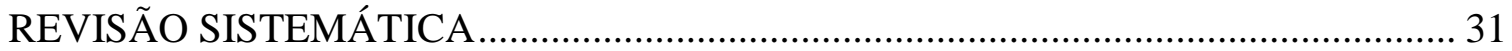

2.1. Construção do estudo de revisão sistemática........................................................... 31

2.2. Características dos artigos encontrados ................................................................. 33

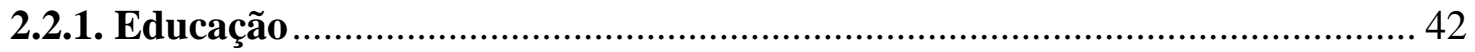

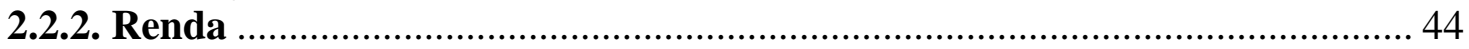

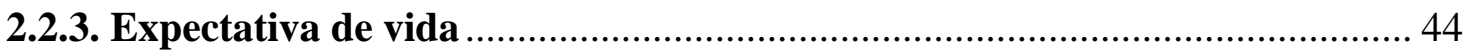

2.2.4. Nível socioeconômico (educação e renda) ………………………………..... 46

2.3. Existem indícios de que a marcha dos idosos possa ser influenciada pelo IDH da região onde viveram por décadas? ................................................................................. 47

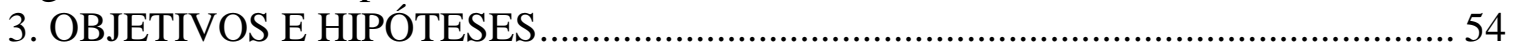

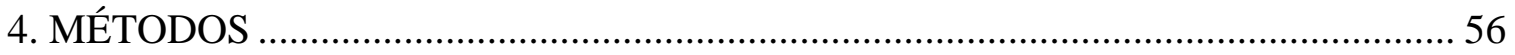

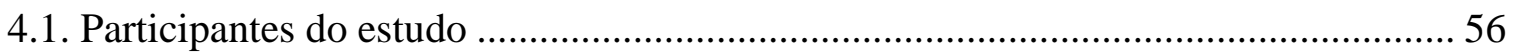

4.2. Características demográficas, sociais e econômicas das regiões ................................. 58

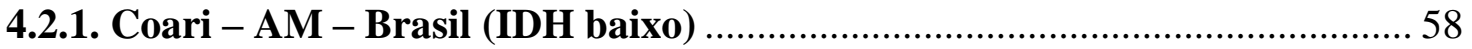

4.2.2. Ribeirão Preto - SP - Brasil (IDH alto) ……………………………........ 59

4.2.2. London - Ontario - Canadá (IDH muito alto) ............................................. 61

4.3. Avaliação sociodemográfica, de saúde e função física............................................. 62

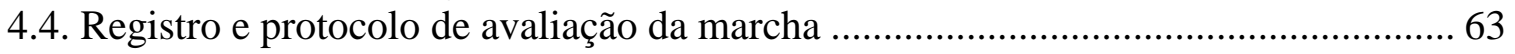

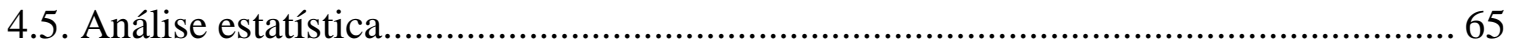

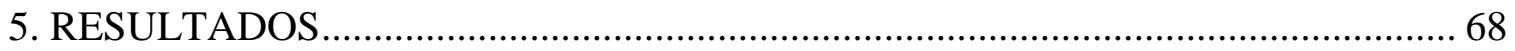

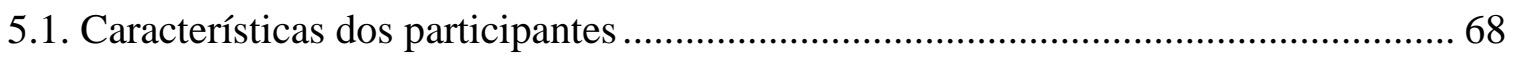

5.2. Desempenho da marcha nos grupos por IDH ......................................................... 71

5.3. Variabilidade da marcha nos grupos por IDH ...................................................... 72

5.4. Custo da dupla-tarefa na marcha nos grupos por IDH............................................ 73

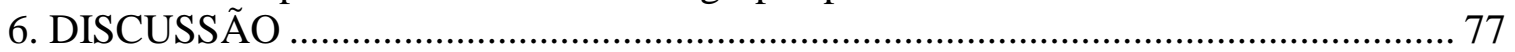

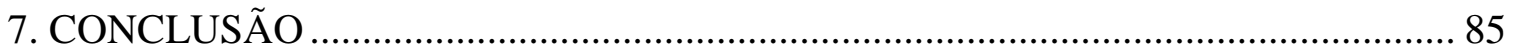

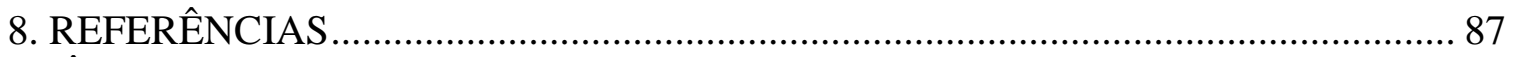

APÊNDICE 1- Termo de Consentimento Livre e Esclarecido ....................................... 102

APÊNDICE 2 - Termos de pesquisa para revisão sistemática........................................ 104

APÊNDICE 3 - Estratégias de pesquisa para PubMed e EMBASE ………………….... 105

APÊNDICE 4 - Questionário Geral ......................................................................... 107

ANEXO I - Aprovação do Comitê de Ética e Pesquisa ................................................... 112

ANEXO II - Short Physical Performance Battery - SPPB ........................................... 115 


\section{Introdução}




\section{INTRODUÇÃO}

$\mathrm{O}$ ato de caminhar é uma habilidade motora fundamental para os idosos na manutenção de uma vida independente, bem como para desempenhar as atividades rotineiras do dia-a-dia como ir ao banheiro, caminhar até o supermercado, ou andar nos entornos de sua rua de forma eficiente. Como um marcador, o desempenho da marcha dos idosos está associado com mudanças na homeostase fisiológica, incapacidades e respostas adversas à saúde no futuro, incluindo quedas, imobilidade, hospitalização, fragilidade e demência (Abellan Van Kan et al., 2009; Fritz \& Lusardi, 2009; Manuel Montero-Odasso et al., 2005).

O controle da marcha envolve não apenas habilidades sensório-motoras periféricas como os sistemas visual, somatosensorial, vestibular e sistema neuromuscular, mas também é controlado pelas funções cognitivas, tais como atenção e função executiva.

Alterações estruturais e funcionais nas regiões corticais do cérebro, incluindo os córtex motor, pré-frontal e parietal, bem como as áreas subcorticais incluindo os gânglios da base e o cerebelo, têm sido associados a declínios no desempenho da marcha (Srikanth, Sanders, Callisaya, Martin, \& Phan, 2010). É importante destacar que o envelhecimento produz alterações nos parâmetros da marcha, o pode ser considerado como uma tentativa de adaptação para alcançar a estabilidade.

Vários estudos têm demonstrado que condições ambientais podem causar estresse para o sistema neurológico de um indivíduo; assim é razoável postular que exposições a longo prazo a estressores ambientais poderia também influenciar no desempenho da marcha. Por exemplo, evidências mostram que o baixo nível socioeconômico (definido por nível educacional, classe ocupacional e riqueza regional) pode aumentar o risco de 
eventos adversos e mortalidade (Coppin et al., 2006). Desta forma, não é de surpreender que indivíduos mais velhos e com baixo nível socioeconômico possam apresentar marcha mais lenta comparados com aqueles que tenham maiores níveis socioeconômicos durante seu curso de vida (Weber, 2016).

Embora o impacto da idade na função orgânica e na marcha seja amplamente discutido na literatura, pouca atenção tem sido dada ao impacto da condição ambiental nessas funções. Existem evidências demonstrando que condições sociais e ambientais como por exemplo educação (Busch et al., 2015; Coppin et al., 2006; Welmer, Kareholt, Rydwik, Angleman, \& Wang, 2013), nível socioeconômico (Thorpe et al., 2011; Weber, 2016), renda (Brunner et al., 2009; Zaninotto, Sacker, \& Head, 2013) e nível de saúde (Sabia et al., 2014; Studenski et al., 2011; Taekema, Gussekloo, Westendorp, de Craen, \& Maier, 2012) podem ter um importante impacto sobre o desempenho da marcha em idosos. Essas condições impactam na integridade orgânica e podem afetar funções neurológicas e musculoesqueléticas durante o curso de vida dos indivíduos.

O Curso de vida é um modelo teórico que busca o entendimento das consequências ao longo da vida, principalmente na fase da velhice, das exposições externas e pode ser definido como o estudo dos efeitos a longo prazo de exposições físicas, socioculturais e econômicas sobre a saúde e/ou a doença (Kuh, Ben-Shlomo, Lynch, Hallqvist, \& Power, 2003). Embora esse conceito esteja presente tradicionalmente nas discussões das ciências sociais, foi a partir da década de 1990 que a perspectiva do curso de vida foi também introduzida para análise de saúde e longevidade (Richter \& Blane, 2013). Desde então, o conhecimento das condições vivenciadas ao longo da vida e 
na velhice em diversas sociedades tem adicionado importantes contribuições para as discussões sobre promoção do envelhecimento saudável.

De fato, as pessoas com maior nível socioeconômico parecem apresentar melhores indicadores de saúde. Avlund, Damsgaard, \& Osler (2004) investigaram a relação entre a posição social e o declínio funcional de uma coorte de homens e mulheres com 75 anos ou mais. Seus resultados mostraram que quanto maior o nível de pobreza material, avaliada pela renda individual e posse/habitação própria, maior foi o declínio funcional e a mortalidade entre os idosos avaliados em ambos os sexos.

Várias condições de saúde podem ser afetadas e/ou influenciadas pelas adversidades sociais e o curso de vida. Estudos prévios tem demonstrado a presença de fragilidade (Alvarado, Zunzunegui, Béland, \& Bamvita, 2008; Gruenewald, Seeman, Karlamangla, \& Sarkisian, 2009), de marcadores inflamatórios e biológicos (Rosa et al., 2011; Tu, Zunzunegui, Guerra, Alvarado, \& Guralnik, 2013); sarcopenia (Sayer \& Cooper, 2006) e menor desempenho físico (Sousa et al., 2014) como exemplos de consequências negativas da exposição a longo prazo dos idosos à condições adversas na vida. Por isso, o status de saúde debilitada pode estar associado a determinantes sociais como pior educação, baixa renda, e o acesso aos cuidados de saúde (Costa-Font \& Hernández-Quevedo, 2012), e dessa forma, identificados como importantes indicadores da influência do ambiente ao longo da vida sobre um indivíduo.

Nos anos 60, as Nações Unidas criaram um índice que estima o nível de condições ambientais importantes para o desenvolvimento humano. $O$ Índice de Desenvolvimento Humano (IDH) é uma medida padronizada composta por três dimensões chaves: educação, estimada como anos esperados de escolaridade e média de 
anos de escolaridade; renda ou padrão de vida estimado como a renda per-capita nacional bruta; e saúde, estimada pela expectativa de vida em anos (United Nations Development Programme, 2016). Desde a sua criação, o IDH tem sido usado para avaliar o bem-estar dos cidadãos na perspectiva do desenvolvimento humano, e no campo político tem ajudado a recomendar políticas que possam melhorar as vidas, escolhas e capacidades de pessoas em uma região ou país. Como medida padronizada, o IDH permite realizar comparações analíticas entre regiões, além de comparações longitudinais para uma mesma região.

Estudos prévios têm apresentado consistentes relações entre baixo IDH e a prevalência de doenças e mortalidade (Soares, Klein, Silva, \& Oliveira, 2016), o bemestar (Cooke, Guimond, \& McWhirter, 2008) e a inatividade física (Dumith, Hallal, Reis, \& Kohl, 2011), os quais estão associados com qualidade de vida e nível de saúde respectivamente. Embora as pesquisas tenham encontrado relações significativas entre IDH e aspectos relacionados à saúde, pouco é conhecido sobre o impacto da exposição por longo tempo à diferentes IDH's sobre o desempenho da marcha na velhice. 


\section{Revisão Sistemática}




\section{DIMENSÕES DO IDH E O DESEMPENHO DA MARCHA EM IDOSOS: UMA REVISÃO SISTEMÁTICA}

Diante da necessidade de se conhecer o que existe na literatura científica a respeito do assunto, uma revisão sistemática de literatura foi conduzida para investigar possíveis associações entre IDH e dimensões do IDH de forma individual (educação, renda e expectativa de vida) e o desempenho da marcha em idosos.

\subsection{Construção do estudo de revisão sistemática}

Esta revisão sistemática foi registrada no Porspective Register of Systematic Reviews - PROSPERO (CRD42017073527), uma base de dados internacional de registro de revisões sistemáticas em saúde a assistência social, saúde púbica, educação e desenvolvimento internacional. As recomendações e critérios do Preferred Reporting items for systematic reviews and Meta-Analyses (PRISMA) foram usados para conduzir essa revisão (Moher, Liberati, Tetzlaff, \& Altman, 2014). A pesquisa bibliográfica foi realizada selecionando artigos publicados no período de 01/1990 a 08/2017. As bases de dados eletrônicas PubMed e EMBASE foram utilizadas para pesquisar por artigos relevantes, e termos MesH e palavras-chaves apropriadas foram aplicados para cada base de dados. Não houve restrição de idioma na pesquisa bibliográfica. Os termos de pesquisa estão descritos no apêndice 2 e a estratégia de busca para PubMed e EMBASE estão apresentadas no apêndice 3. Uma busca manual das referências bibliográficas citadas foi realizada nos artigos finais extraídos para identificar estudos que se encaixavam nos critérios de pesquisa, mas não foram encontrados na busca eletrônica. 
Os artigos encontrados usando a estratégia de busca foram selecionados por título e resumos de acordo com os seguintes critérios de inclusão: indivíduos que viviam na comunidade; idade de 60 anos ou mais; análise de pelo menos uma variável quantitativa da marcha; estudo observacional; Índice de Desenvolvimento Humano (IDH) ou renda ou educação ou expectativa de vida. Ensaios clínicos, relatórios técnicos, resumos publicados em anais de congresso, dissertações e teses foram excluídos do rol de artigos encontrados durante a busca eletrônica.

O instrumento de análise da qualidade de estudos de coorte observacionais e estudos transversais da "National Institutes of Health" (NIH) foi utilizada para avaliar a qualidade dos estudos selecionados (National Heart, Blood and Lung Institute [NIH], 2014). Essa ferramenta possui 14 critérios e avalia a validade interna dos estudos. Cada item recebe uma pontuação que indica a presença de cada critério no artigo selecionado: "Sim" = 1 ponto ou "Não" = 0 ponto. Assim, quanto maior o escore, maior é a qualidade do estudo e menor o risco de viés (anexo 1). Para esta revisão, os artigos foram categorizados como "Bom" (atenderam de 10 a 14 critérios), "Razoável" (atenderam de 5 a 9 critérios), e "Ruim" (atenderam de 0 a 4 critérios) (Woolford, Weller, \& Ibrahim, 2017). Artigos que não atingiram escore mínimo 5 não foram incluídos no estudo. Dois revisores avaliaram independentemente a qualidade dos estudos. Desacordo (s) entre os revisores em relação a elegibilidade e pontuação de qualidade foram resolvidos por um terceiro revisor sênior.

As seguintes informações foram extraídas dos artigos selecionados para análise final nesta revisão sistemática, incluindo: autores, data da publicação, características dos participantes (sexo, idade, local de residência), desenho do estudo (transversal ou 
longitudinal), protocolo de avaliação da marcha, medidas da marcha, variável de nível individual relacionada às dimensões do IDH analisadas e resultados. A variável independente extraída de cada estudo foi categorizada de acordo com as dimensões do IDH - educação, renda e expectativa de vida.

\subsection{Características dos artigos encontrados}

O processo de seleção dos artigos está representado no fluxograma da figura 1.

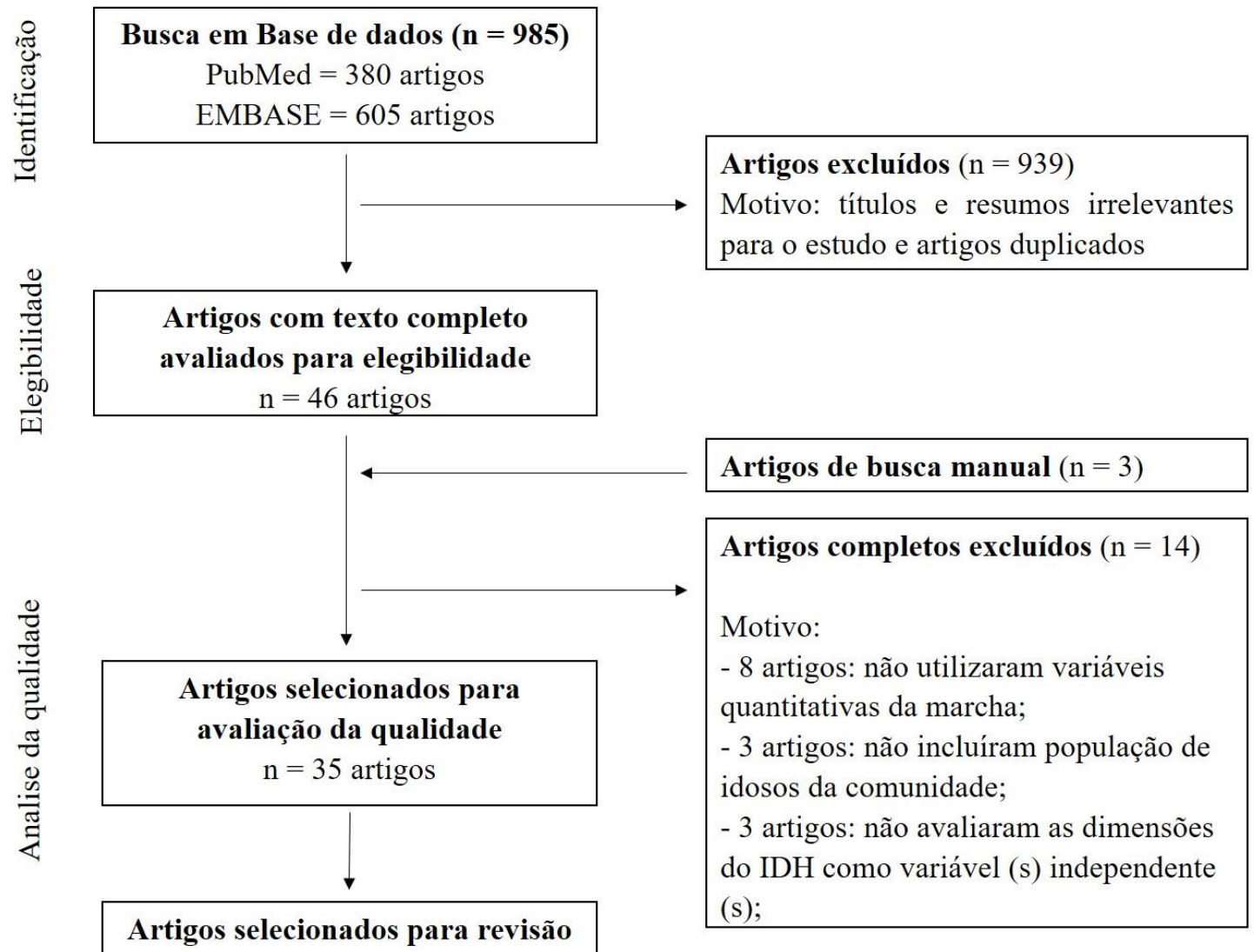

$\mathrm{n}=35$ artigos

Figura 1 - Fluxograma do processo de seleção dos estudos 
Um total de 985 artigos foram inicialmente identificados pela busca eletrônica na PubMed $(\mathrm{n}=380)$ e EMBASE $(\mathrm{n}=605)$; no entanto, apenas 46 artigos foram selecionados para análise posterior $($ PubMed $=29$; EMBASE $=17)$. Quatorze artigos não atenderam aos critérios de inclusão e 3 artigos foram incluídos por pesquisa manual, permanecendo assim 35 artigos para a etapa de análise de qualidade. Após a análise da qualidade, todos os 35 artigos foram incluídos nesta revisão sistemática. Dos 35 artigos, 10 artigos eram estudos transversais e 25 longitudinais, publicados entre 1999 a 2016 (tabela 1). 
Tabela 1 - Características dos 35 estudos selecionados

\begin{tabular}{|c|c|c|c|c|c|}
\hline $\begin{array}{c}\text { Autores e ano } \\
\text { do estudo }\end{array}$ & Participantes & $\begin{array}{c}\text { Protocolo de } \\
\text { avaliação da marcha } \\
\end{array}$ & $\begin{array}{c}\text { Variável da } \\
\text { marcha }\end{array}$ & $\begin{array}{c}\text { Dimensões do } \\
\text { IDH }\end{array}$ & Resumo dos resultados \\
\hline $\begin{array}{l}\text { Gonzalez } \\
(2016)\end{array}$ & $\begin{array}{l}\text { - Baixo NSE }(\mathrm{n}=33 ; \\
\text { Média }=69 \pm 5,0 \text { anos }) \\
\text { e alto NSE }(\mathrm{n}=30 ; \\
\text { Média }=71 \pm 6,0 \text { anos }) \\
\text { - Chile }\end{array}$ & $\begin{array}{l}\text { Caminhada habitual } \\
\text { por } 3 \text { min em um } \\
\text { circuito elíptico de } \\
40-\mathrm{m} \text { (captura por } \\
\text { vídeo) }\end{array}$ & $\begin{array}{l}\text { Variabilidade do } \\
\text { comprimento da } \\
\text { passada } \\
\text { (Coeficiente de } \\
\text { variação \%) }\end{array}$ & Educação e renda & $\begin{array}{l}\text { Variabilidade do comprimento } \\
\text { da passada foi maior nos } \\
\text { indivíduos com baixo nível } \\
\text { socioeconômico (NSE) - } \\
\text { educação e renda }-(\mathrm{CV} \%=3,5 \\
\pm 1,5) \text { comparados com alto NSE } \\
(\mathrm{CV} \%=2,4 \pm 1,5)\end{array}$ \\
\hline $\begin{array}{l}\text { Plouvier et al. } \\
\text { (2016) }\end{array}$ & $\begin{array}{l}\text { - Homens }(n=397) \text { e } \\
\text { mulheres }(n=339) ; \\
\text { com idades de } 55 \text { a } 69 \\
\text { anos } \\
\text { - França }\end{array}$ & $\begin{array}{l}\text { Caminhada habitual } \\
\text { em 3-m, mensurada } \\
\text { por cronômetro }\end{array}$ & $\begin{array}{l}\text { Velocidade da } \\
\text { marcha }\end{array}$ & Educação & $\begin{array}{l}\text { Indivíduos com menor classe } \\
\text { ocupacional (CO) (educação) } \\
\text { apresentaram menor velocidade } \\
\text { de marcha (VM) }\end{array}$ \\
\hline Weber $(2016)^{3}$ & $\begin{array}{l}-\mathrm{n}=11711(5490 \\
\text { homens e } 6221 \\
\text { mulheres; Média }=70,6 \\
\pm 7,4 \text { anos }) \\
\text { - Inglaterra }\end{array}$ & $\begin{array}{l}\text { Caminhada habitual } \\
\text { em 2,4-m, mensurada } \\
\text { por cronômetro }\end{array}$ & $\begin{array}{l}\text { Velocidade da } \\
\text { marcha }\end{array}$ & Educação e renda & $\begin{array}{l}\text { Maiores níveis de educação, } \\
\text { maior nível ocupacional e viver } \\
\text { em regiões mais ricas foram } \\
\text { associados com maior VM }\end{array}$ \\
\hline $\begin{array}{l}\text { Nofuji et al. } \\
\text { (2016) }\end{array}$ & $\begin{array}{l}-\mathrm{n}=1,085 ; \text { com idades } \\
\text { de } 65 \text { a } 89 \text { anos } \\
\text { - Japão }\end{array}$ & $\begin{array}{l}\text { Caminhada habitual } \\
\text { em 5-m, mensurada } \\
\text { por cronômetro }\end{array}$ & $\begin{array}{l}\text { Velocidade da } \\
\text { marcha }\end{array}$ & $\begin{array}{l}\text { Expectativa de } \\
\text { vida }\end{array}$ & $\begin{array}{l}\text { Menor VM foi associada com a } \\
\text { mortalidade por todas as causas, } \\
\text { cardiovascular e outras causas. } \\
\text { Nenhuma associação com } \\
\text { mortalidade por câncer }\end{array}$ \\
\hline $\begin{array}{l}\text { Arnau et al. } \\
\text { (2016) }\end{array}$ & $\begin{array}{l}-\mathrm{n}=315 ; \text { Média }=81,9 \\
\pm 4,7 \text { anos } \\
\text { - Espanha }\end{array}$ & $\begin{array}{l}\text { Caminhada habitual } \\
\text { em 2,4-m (SPPB) } \\
\text { mensurada por } \\
\text { cronômetro }\end{array}$ & $\begin{array}{l}\text { Velocidade da } \\
\text { marcha }\end{array}$ & $\begin{array}{l}\text { Expectativa de } \\
\text { vida }\end{array}$ & $\begin{array}{l}\text { VM foi um preditor de sobrevida } \\
\text { a longo prazo }\end{array}$ \\
\hline $\begin{array}{l}\text { Brown et al. } \\
(2016)^{1}\end{array}$ & $\begin{array}{l}\text { - } \mathrm{n}=3075 ; \text { Média }= \\
73,6 \pm 2,87 \text { anos } \\
\text { - Estados Unidos }\end{array}$ & $\begin{array}{l}\text { Caminhada habitual } \\
\text { em 6-m e em 20-m }\end{array}$ & $\begin{array}{l}\text { Velocidade da } \\
\text { marcha }\end{array}$ & $\begin{array}{l}\text { Expectativa de } \\
\text { vida }\end{array}$ & $\begin{array}{l}\mathrm{VM}<1 \mathrm{~m} / \mathrm{s} \text { foi associado com } \\
\text { maior risco de morte }\end{array}$ \\
\hline Gutierrez- & $-<0,8 \mathrm{~m} / \mathrm{s}(\mathrm{n}=314$ & Caminhada habitual & Velocidade da & Expectativa de & Indivíduos lentos $(<0,8 \mathrm{~m} / \mathrm{s})$ \\
\hline
\end{tabular}




\begin{tabular}{|c|c|c|c|c|c|}
\hline $\begin{array}{l}\text { Misis et al. } \\
(2015)\end{array}$ & $\begin{array}{l}\text { Média }=81 \pm 7,0 \text { anos }) \\
\mathrm{e} \geq 0,8 \mathrm{~m} / \mathrm{s}(\mathrm{n}=475 \\
\text { Média }=73,9 \pm 6,3 \\
\text { anos }) \\
\text { - Espanha }\end{array}$ & $\begin{array}{l}\text { em } 3 \text {-m mensurada } \\
\text { por cronômetro }\end{array}$ & marcha & vida & $\begin{array}{l}\text { com baixos níveis de pressão } \\
\text { arterial sistólica apresentaram } \\
\text { maior risco de mortalidade por } \\
\text { todas as causas }\end{array}$ \\
\hline $\begin{array}{l}\text { Tabue-Teguo } \\
\text { et al. }(2015)^{4}\end{array}$ & $\begin{array}{l}-\mathrm{n}=1365 ; \text { Média }= \\
75,7 \pm 5.4 \text { anos } \\
\text { - França }\end{array}$ & $\begin{array}{l}\text { Caminhada habitual } \\
\text { em 6-m mensurada } \\
\text { por cronômetro }\end{array}$ & $\begin{array}{l}\text { Velocidade da } \\
\text { marcha }\end{array}$ & $\begin{array}{l}\text { Expectativa de } \\
\text { vida }\end{array}$ & $\begin{array}{l}\mathrm{VM} \text { mais lenta foi associada a } \\
\text { maior risco de morte }\end{array}$ \\
\hline $\begin{array}{l}\text { Gomes et al. } \\
\text { (2015) }\end{array}$ & $\begin{array}{l}\text { - Mulheres }(\mathrm{n}=92) \\
\text { com idades de } 69 \text { a } 79 \\
\text { anos } \\
\text { - Brasil }\end{array}$ & $\begin{array}{l}\text { Teste Timed Up and } \\
\text { Go (TUG) com e sem } \\
\text { Dupla-tarefa (DT) }\end{array}$ & $\begin{array}{l}\text { Velocidade da } \\
\text { marcha }\end{array}$ & Educação & $\begin{array}{l}\text { Mulheres com maiores níveis de } \\
\text { educação desempenharam } \\
\text { melhor o TUG com e sem DT }\end{array}$ \\
\hline $\begin{array}{l}\text { Quiben \& } \\
\text { Hazuda (2015) }\end{array}$ & $\begin{array}{l}\text { - } \mathrm{n}=703 ; \text { Média }= \\
69,64 \pm 3,36 \text { anos } \\
\text { - Estados Unidos }\end{array}$ & $\begin{array}{l}\text { Caminhada habitual } \\
\text { em } 15,24-\mathrm{m} \\
\text { mensurada por } \\
\text { cronômetro }\end{array}$ & $\begin{array}{l}\text { Velocidade da } \\
\text { marcha }\end{array}$ & Educação e renda & $\begin{array}{l}\text { Fatores contextuais (idade, sexo, } \\
\text { NSE) explicaram } 20,3 \% \text { da } \\
\text { variância na VM, sendo que NSE } \\
\text { (educação e renda) sozinho } \\
\text { representou } 14 \% \text { dessa variância }\end{array}$ \\
\hline $\begin{array}{l}\text { Weidung et al. } \\
(2015)^{2}\end{array}$ & $\begin{array}{l}\text { - } \mathrm{n}=806 ; \text { Média }=89,6 \\
\pm 4,6 \text { anos } \\
\text { - Suécia e Finlândia }\end{array}$ & $\begin{array}{l}\text { Caminhada habitual } \\
\text { em 2,4-m mensurada } \\
\text { por cronômetro }\end{array}$ & $\begin{array}{l}\text { Velocidade da } \\
\text { marcha }\end{array}$ & $\begin{array}{l}\text { Expectativa de } \\
\text { vida }\end{array}$ & $\begin{array}{l}\mathrm{VM}<0,5 \mathrm{~m} / \mathrm{s} \text { foi associado com } \\
\text { maior risco de morte }\end{array}$ \\
\hline $\begin{array}{l}\text { Busch et al. } \\
\text { (2015) }\end{array}$ & $\begin{array}{l}-\mathrm{n}=1112 ; \text { com idade } \\
\text { de } 60 \text { ou mais } \\
- \text { Brasil }\end{array}$ & $\begin{array}{l}\text { Caminhada habitual } \\
\text { em 3-m mensurada } \\
\text { por cronômetro }\end{array}$ & $\begin{array}{l}\text { Velocidade da } \\
\text { marcha }\end{array}$ & Educação & $\begin{array}{l}\text { VM aumentou com o maior nível } \\
\text { de educação }(\text { OR } 3,20)\end{array}$ \\
\hline $\begin{array}{l}\text { Jancova- } \\
\text { Vseteckova et } \\
\text { al. (2015) }\end{array}$ & $\begin{array}{l}\text { - Homens }(\mathrm{n}=1399 ; \\
\text { Média }=67,2 \pm 3,9 \\
\text { anos) e mulheres }(\mathrm{n}= \\
1528 ; \text { Média }=67 \pm 3,9 \\
\text { anos) } \\
\text { - República Checa }\end{array}$ & $\begin{array}{l}\text { Caminhada habitual } \\
\text { em 2,4-m }\end{array}$ & $\begin{array}{l}\text { Velocidade da } \\
\text { marcha }\end{array}$ & Educação e renda & $\begin{array}{l}\text { O maior nível educacional foi } \\
\text { associado com maior VM. Essa } \\
\text { relação não foi observada com } \\
\text { circunstâncias materiais (renda) }\end{array}$ \\
\hline $\begin{array}{l}\text { Bez \& Neri } \\
(2014)\end{array}$ & $\begin{array}{l}-\mathrm{n}=689 ; \text { Média }= \\
72,28 \pm 5,4 \text { anos } \\
- \text { Brasil }\end{array}$ & $\begin{array}{l}\text { Caminhada habitual } \\
\text { em 4,6-m. }\end{array}$ & $\begin{array}{l}\text { Velocidade da } \\
\text { marcha }\end{array}$ & Renda & $\begin{array}{l}\text { Menor VM foi associado com } \\
\text { pior renda, e pior autoavaliação } \\
\text { de saúde }\end{array}$ \\
\hline Sabia et al. & $-\mathrm{n}=4016 ;$ Média $=$ & Caminhada rápida & Velocidade da & Expectativa de & VM da CR no baseline e o \\
\hline
\end{tabular}




\begin{tabular}{|c|c|c|c|c|c|}
\hline$(2014)^{4}$ & $\begin{array}{l}73,4 \pm 4,7 \text { anos } \\
\text { - França }\end{array}$ & $\begin{array}{l}(\mathrm{CR}) \text { em 6-m } \\
\text { mensurada por duas } \\
\text { células fotoelétricas } \\
\text { conectadas a um } \\
\text { cronômetro }\end{array}$ & marcha & vida & $\begin{array}{l}\text { declínio da VM na CR previu } \\
\text { mortalidade }\end{array}$ \\
\hline $\begin{array}{l}\text { Brown, } \\
\text { Harhay, \& } \\
\text { Harhay }(2014)^{5}\end{array}$ & $\begin{array}{l}-\mathrm{n}=5000 ; \text { Média }= \\
70,6 \pm 0,1 \text { anos } \\
\text { - Estados Unidos }\end{array}$ & $\begin{array}{l}\text { Caminhada habitual } \\
\text { em 2,4-m }\end{array}$ & $\begin{array}{l}\text { Cadência } \\
\text { (passos/min) }\end{array}$ & $\begin{array}{l}\text { Expectativa de } \\
\text { vida }\end{array}$ & $\begin{array}{l}\text { Cadência }>100 \text { passos/min } \\
\text { previu redução de mortalidade } \\
\text { entre os idosos }\end{array}$ \\
\hline $\begin{array}{l}\text { Welmer et al. } \\
\text { (2013) }\end{array}$ & $\begin{array}{l}\text { - } \mathrm{n}=3212 ; \text { Média }= \\
74,2 \pm 11,0 \text { anos } \\
\text { - Suécia }\end{array}$ & $\begin{array}{l}\text { Caminhada habitual } \\
\text { em 2,4- ou 6-m }\end{array}$ & $\begin{array}{l}\text { Velocidade da } \\
\text { marcha }\end{array}$ & Educação & $\begin{array}{l}\text { O maior nível de escolaridade foi } \\
\text { associado com maior VM. Essa } \\
\text { diferença na VM relacionada a } \\
\text { educação foi observada entre } \\
\text { trabalhadores não-manuais de } \\
\text { ambos os sexos }\end{array}$ \\
\hline $\begin{array}{l}\text { Toots et al. } \\
(2013)^{2}\end{array}$ & $\begin{array}{l}\text { - } \mathrm{n}=772 ; \text { Média }=89,6 \\
\pm 4,6 \text { anos } \\
\text { - Suécia e Finlândia }\end{array}$ & $\begin{array}{l}\text { Caminhada habitual } \\
\text { em } 2,4-m \text { mensurada } \\
\text { por cronômetro }\end{array}$ & $\begin{array}{l}\text { Velocidade da } \\
\text { marcha }\end{array}$ & $\begin{array}{l}\text { Expectativa de } \\
\text { vida }\end{array}$ & $\begin{array}{l}\mathrm{VM}<0,5 \mathrm{~m} / \mathrm{s} \text { foi preditor de } \\
\text { mortalidade entre idosos com } 85 \\
\text { anos ou mais }\end{array}$ \\
\hline $\begin{array}{l}\text { Zaninotto, } \\
\text { Sacker, \& } \\
\text { Head }(2013)^{3}\end{array}$ & $\begin{array}{l}\text { - } \mathrm{n}=7225 ; \text { Média }= \\
71,2 \pm 7,9 \text { anos } \\
\text { - Inglaterra }\end{array}$ & $\begin{array}{l}\text { Caminhada habitual } \\
\text { em 2,4-m }\end{array}$ & $\begin{array}{l}\text { Velocidade da } \\
\text { marcha }\end{array}$ & Renda & $\begin{array}{l}\text { Maior VM foi associada com } \\
\text { maior renda. Declínio da VM } \\
\text { durante o acompanhamento do } \\
\text { estudo foi menor entre as pessoas } \\
\text { mais pobres, entretanto, as } \\
\text { diferenças na VM permaneceram }\end{array}$ \\
\hline $\begin{array}{l}\text { Idland, } \\
\text { Engedal, \& } \\
\text { Bergland } \\
(2013) \\
\end{array}$ & $\begin{array}{l}\text { - Mulheres }(\mathrm{n}=300 \\
\text { Média }=80,9 \pm 4,1 \text { anos } \\
\text { - Noruega }\end{array}$ & Caminhada em 29-m & $\begin{array}{l}\text { Velocidade da } \\
\text { marcha }\end{array}$ & $\begin{array}{l}\text { Expectativa de } \\
\text { vida }\end{array}$ & $\begin{array}{l}\text { Menor VM foi um forte preditor } \\
\text { de mortalidade por todas as } \\
\text { causas }\end{array}$ \\
\hline $\begin{array}{l}\text { White et al. } \\
(2013)^{1}\end{array}$ & $\begin{array}{l}\text { - } \mathrm{n}=2364 ; \text { Média }= \\
73,5 \pm 2,9 \text { anos } \\
\text { - Estados Unidos }\end{array}$ & $\begin{array}{l}\text { Caminhada habitual } \\
\text { em 20-m }\end{array}$ & $\begin{array}{l}\text { Velocidade da } \\
\text { marcha }\end{array}$ & $\begin{array}{l}\text { Expectativa de } \\
\text { vida }\end{array}$ & $\begin{array}{l}\text { Indivíduos que andam a uma VM } \\
<1,0 \mathrm{~m} / \mathrm{s} \text { mostraram declínio na } \\
\text { trajetória da VM mais acelerado, } \\
\text { e tinham } 2,1 \text { vezes mais risco de } \\
\text { mortalidade por todas as causas }\end{array}$ \\
\hline Taekema et al. & $-\mathrm{n}=599 ;$ todos com 85 & Caminhada rápida & Velocidade da & Expectativa de & Para idosos mais lentos a VM (> \\
\hline
\end{tabular}




\begin{tabular}{|c|c|c|c|c|c|}
\hline$(2012)$ & $\begin{array}{l}\text { anos no início do } \\
\text { estudo } \\
\text { - Holanda }\end{array}$ & $\begin{array}{l}(\mathrm{CR}) \text { em } 6-\mathrm{m} \\
\text { mensurada por } \\
\text { cronômetro }\end{array}$ & marcha & vida & $\begin{array}{l}0,41 \mathrm{~m} / \mathrm{s} \text { para mulheres e }>0,46 \\
\mathrm{~m} / \mathrm{s} \text { para homens) foi preditor de } \\
\text { sobrevida em } 12 \text { anos. }\end{array}$ \\
\hline $\begin{array}{l}\text { Thorpe et al. } \\
(2011)^{1}\end{array}$ & $\begin{array}{l}\text { - } \mathrm{n}=2969 \text { brancos } \\
\text { (Média }=73,6 \pm 2,8 \\
\text { anos) e negros (Média } \\
=73,4 \pm 2,9 \text { anos) } \\
\text { - Estados Unidos }\end{array}$ & $\begin{array}{l}\text { Caminhada habitual } \\
\text { em 6-m }\end{array}$ & $\begin{array}{l}\text { Velocidade da } \\
\text { marcha }\end{array}$ & Educação e renda & $\begin{array}{l}\text { Indivíduos negros tiveram menor } \\
\text { VM, e maior declínio da VM do } \\
\text { que os indivíduos brancos. NSE } \\
\text { (educação e renda) foi um forte } \\
\text { mediador desta diferença }\end{array}$ \\
\hline $\begin{array}{l}\text { Studenski et al. } \\
(2011)^{2,5,6,7,8}\end{array}$ & $\begin{array}{l}\text { - } \mathrm{n}=34485 ; \text { Média }= \\
73,5 \pm 5,9 \text { anos } \\
\text { - } 9 \text { coortes (Estados } \\
\text { Unidos e Itália) }\end{array}$ & $\begin{array}{l}\text { Caminhada habitual } \\
\text { (distância variou de } \\
\text { 2,4- a 6-m) }\end{array}$ & $\begin{array}{l}\text { Velocidade da } \\
\text { marcha }\end{array}$ & $\begin{array}{l}\text { Expectativa de } \\
\text { vida }\end{array}$ & $\begin{array}{l}\mathrm{VM}(>0,8 \mathrm{~m} / \mathrm{s}) \text { foi associada ao } \\
\text { aumento da sobrevida em idosos }\end{array}$ \\
\hline $\begin{array}{l}\text { Dumurgier et } \\
\text { al. (2009) }\end{array}$ & $\begin{array}{l}\text { - } \mathrm{n}=3208 ; \text { Média }= \\
73,2 \pm 4,6 \text { anos } \\
\text { - França }\end{array}$ & $\begin{array}{l}\text { Caminhada habitual } \\
\text { em 6-m mensurada } \\
\text { por duas células } \\
\text { fotoelétricas } \\
\text { conectadas a um } \\
\text { cronômetro }\end{array}$ & $\begin{array}{l}\text { Velocidade da } \\
\text { marcha }\end{array}$ & $\begin{array}{l}\text { Expectativa de } \\
\text { vida }\end{array}$ & $\begin{array}{l}\text { Menor VM foi associada com } \\
\text { mortalidade cardiovascular, mas } \\
\text { essa relação não foi encontrada } \\
\text { na mortalidade por câncer }\end{array}$ \\
\hline $\begin{array}{l}\text { Brunner et al. } \\
\text { (2009) }\end{array}$ & $\begin{array}{l}\text { - } \mathrm{n}=6345 ; \text { Média }= \\
61,1 \pm 6,0 \text { anos } \\
\text { - Inglaterra }\end{array}$ & $\begin{array}{l}\text { Caminhada habitual } \\
\text { em 2,4-m mensurada } \\
\text { por cronômetro }\end{array}$ & $\begin{array}{l}\text { Velocidade da } \\
\text { marcha }\end{array}$ & Renda & $\begin{array}{l}\text { Menor VM foi relacionada a } \\
\text { indivíduos com menor posição } \\
\text { socioeconômica (renda) }\end{array}$ \\
\hline $\begin{array}{l}\text { M Cesari et al. } \\
(2009)^{1}\end{array}$ & $\begin{array}{l}\text { - } \mathrm{n}=3024 ; \text { Média }= \\
73,6 \pm 2,9 \text { anos } \\
\text { - Estados Unidos }\end{array}$ & $\begin{array}{l}\text { Caminhada habitual } \\
\text { em 6-m mensurada } \\
\text { por cronômetro }\end{array}$ & $\begin{array}{l}\text { Velocidade da } \\
\text { marcha }\end{array}$ & $\begin{array}{l}\text { Expectativa de } \\
\text { vida }\end{array}$ & $\begin{array}{l}\text { Menor VM }(<1 \mathrm{~m} / \mathrm{s}) \text { foi preditor } \\
\text { de vários eventos adversos } \\
\text { relacionados à saúde e } \\
\text { mortalidade }\end{array}$ \\
\hline $\begin{array}{l}\text { Cesari et al. } \\
(2009)^{6}\end{array}$ & $\begin{array}{l}\text { - } \mathrm{n}=2139 ; \text { Média }= \\
72,1 \pm 5,0 \text { anos } \\
\text { - Estados Unidos }\end{array}$ & $\begin{array}{l}\text { Caminhada rápida em } \\
\text { 2,4-m mensurada por } \\
\text { cronômetro }\end{array}$ & $\begin{array}{l}\text { Velocidade da } \\
\text { marcha }\end{array}$ & $\begin{array}{l}\text { Expectativa de } \\
\text { vida }\end{array}$ & $\begin{array}{l}\text { Menor VM }(<0,81 \mathrm{~m} / \mathrm{s}) \text { foi } \\
\text { preditor de mortalidade }\end{array}$ \\
\hline $\begin{array}{l}\text { Cesari et al. } \\
(2008)\end{array}$ & $\begin{array}{l}\text { - } \mathrm{n}=335 ; \text { Média }=85,6 \\
\pm 4,8 \text { anos } \\
\text { - Itália }\end{array}$ & $\begin{array}{l}\text { Caminhada habitual } \\
\text { em 4-m mensurada } \\
\text { por cronômetro }\end{array}$ & $\begin{array}{l}\text { Velocidade da } \\
\text { marcha }\end{array}$ & $\begin{array}{l}\text { Expectativa de } \\
\text { vida }\end{array}$ & $\begin{array}{l}\text { Menor VM foi preditor de } \\
\text { mortalidade }\end{array}$ \\
\hline $\begin{array}{l}\text { Rosano et al. } \\
(2008)^{7}\end{array}$ & $\begin{array}{l}-\mathrm{n}=3156 ; \text { Média }= \\
70,4 \pm 4,6 \text { anos }\end{array}$ & $\begin{array}{l}\text { Caminhada habitual } \\
\text { em 4,5-m mensurada }\end{array}$ & $\begin{array}{l}\text { Velocidade da } \\
\text { marcha }\end{array}$ & $\begin{array}{l}\text { Expectativa de } \\
\text { vida }\end{array}$ & $\begin{array}{l}\text { Menor VM }(<1,0 \mathrm{~m} / \mathrm{s}) \text { foi um } \\
\text { fator de risco para mortalidade }\end{array}$ \\
\hline
\end{tabular}




\begin{tabular}{|c|c|c|c|c|c|}
\hline & - Estados Unidos & por cronômetro & & & $\begin{array}{l}\text { em idosos com boa } \\
\text { funcionalidade }\end{array}$ \\
\hline $\begin{array}{l}\text { Hardy et al. } \\
(2007)\end{array}$ & $\begin{array}{l}\text { - } \mathrm{n}=439 \text { com idades de } \\
65 \text { anos ou mais } \\
\text { - Estados Unidos }\end{array}$ & $\begin{array}{l}\text { Caminhada habitual } \\
\text { em 4-m mensurada } \\
\text { por cronômetro }\end{array}$ & $\begin{array}{l}\text { Velocidade da } \\
\text { marcha }\end{array}$ & $\begin{array}{l}\text { Expectativa de } \\
\text { vida }\end{array}$ & $\begin{array}{l}\text { Melhora na VM em } 1 \text { ano foi } \\
\text { associada com sobrevida. Um } \\
\text { aumento da VM habitual ao } \\
\text { longo de } 1 \text { ano reduziu } 58 \% \text { o } \\
\text { risco relativo e } 17,7 \% \text { o risco } \\
\text { absoluto de morte }\end{array}$ \\
\hline $\begin{array}{l}\text { Rolland et al. } \\
\text { (2006) }\end{array}$ & $\begin{array}{l}\text { - Mulheres }(\mathrm{n}=7250 ; \\
\text { Média }=80,5 \pm 3,7 \\
\text { anos }) \\
\text { - França }\end{array}$ & $\begin{array}{l}\text { Caminhada em 6-m } \\
\text { mensurada por } \\
\text { cronômetro (SPPB) }\end{array}$ & $\begin{array}{l}\text { Velocidade da } \\
\text { marcha }\end{array}$ & $\begin{array}{l}\text { Expectativa de } \\
\text { vida }\end{array}$ & $\begin{array}{l}\text { Menor VM foi associada com } \\
\text { maior risco de morte }\end{array}$ \\
\hline $\begin{array}{l}\text { Coppin et al. } \\
(2006)^{8}\end{array}$ & $\begin{array}{l}\text { - } \mathrm{n}=1025 ; \text { Média }= \\
75,5 \pm 7,3 \text { anos } \\
\text { - Itália }\end{array}$ & $\begin{array}{l}\text { Caminhada rápida em } \\
\text { 400-m }\end{array}$ & $\begin{array}{l}\text { Velocidade da } \\
\text { marcha }\end{array}$ & Educação & $\begin{array}{l}\text { Menor VM foi associada com } \\
\text { menor nível de escolaridade }\end{array}$ \\
\hline $\begin{array}{l}\text { Perera et al. } \\
(2005)\end{array}$ & $\begin{array}{l}-\mathrm{n}=439 \text { com idade de } \\
65 \text { anos ou mais } \\
\text { - Estados Unidos }\end{array}$ & $\begin{array}{l}\text { Caminhada habitual } \\
\text { em 4-m. (Declínio } \\
\text { considerado de } 0,1 \\
\mathrm{~m} / \mathrm{s} \text { ) }\end{array}$ & $\begin{array}{l}\text { Velocidade da } \\
\text { marcha }\end{array}$ & $\begin{array}{l}\text { Expectativa de } \\
\text { vida }\end{array}$ & $\begin{array}{l}\text { Idosos que tiveram um declínio } \\
\text { da VM de } 0,1 \mathrm{~m} / \mathrm{s} \text { em } 5 \text { anos } \\
\text { apresentaram, em média, } 2,23 \\
\text { mais chances de morrer }\end{array}$ \\
\hline $\begin{array}{l}\text { Woo, Ho, \& } \\
\text { Yu (1999) }\end{array}$ & $\begin{array}{l}\text { - Homens }(n=559) \text { e } \\
\text { mulheres }(n=612) \text { com } \\
\text { idades de } 70 \text { anos ou } \\
\text { mais } \\
\text { - Hong Kong, China. }\end{array}$ & $\begin{array}{l}\text { Caminhada habitual } \\
\text { em 4,8-m registrando } \\
\text { o tempo e o número } \\
\text { de passos dados }\end{array}$ & $\begin{array}{l}\text { Tempo de } \\
\text { caminhada } \\
\text { (segundos) } \\
\text { Comprimento da } \\
\text { passada (estimado } \\
\text { pelo número de } \\
\text { passos) }\end{array}$ & $\begin{array}{l}\text { Expectativa de } \\
\text { vida }\end{array}$ & $\begin{array}{l}\text { Maior tempo de caminhada e } \\
\text { menor comprimento da passada } \\
\text { foram associados com } \\
\text { mortalidade em idosos }\end{array}$ \\
\hline
\end{tabular}

Nota: NSE, nível socioeconômico; CV\%, coeficiente de variação; CO, classe ocupacional; VM, velocidade da marcha; TUG, Timed up and go;

DT, dupla-tarefa; OR, odds ratio; CR, caminhada rápida; SPPB; Short Physical Performance Battery.

1 , estudos usando dados do Heath, Aging, and Body Composition (Health ABC) Study; ${ }^{2}$, estudos usando dados do UEMA 85+/GERDA

(Gerontological Regional Database) Study; ${ }^{3}$, estudos usando dados do English Longitudinal Study of Ageing; ${ }^{4}$, estudos usando dados do 3 City

Study (3C); ${ }^{5}$, estudos usando dados do Third National Health and Nutrition Examination Survey (NHANES III); ${ }^{6}$, estudos usando dados do

Hispanic Established Populations for Epidemiologic Studies of the Elderly (H-EPESE); ${ }^{7}$, estudos usando dados do Cardiovascular Health Study

(CHS); ${ }^{8}$, estudos usando dados do InChianti Study 
Em relação aos participantes dos estudos, a média de idade variou entre $61,1 \pm$ 6,0 anos (Brunner et al., 2009) e 89,6 anos \pm 4,6 anos (Toots et al., 2013; Weidung et al., 2015), e três artigos avaliaram apenas mulheres (Gomes et al., 2015; Idland et al., 2013; Rolland et al., 2006). Os artigos selecionados foram desenvolvidos em 14 países classificados como IDH alto (Brasil $=0,754)$ ou muito alto (Chile $=0,847$; Republica tcheca $=0,878 ;$ Espanha $=0.884 ;$ Itália $=0,887 ;$ Finlândia $=0,895 ;$ França $=0,897$; Japão $=0,903 ;$ Inglaterra $=0,909 ;$ Suécia $=0,913 ;$ Hong Kong, China $=0,917 ;$ Estados Unidos $=0,920 ;$ Holanda $=0,924 ;$ e Noruega $=0,949)($ United Nations Development Programme - UNDP, 2016). Cerca de um terço dos estudos (11 artigos, 35,4\%) avaliaram idosos residentes nos Estados Unidos. A velocidade da marcha foi a variável mais estudada (32 artigos, 91,4\%). Um artigo avaliou a variabilidade do comprimento da passada (Medina Gonzalez, 2016), 1 artigo avaliou o comprimento da passada (Woo et al., 1999) e 1 artigo avaliou a cadência (J. C. Brown et al., 2014) como variável dependente principal. Vinte e nove artigos $(82,8 \%)$ mensuraram a velocidade da marcha usando cronômetro, em distâncias que variaram de 2,4 a 400 metros. Contudo, a maioria dos 29 artigos avaliou a velocidade da marcha em 2,4 m (10 artigos) ou $6 \mathrm{~m}$ (9 artigos). Três artigos mesuraram a velocidade da marcha eletronicamente, utilizando fotocélulas (Dumurgier et al., 2009; Sabia et al., 2014) e gravações de vídeo (Medina Gonzalez, 2016) em distâncias variando de 6 a $40 \mathrm{~m}$. Um artigo (2,8\%) (Gomes et al., 2015) avaliou a velocidade da marcha através do paradigma da dupla-tarefa (caminhando enquanto excuta cálculos matemáticos de subtrações, ou caminhando enquanto segura uma bandeja mantendo uma bolsa estável em seu centro). Cinco artigos (14,3\%) avaliaram as mudanças na velocidade da marcha 
ao longo dos anos (observações variando de 1 a 12 anos) (Hardy et al., 2007; Perera et al., 2005; Sabia et al., 2014; White et al., 2013; Zaninotto et al., 2013).

Nenhum estudo utilizou o IDH como uma variável independente. No entanto, todos os artigos selecionados encontraram relações do desempenho da marcha com um ou dois componentes de nível individual, incluindo educação, renda e expectativa de vida. Estes são componentes básicos para calcular as principais dimensões do desenvolvimento humano. O IDH é composto por três dimensões que refletem as características educacionais, de renda e de saúde no nível populacional de uma cidade, estado ou país. Por exemplo, para calcular o IDH de uma região geográfica é necessário a média da expectativa de vida ao nascer, da média de anos de escolaridade e renda bruta per capta, de modo que a média geométrica desses três índices pode ser transformada no IDH (United Nations Development Programme - UNDP, 2016). Como não foi encontrado nenhum estudo que avaliou a relação entre o IDH completo e o desempenho da marcha, essa relação será discutida nessa revisão sistemática considerando o impacto das características individuais das dimensões do IDH. A distribuição dos artigos por dimensões do IDH está apresentada na figura 2. 


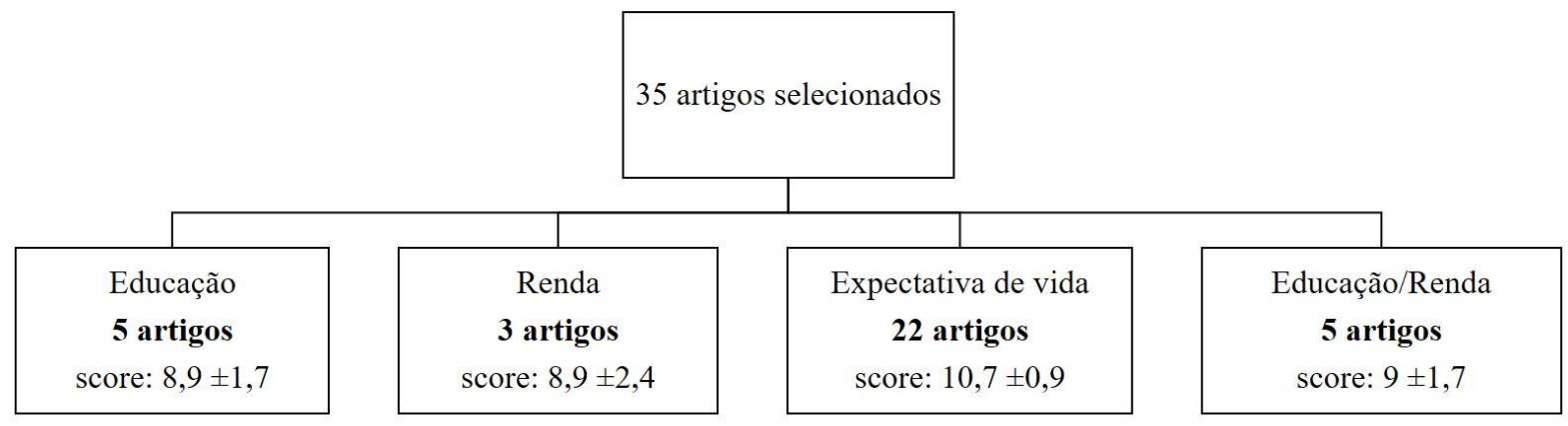

*Score: Média do score dos artigos de acordo com o instrumento de análise da qualidade de estudos de coorte observacionais e estudos transversais $=5$ - 9 (Razoável); $10-14$ (Bom)

Figura 2 - Distribuição dos artigos selecionados para revisão por dimensões do IDH

Vinte e dois artigos $(62,8 \%)$ avaliaram a relação do desempenho da marcha com a mortalidade ou sobrevida (expectativa de vida), cinco artigos (14,3\%) avaliaram a relação entre educação e velocidade da marcha, três artigos $(8,6 \%)$ avaliaram a relação entre renda e velocidade da marcha, e cinco $(14,3 \%)$ avaliaram o impacto da educação e renda no desempenho da marcha. Nenhum artigo avaliou em um mesmo estudo a relação ou o impacto das três dimensões juntas (educação, renda e expectativa de vida) no desempenho da marcha. Assim, para uma melhor compreensão do tema da pesquisa, as sessões de resultados desta revisão sistemática foram organizadas em subitens de acordo com cada dimensão do IDH.

\subsubsection{Educação}

Cinco artigos (Busch et al., 2015; Coppin et al., 2006; Gomes et al., 2015; Plouvier et al., 2016; Welmer et al., 2013) avaliaram a associação entre educação e velocidade da marcha. Estes estudos demonstraram que o maior nível de educação foi 
associado à maior velocidade da marcha. Por exemplo, em uma coorte de 1112 indivíduos com 60 anos ou mais (Busch et al., 2015) o analfabetismo foi associado à velocidade de marcha mais lenta $(\mathrm{OR}=3,20)$, indicando que a educação, como um determinante social, poderia ter um papel significante na velocidade de marcha em idosos. Similarmente, outro estudo (Welmer et al., 2013) identificou uma correlação entre o nível de educação e velocidade de marcha. Idosos com formação de nível superior caminharam com uma velocidade $18 \%$ maior comparado a idosos que tinham o ensino fundamental (elementary school education), e ainda, aqueles idosos que possuíam o ensino médio (High school education) caminharam 7\% mais rápidos comparados aos mesmos idosos com o ensino fundamental (elementary school education). Um estudo (Coppin et al., 2006) investigou a relação entre educação e velocidade de marcha ajustado por várias medidas cognitivas, fisiológicas e físicas (nível cognitivo, velocidade de condução nervosa, potência muscular de membros inferiores, amplitude de movimento de membros inferiores, circulação arterial periférica) que podem ser críticas para o funcionamento orgânico, e portanto, para o desempenho da marcha. Este estudo constatou que a velocidade de marcha foi influenciada pelo nível de escolaridade, independentemente dos fatores de confusão. Outro estudo (Gomes et al., 2015) verificou o impacto da educação sobre a velocidade de marcha durante uma tarefa de caminhada com maior desafio do controle postural (timed up and go; TUG) com e sem dupla-tarefa. Este estudo verificou que mulheres idosas com mais anos de escolaridade finalizavam o TUG mais rápido do que as mulheres com menos anos de escolaridade, particularmente durante o TUG associado à dupla-tarefa. 


\subsubsection{Renda}

De acordo com 3 artigos (Bez \& Neri, 2014; Brunner et al., 2009; Zaninotto et al., 2013) a velocidade de marcha foi altamente sensível ao status econômico. Estes estudos constataram que idosos da comunidade, classificados como baixa renda também apresentavam velocidade de marcha mais lenta quando comparados aos idosos com maior renda. Um estudo (Zaninotto et al., 2013) avaliou o impacto do status econômico nas trajetórias da marcha ao longo de um período de 6 anos em idosos com 60 anos ou mais. O estudo demonstrou que idosos com maior renda caminhavam mais rápidos quando comparados àqueles com baixa renda. Curiosamente, os idosos com maior renda sofreram um declínio mais abrupto na velocidade da marcha durante o período de seguimento do estudo; no entanto, esses mesmos idosos com maior renda permaneceram com velocidades maiores de caminhada em relação aos de baixa renda até o final do período de acompanhamento. Esse resultado demonstra que a marcha declinará inevitavelmente ao longo dos anos, mas uma renda maior pode contribuir para um melhor desempenho, por mais anos. É importante mencionar que os estudos que avaliaram a relação entre renda e desempenho da marcha não realizam análise ajustadas por educação e nível ocupacional.

\subsubsection{Expectativa de vida}

Os artigos categorizados na dimensão expectativa de vida demonstraram robustas evidências de uma relação entre desempenho da marcha (velocidade, cadência e comprimento da passada) e mortalidade e sobrevida. A velocidade mais lenta da marcha foi associada com maior risco de morte entre idosos da comunidade, e o ponto de corte 
variou entre 0,8 m/s (Gutierrez-Misis et al., 2015; Studenski et al., 2011) a $1 \mathrm{~m} / \mathrm{s}$ (Brown et al., 2016; Cesari et al., 2009a, b; Rosano, Newman, Katz, Hirsch, \& Kuller, 2008). Três estudos (Taekema et al., 2012; Toots et al., 2013; Weidung et al., 2015) identificaram que uma velocidade de marcha $<0,5 \mathrm{~m} / \mathrm{s}$ foi um preditor de mortalidade apenas entre os idosos com 85 anos ou mais.

A magnitude do declínio da velocidade da marcha ao longo dos anos também é um preditor da expectativa de vida (Sabia et al., 2014). Ainda, aqueles com dificuldades para andar em um ritmo mais rápido de forma voluntária parecem ser menos protegidos quando comparados àqueles com capacidade preservada para aumentar a velocidade de marcha voluntariamente. Em um estudo (White et al., 2013), idosos que apresentaram um declínio de $0,1 \mathrm{~m} / \mathrm{s}$ na sua velocidade de caminhada usual ao longo de 5 anos, aumentaram em 2 vezes o risco de morte. Outro estudo (Perera et al., 2005) mostrou que esse declínio na velocidade da marcha acontece de forma mais rápida entre os idosos que andavam a uma velocidade menor que $1 \mathrm{~m} / \mathrm{s}$ no baseline, sugerindo que esses indivíduos provavelmente terão um declínio mais rápido na velocidade de marcha, produzindo um efeito amplificado do risco de mortalidade nessa população. É importante ressaltar, que a melhora na velocidade da marcha foi positivamente associada com sobrevida (ou seja, maior expectativa de vida). Um estudo (Hardy et al., 2007) encontrou que o aumento da velocidade da marcha habitual ao longo de 1 ano reduziu substancialmente o risco de morte em idosos após 8 anos de acompanhamento.

A associação entre mortalidade e cadência da marcha foi investigada em um estudo (Brown et al., 2014). Após acompanharem por 13 anos uma coorte de 4016 idosos da comunidade, os autores encontraram que uma cadência $\geq 100$ passos/min previu uma 
redução de $21 \%$ no risco de mortalidade. Além disso, o estudo não observou diferença na capacidade discriminativa entre cadência e velocidade de marcha na tentativa de predizer mortalidade em 5 e 10 anos. Um estudo (Woo et al., 1999) avaliou o comprimento da passada em uma amostra de 2032 indivíduos com idade de 70 anos ou mais. O menor comprimento da passada foi significativamente associado com o aumento do risco de mortalidade em homens $(\mathrm{OR}=0.238 ; \mathrm{p}<0.001)$ e mulheres $(\mathrm{OR}=0.230 ; \mathrm{p}<0.001)$ em 36 meses de acompanhamento.

\subsubsection{Nível socioeconômico (educação e renda)}

Um total de 5 artigos selecionados na revisão sistemática investigou o impacto do nível socioeconômico (NSE) no desempenho da marcha. Nesses estudos, a velocidade de marcha (Jancova-Vseteckova et al., 2015; Quiben \& Hazuda, 2015; Thorpe et al., 2011; Weber, 2016) e a variabilidade do comprimento da passada (Medina Gonzalez, 2016) foram associados com NSE em idosos da comunidade. Dois artigos (Thorpe et al., 2011; Weber, 2016) identificaram NSE como um mediador das diferenças na velocidade da marcha. Esses estudos mostraram que indivíduos com pior NSE apresentavam menor velocidade de caminhada, mesmo quando as diferenças raciais foram consideradas. Um artigo (Weber, 2016) identificou diferenças na velocidade de marcha entre duas subpopulações de idosos separados por educação e riqueza regional. Indivíduos com maiores níveis de escolaridade vivendo em regiões mais ricas apresentavam maior velocidade de marcha em comparação àqueles com níveis de escolaridade mais baixos vivendo em regiões mais pobres. Em um estudo (Medina Gonzalez, 2016) a variabilidade do comprimento da passada foi avaliada em idosos da comunidade 
categorizados de acordo com seu NSE. Indivíduos com menor NSE apresentaram maior variabilidade do comprimento da passada comparados com indivíduos com maior NSE, indicando possíveis influências negativas do NSE no controle espacial do passo durante a marcha.

\subsection{Existem indícios de que a marcha dos idosos possa ser influenciada pelo IDH da região onde viveram por décadas?}

Esta revisão sistemática investigou o impacto do IDH no desempenho da marcha. Não foram encontrados estudos mostrando o impacto direto do IDH no desempenho da marcha em idosos. Entretanto, um total de 35 artigos investigaram a associação de componentes de nível individual relacionados às dimensões do IDH (educação, renda e expectativa de vida) no desempenho da marcha, individualmente. Cinco artigos investigaram o impacto de anos de educação ou nível educacional na velocidade da marcha. Três artigos investigaram a influência da renda na velocidade da marcha. Vinte e dois artigos investigaram a associação entre expectativa de vida e variáveis da marcha, incluindo velocidade, cadência e comprimento da passada. Cinco artigos identificaram o impacto do nível socioeconômico definido por educação e renda (juntos) na velocidade de marcha e variabilidade do comprimento da passada. De maneira geral, baixa escolaridade, baixa renda, e menor expectativa de vida foram associadas ao pior desempenho da marcha, identificada como velocidade mais lenta, passadas mais curtas

ou maior flutuações do comprimento da passada (i.e., variabilidade). É importante destacar que o desempenho da marcha foi descrito pela velocidade da marcha em 91,4\% 
de todos os estudos incluídos nessa revisão sistemática. A influência dos domínios do IDH é discutida mais adiante.

A educação tem sido reconhecida como um forte fator de proteção contra o declínio na saúde (Brunello, Fort, Schneeweis, \& Winter-Ebmer, 2016). Indivíduos com mais anos de estudos ou maior nível de escolaridade podem tomar melhores decisões sobre importantes fatores de risco à saúde (p. ex. estilo de vida, nutrição, tabagismo, etc.). Essas decisões têm implicações para a saúde na velhice, resultando em atraso no aparecimento de morbidades e menor risco de incidência de incapacidades. Esse impacto protetor da educação sobre o estado de saúde também pode ser observado na velocidade da marcha devido à sua relação com eventos adversos (p. ex. hospitalizações) (Manuel Montero-Odasso et al., 2005), e integridade neurológica (Srikanth et al., 2010). De acordo com os estudos analisados, dois principais fatores poderiam explicar as diferenças no desempenho da marcha relacionadas à educação: nível ocupacional e reserva cognitiva. Indivíduos com níveis de escolaridade mais baixos são mais propensos a terem ocupações manuais, como transportar cargas pesadas e executarem trabalhos repetitivos. A exposição a esses tipos de ocupações por muitos anos pode trazer consequências negativas para as capacidades físicas e de saúde geral mais tarde na vida. O outro fator identificado é o impacto da educação na função cognitiva. Indivíduos com maiores níveis de educacionais são capazes de manter normal o desempenho cognitivo por mais anos em comparação com aqueles com níveis educacionais mais baixos. De fato, estudos tem mostrado o efeito positivo da educação na cognição relacionados a aspectos comportamentais e neurais, sugerindo que indivíduos com maior nível de escolaridade apresentam maior "reserva cognitiva" (Tucker \& Stern, 2011). Reserva cognitiva é um 
termo usado para definir a flexibilidade e eficiência do indivíduo em fazer uso dos recursos cerebrais disponíveis adquiridos ao longo da vida para atingir objetivos externos (Tucker \& Stern, 2011). A reserva cognitiva permite que os indivíduos processem as tarefas de maneira mais eficaz, provavelmente devido as estratégias cognitivas aprimoradas que também podem proteger os indivíduos dos estressores ambientais. A cognição, por sua vez, tem um papel global no desempenho da marcha, influenciando na velocidade da marcha, variabilidade no tempo e distância e interferência na dupla-tarefa (Parihar, Mahoney, \& Verghese, 2013).

A renda ou condições econômicas podem também influenciar a velocidade da marcha de maneira similar à educação. Indivíduos com maior nível de escolaridade são mais propensos a obterem um bom nível de emprego do que aqueles com menor nível de escolaridade, e consequentemente terão mais chances de atingir um nível econômico mais elevado. Assim como a educação, a maior renda também pode ter contribuições importantes para comportamentos mais saudáveis, muitas vezes traduzidos em maior uso de serviços preventivos de saúde durante o curso de vida dos indivíduos. Esse comportamento preventivo tem sido observado na melhora do bem-estar e no funcionamento físico na vida adulta (Brunner et al., 2009; Zaninotto et al., 2013). Essa revisão sistemática também encontrou estudos que mostraram que a insegurança financeira (i.e., renda insuficiente para as necessidades básicas) explicou o impacto das diferenças sociais na velocidade de marcha em idosos da comunidade (Brunner et al., 2009). Além disso, a velocidade de caminhada mais lenta em indivíduos com baixa renda persistiu ao longo de suas vidas, independentemente de mudanças de renda no final da vida. Curiosamente, um estudo mostrou que indivíduos que vivem em regiões mais ricas 
andam com maior velocidade em comparação com indivíduos que vivem em regiões mais pobres (Weber, 2016). Essa associação entre região e velocidade da marcha é apoiada por um estudo prévio que encontrou associação positiva dos fatores regionais (taxa de desemprego e desenvolvimento regional) com o bem-estar e com a capacidade funcional (Gerstorf et al., 2010). Esse estudo sugere que fatores socioeconômicos podem moldar a natureza e o curso dos processos que ocorrem individualmente. Em conjunto, esses estudos apoiam a hipótese de que a velocidade da marcha em idosos pode ser fortemente afetada pelo IDH da região onde esses indivíduos viveram por décadas. Uma ressalva importante que se deve fazer em relação aos estudos que investigaram a relação entre renda e velocidade de marcha, é a falta de ajustes para a escolaridade e/ou nível ocupacional. Isso impede conclusões mais consistentes sobre o efeito da renda na velocidade da marcha.

De acordo com os estudos revisados, existe evidências robustas para confirmar que a velocidade da marcha é um importante marcador do status de saúde e da expectativa de vida. Exposições a diferentes condições ambientais adversas podem afetar profundamente a expectativa de vida dos indivíduos mais velhos, provavelmente devido à carga de estresse sobre o seu funcionamento orgânico. O pior estado de saúde é frequentemente traduzido em pior desempenho da marcha, particularmente na velocidade. A mortalidade e a sobrevida estão fortemente associadas à velocidade com que o indivíduo idoso caminha, além de outras variáveis subjacentes da marcha, incluindo cadência e comprimento da passada (J. C. Brown et al., 2014; Studenski et al., 2011; Woo et al., 1999). De maneira geral, a relação entre velocidade de marcha e mortalidade pode ocorrer porque a caminhada requer suporte dos sistemas 
cardiorrespiratório, nervoso e musculoesquelético. Em média, velocidades abaixo de 1 $\mathrm{m} / \mathrm{s}$ são um forte preditor de mortalidade dentro de um período de 5 a 10 anos. Além disso, a força de predição de mortalidade aumenta à medida que a marcha se torna mais lenta nos idosos. Mortalidade e sobrevida são fatores que refletem diretamente a expectativa de vida, como mencionado anteriormente. Portanto, a velocidade de marcha poderia sofrer influência do IDH, uma vez que a expectativa de vida é uma das três dimensões utilizadas para calcular tal índice.

Esta revisão sistemática tem limitações que precisam ser reconhecidas. Apenas 3 estudos $(8,5 \%)$ avaliaram outras variáveis da marcha além da velocidade. Sabe-se que a variabilidade da marcha, a interferência da marcha pela dupla-tarefa, bem como mudanças na base de suporte têm forte associação com a estabilidade da marcha, com o controle postural e com o nível cognitivo de idosos, e, portanto, são variáveis importantes para entender as mudanças orgânicas causadas pela exposição a longo prazo a regiões com baixo IDH. Embora renda tenha sido associada com velocidade de marcha, os três estudos que avaliaram essa relação, não realizaram ajustes por educação e nível ocupacional. Assim, a possibilidade da educação e nível ocupacional mediarem essa relação não pode ser descartada. Portanto, a associação entre renda e marcha pode não ser tão robusta quanto a educação e o status de saúde. Outro ponto, indivíduos com diferentes etnias podem ser influenciados pelas condições sociais de diferentes maneiras. Assim, os aspectos de mobilidade também podem ser diferentemente impactados pelo IDH. Embora dois artigos tenham identificado nível socioeconômico como um importante mediador das diferenças na velocidade da marcha entre grupos étnicos, não é possível descartar que a heterogeneidade étnica influenciou os resultados dos outros estudos citados nesta 
revisão sistemática. Uma importante limitação foi a ausência de estudos avaliando o desempenho da marcha como um produto da medida completa do IDH. Essa limitação da revisão sistemática impede que se faça conclusões mais fortes sobre a relação entre IDH e desempenho da marcha. Por outro lado, as características de educação, renda e expectativa de vida de uma população podem influenciar o cálculo das dimensões do IDH. Isso permite inferir que a relação entre fatores avaliados de maneira individual das dimensões do IDH e o desempenho da marcha pode refletir os indicadores das dimensões do IDH de uma região. 


\section{Objetivos e Hipóteses}




\section{OBJETIVOS E HIPÓTESES}

Com base nos estudos que mostram que a exposição a longo prazo às condições ambientais pode afetar a capacidade orgânica de indivíduos durante seu curso de vida, e o desempenho da marcha frequentemente reflete essas mudanças, o objetivo deste estudo foi avaliar os padrões de marcha de idosos que nasceram, cresceram e vivem atualmente em regiões com diferentes IDH's, sob condições de marcha normal e associada à duplatarefa.

A primeira hipótese deste estudo é que idosos vivendo em regiões com baixo IDH mostrem pior desempenho na marcha comparados com indivíduos vivendo em regiões com maiores IDH's. Complementarmente, tem-se como segunda hipótese que a duplatarefa pode revelar ou amplificar as diferenças na marcha naqueles indivíduos que passaram suas vidas em regiões com baixo IDH, enquanto aqueles que vivem em regiões com IDH's mais elevados apresentariam mudanças mínimas no desempenho da marcha. 
Métodos 


\section{MÉTODOS}

\subsection{Participantes do estudo}

O estudo foi conduzido em três regiões com diferentes classificações de IDH: Coari, localizado no estado do Amazonas (região norte do Brasil) classificado com IDH baixo $(0,586)$; Ribeirão Preto, localizado no estado de São Paulo (região sudeste do Brasil) classificado com IDH alto $(0,800)$; e London, localizado na província de Ontario (Canadá) classificado com IDH muito alto $(0,905)$.

Os participantes residentes no Brasil foram avaliados entre junho de 2013 a julho de 2016 (Uguccioni, 2016; United Nations Development Programme, 2013). Os dados sociodemográficos e da marcha dos participantes de London (Ontario-Canadá) foram extraídos do banco de dados "Gait and Brain Study” de 2010 a 2017 (clinicaltrials.gov \#NCT03020381).

O "Gait and Brain Study" é um estudo de coorte prospectivo desenvolvido para determinar se os prejuízos quantitativos na marcha podem predizer o declínio cognitivo e de mobilidade, a progressão para demência e o status de fragilidade entre idosos (Manuel Montero-Odasso et al., 2014). A amostra de London foi utilizada como um parâmetro de IDH muito alto no continente americano. O Canadá é atualmente o país com o maior IDH de todas as Américas e tem permanecido nas duas primeiras posições desde que o ranking do IDH foi criado nos anos 60 (United Nations Development Programme, 2018). O protocolo para avaliação da marcha do "Gait and Brain Study" foi adotado para realizar todas as coletas de dados neste estudo, incluindo as duas cidades brasileiras.

Os critérios gerais de inclusão foram idade de 60 anos ou mais e capacidade de andar de forma independente sem auxílio externo para marcha (bengala ou andador). Os 
critérios de exclusão incluíram comprometimentos graves do equilíbrio, qualquer distúrbio neurológico com déficits motores residuais, distúrbios musculoesqueléticos (por exemplo, artrite graves de membros inferiores e presença de dor em membros inferiores) ou histórico de próteses de joelho/quadril afetando o desempenho da marcha ao exame clínico, uso de medicação psicotrópica (neurolépticos ou benzodiazepínicos), depressão grave e presença de comprometimento cognitivo identificados pelo Mini exame do estado mental (MEEM). Os participantes com seguintes scores do MEEM foram excluídos do estudo: menor do que 13 pontos para idosos analfabetos (sem escolaridade); 18 pontos para aqueles com 1-7 anos de estudos (baixa/média escolaridade); e 26 pontos para os idosos que tinham 8 ou mais anos de estudos (alta escolaridade) (Bertolucci, Brucki, Campacci, \& Juliano, 1994).

Para o cálculo do tamanho da amostra, a velocidade da marcha foi considerada como variável principal e a sua média e desvio-padrão obtidos a partir de um estudo piloto nas duas regiões brasileiras selecionadas para este estudo. $\mathrm{O}$ cálculo revelou um mínimo de 192 idosos (96 indivíduos de Coari e 96 indivíduos de Ribeirão Preto), considerando um "effect size" de 0,55, um nível de alfa de 0,05 e poder de 0,95. O cálculo foi desenvolvido usando o G*Power Software, versão 3.1.92 (Universitat Kiel Alemanha).

Os participantes foram recrutados aleatoriamente de comunidades locais ou bairros cobrindo as regiões norte, sul, leste e oeste em cada cidade onde os participantes foram testados. Após o aceite do idoso para participar do estudo, no dia do primeiro contato o mesmo era submetido a uma breve avaliação sociodemográfica e cognitiva para testar a elegibilidade do estudo. Depois de confirmar a elegibilidade, os participantes 
foram convidados a comparecer ao laboratório de avaliação. Em Coari - AM, os testes foram realizados no Laboratório de fisioterapia do Instituto de Saúde e Biotecnologia da Universidade Federal do Amazonas - ISB/UFAM. Em Ribeirão Preto - SP, a aplicação dos testes aconteceu no Laboratório de Avaliação e Reabilitação do Equilíbrio (LARE) da Faculdade de Medicina de Ribeirão Preto - FMRP/USP. E por fim, os participantes de London - ON foram avaliados no Gait and Brain Lab - Parkwood Institute London of University of Western Ontario. Todos os indivíduos inscritos neste estudo nasceram, foram criados e estavam atualmente morando na mesma região durante a maior parte de sua vida, de acordo com o autorrelato. O estudo foi aprovado pelo comitê de ética da Universidade Federal do Amazonas - UFAM - Coari - Brasil (anexo 2) e seguiu o protocolo de Helsinki para estudos com seres humanos (CAAE: 21609213.7.0000.5020).

\subsection{Características demográficas, sociais e econômicas das regiões}

\subsubsection{Coari-AM-Brasil (IDH baixo)}

Coari está geograficamente localizada às margens do Rio Solimões, no estado do Amazonas, e o acesso à cidade só pode ser alcançado por via fluvial (barcos) ou aérea (avião). Uma vez que as cidades do interior do Amazonas estão interligadas apenas por rios e as rodovias intermunicipais não estão disponíveis, o acesso a essas cidades é muito limitado (Freire Junior, Fernandes, Borges, Guerra, \& de Abreu, 2018).

De acordo com dados do Censo de 2010 (Instituto Brasileiro de Geografia e Estatística. IBGE, 2011), Coari possui 75.965 habitantes, sendo que 4,5\% destes, são indivíduos com idade de 60 anos ou mais. A expectativa de vida é de 71,8 anos, e a renda da população é baixa de acordo com os padrões brasileiros. Aproximadamente 64,9\% 
deles ganham menos de 1 salário mínimo mensal. A porcentagem de analfabetismo entre a população de Coari é de $17,3 \%$ e esta taxa atinge $55,1 \%$ entre a população idosa (Instituto Brasileiro de Geografia e Estatística. IBGE, 2011). As Nações Unidas classificam o IDH de Coari como o $4495^{\circ}$ entre 5565 cidades brasileiras (United Nations Development Programme, 2013). Este ranking é estimado com base nos IDH's de todas as cidades do país.

\subsubsection{Ribeirão Preto - SP - Brasil (IDH alto)}

Ribeirão está localizada no estado de São Paulo e a sua localização geográfica pode ser acessada através de modernas rodovias que também conectam a cidade aos principais polos industriais e financeiros do Brasil. De acordo com dados do Censo de 2010 (Instituto Brasileiro de Geografia e Estatística. IBGE, 2011), Ribeirão Preto possui 604.682 habitantes, sendo 12,5\% indivíduos com idade de 60 anos ou mais. Aproximadamente $11 \%$ da população ganha menos de 1 salário mínimo mensal, e a taxa de analfabetismo é baixa (3\%) comparada com outras cidades brasileiras. Entre os idosos, essa taxa de analfabetismo é de $8,7 \%$. A expectativa de vida dos moradores de Ribeirão Preto alcança 75,7 anos, superando a medida nacional de 73,9 anos. Ela é considerada umas das 40 melhores cidades brasileiras para se viver de acordo com o ranking das Nações Unidas estimado pelo IDH (United Nations Development Programme, 2013). A tabela 2 apresenta um quadro comparativo das principais características socioeconômicas dos dois municípios brasileiros onde se recrutou os idosos participantes deste estudo. 
Tabela 2 - Quadro comparativo das características socioeconômicas entre os dois municípios brasileiros - Coari - AM e Ribeirão Preto - SP

\begin{tabular}{lcc}
\hline & Coari- AM* & Ribeirão Preto - SP* \\
\hline Renda domiciliar (R\$) & 314,89 & $1.283,15$ \\
\hline Pessoas c/ baixa renda (até $\mathbf{1} \mathbf{2}$ SM) & $64,95 \%$ & $11 \%$ \\
\hline Analfabetismo total & $17,3 \%$ & $3 \%$ \\
\hline Analfabetismo entre idosos & $55,1 \%$ & $8,7 \%$ \\
\hline Expectativa de vida & 71,8 anos & 75,7 anos \\
\hline IDH & 0,586 & 0,800 \\
\hline
\end{tabular}

*Dados extraídos do Banco de dados Cidades@ do IBGE; SM, salário mínimo; IDH, Índice de desenvolvimento Humano

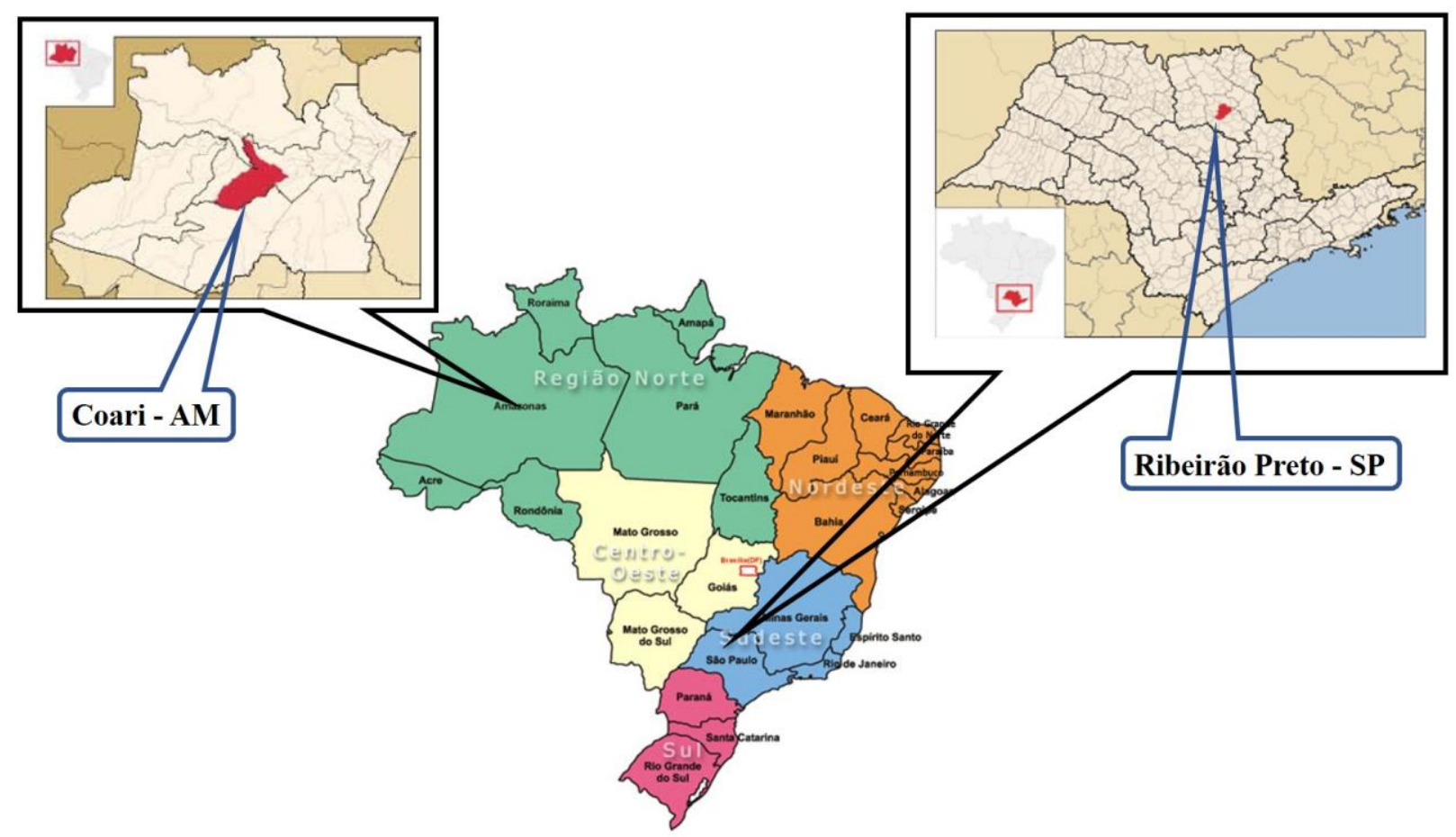

Figura 3 - Mapa do Brasil destacando o estado do Amazonas - com a delimitação em vermelho do município de Coari, e o estado de São Paulo - com delimitação em vermelho do município de Ribeirão Preto 


\subsubsection{London - Ontario - Canadá (IDH muito alto)}

London está localizada no sudoeste de Ontario e é considerada um importante centro industrial e de transporte, como resultado de sua localização estratégica. Ela está no centro de extensas redes ferroviárias e rodovias (Rodovias 401 e 402). De acordo com dados do Censo 2011, London possui 366.151 habitantes, e 20,47\% são indivíduos com idade de 65 anos ou mais (Uguccioni, 2016). Em 2011, 11,8\% da população vivia com renda menor do que é considerado o mínimo necessário de acordo com "after-tax lowincome cut-off" (LICO). Entre indivíduos com idade de 65 anos ou mais essa taxa foi de 3,8\%. A LICO é a medida mais comumente utilizada no Canadá para estimativas socioeconômicas. É definida como o limiar de renda abaixo da renda média nacional das famílias canadenses, dos quais uma família provavelmente dedicará uma parcela maior de sua renda do que é esperado para às necessidades de comida, moradia e vestuário.

Em relação ao nível de escolaridade, mais da metade $(55,6 \%)$ dos indivíduos com idade igual ou superior a 15 anos alcançou o ensino superior e cerca de $28 \%$ concluíram o ensino médio ou adquiriram grau equivalente (Census, 2016). Com sua atividade econômica centrada na educação, pesquisa médica e tecnologia da informação, London está localizada em uma região (Ontário) com um dos maiores IDH's do continente americano $(\mathrm{IDH}=0,905)$. 


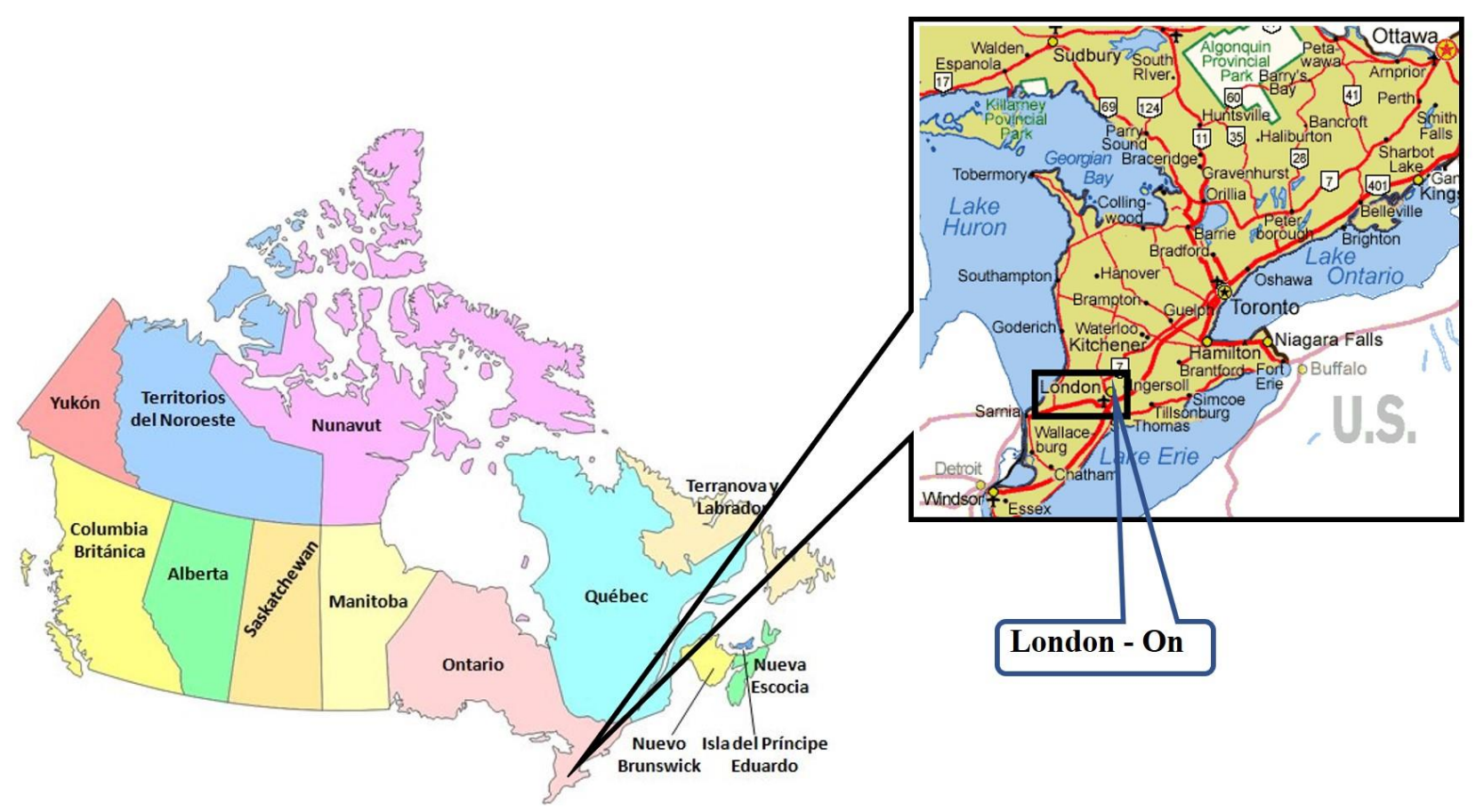

Figura 4 - Mapa do Canadá destacando uma parte da Província de Ontario e a cidade de London

\subsection{Avaliação sociodemográfica, de saúde e função física}

Durante a entrevista presencial inicial, os dados sociodemográficos foram extraídos incluindo: sexo, idade, peso, altura, índice de massa corporal (IMC), renda e classe ocupacional, anos de estudo, comorbidades, e quantidade de medicamentos de uso contínuo. Informações sobre renda e classe ocupacional foram obtidas apenas para os participantes brasileiros. Para homogeneizar as ocupações de trabalho e facilitar as análises, a classe ocupacional foi categorizada de acordo com estudo prévio (Sousa et al., 2014) da seguinte forma: a) Trabalho não manual, considerando as profissões de maior qualificação intelectual; b) trabalho manual especializado, como operadores de máquinas, trabalhadores de indústrias, trabalho com exigências de poucos anos de estudo, artesãos; 
c) trabalho manual semiespecializado, caracterizado pelos serviços de ocupações elementares; d) o trabalho doméstico não remunerado; e em uma categoria separada e) agricultores. Os indivíduos também foram solicitados a relatar as condições de saúde crônicas, o histórico de quedas nos últimos seis meses e se tinham medo de cair (apêndice 3).

A função física foi avaliada usando o Short Physical Performance Battery - SPPB (Guralnik et al., 1994). O SPPB mede três importantes capacidades funcionais: equilíbrio em pé (semi-estático), velocidade da marcha (caminhada) em um percurso de caminhada de 4 metros e o tempo gasto para realizar o teste de levantar e sentar da cadeira 5 vezes (força dos membros inferiores) (anexo 3). Cada componente do SPPB apresenta um score que vai de 0 (incapacidade) até 4 (alto desempenho). Ao final do teste a soma dos scores dos três componentes gera um valor (amplitude 0-12). Um escore abaixo de 7 pontos sugere probabilidade de incapacidade. A validade e confiabilidade da aplicação do SPPB tem sido reconhecida tanto para idosos brasileiros quanto idosos canadenses (Freire, Guerra, Alvarado, Guralnik, \& Zunzunegui, 2012).

\subsection{Registro e protocolo de avaliação da marcha}

O desempenho da marcha foi avaliado em todos os campos deste projeto utilizando uma passarela eletrônica (GAITRite Platinum 26', CIR Systems Sparta, New York, USA; $800 \mathrm{~cm}$ x 90cm) registrada em $100 \mathrm{~Hz}$, a qual fornece dados para os parâmetros espaciais e temporais da marcha. Um software personalizado quantificou vários parâmetros da marcha, incluindo velocidade de marcha $(\mathrm{cm} / \mathrm{s})$, cadência (passos/min), tempo da passada (milissegundos), comprimento do passo (cm) e largura da 
passada $(\mathrm{cm})$, além das flutuações passo a passo, determinadas pela variabilidade da marcha.

Os idosos iniciavam sua caminhada 1 metro antes da passarela eletrônica e finalizavam 1 metro depois para evitar a interferência da aceleração/desaceleração durante os registros. Para todos os testes os idosos eram solicitados a caminharem no seu ritmo habitual. O desempenho da marcha foi registrado sob duas condições: tarefa única (caminhada no ritmo habitual) e dupla-tarefa (caminhar enquanto nomeia animais) (Montero-Odasso, Muir, \& Speechley, 2012). A tarefa cognitiva de "nomear animais" como dupla-tarefa principal, foi escolhida porque ela possui baixo viés sociocultural, já que nomes dos animais podem ser aprendidos virtualmente em qualquer contexto, independentemente do nível de escolaridade. A ordem de avaliação da marcha (tarefa única e dupla tarefa) foi randomizada e três coletas para cada situação foram realizadas. Além disso, os registros da marcha deveriam totalizar um mínimo de vinte e cinco a trinta e seis passos para que fosse possível uma melhor visualização da variabilidade da marcha, de acordo com as recomendações da literatura (Lord, Howe, Greenland, Simpson, \& Rochester, 2011).

A variabilidade da marcha foi determinada por um parâmetro temporal (tempo da passada) e um parâmetro espacial (comprimento do passo) usando o coeficiente de variação (COV\%), dada pela razão entre o desvio-padrão e a média da variável, multiplicado por 100: $\mathrm{COV}=(\mathrm{DP} / \mathrm{Média}) * 100$ (Montero-Odasso et al., 2011). Trata-se de uma medida padronizada de variabilidade amplamente utilizada nos estudos que avaliam dados espaço-temporais da marcha e que permite a comparação de variáveis expressas em diferentes unidades, com diferentes médias e amplitude de valores. 
O custo da dupla-tarefa criado pela interferência da tarefa cognitiva realizada durante a caminhada foi calculado da seguinte forma: ([desempenho da marcha na tarefa única - desempenho da marcha na dupla-tarefa] / desempenho da marcha na tarefa única) x 100 (Hall, Echt, Wolf, \& Rogers, 2011; Manuel Montero-Odasso et al., 2014).

\subsection{Análise estatística}

As características sociodemográficas, de saúde e função física foram resumidas usando médias e desvios-padrão, ou frequências e porcentagens conforme apropriado. Teste de Shapiro-wilk foi usado para testar a normalidade dos dados da marcha. As diferenças entre os grupos por IDH nas características sociodemográficas, de comorbidades e de função física foram analisadas utilizando-se ANOVA one-way para variáveis contínuas e teste qui-quadrado para variáveis categóricas.

A comparação dos padrões de marcha entre os grupos foi desenvolvida usando um modelo linear geral multivariado (Wilks Lambda). A comparação da variabilidade da marcha e do custo da dupla-tarefa foi desenvolvida usando o modelo linear geral univariado - análise de variância (ANOVA). O teste post-hoc de Bonferroni foi usado para determinar as diferenças entre os grupos quando apropriado.

Covariáveis foram definidas com base nas influências reconhecidas das condições clínicas no desempenho da marcha e na mobilidade em idosos. Como essas variáveis podem ser importantes fatores de confusão na análise, três modelos estatísticos foram criados: modelo 1 (não ajustado); modelo 2, ajustado por sexo, idade, altura, peso, quantidade de medicamentos, MEEM, número de quedas, medo de cair, SPPB; e modelo

3, apresentando os ajustes do modelo $2+$ anos de estudo. A significância estatística foi 
estabelecida em $\mathrm{p} \leq 0,05$ (two-sided). As análises estatísticas foram desenvolvidas utilizando o programa SPSS (versão 18.0, IBM Corporation, Chicago, IL). 


\section{Resultados}




\section{RESULTADOS}

\subsection{Características dos participantes}

Um total de 373 participantes foram avaliados nesse estudo, sendo 124 idosos residentes em Coari (IDH-baixo), 109 em Ribeirão Preto (IDH-alto) e 140 em London (IDH-muito alto). As características sociodemográficas e antropométricas dos participantes estão resumidas na tabela 3 .

Tabela 3 - Características sociodemográficas e antropométricas dos três grupos

\begin{tabular}{|c|c|c|c|c|}
\hline Variáveis & $\begin{array}{c}\text { IDH-Baixo } \\
\mathrm{n}=124\end{array}$ & $\begin{array}{c}\text { IDH-Alto } \\
\mathrm{n}=109\end{array}$ & $\begin{array}{l}\text { IDH-Muito alto } \\
\qquad \mathrm{n}=140\end{array}$ & $\begin{array}{c}\text { Valor de } \\
\mathrm{p}^{*}\end{array}$ \\
\hline Sexo (feminino) N (\%) & $76(61,3 \%)$ & $74(67,9 \%)$ & $75(53,5 \%)$ & ,070 \\
\hline Idade Média \pm DP & $71,06 \pm 7,6^{\mathrm{a}, \mathrm{b}}$ & $68,56 \pm 5,4^{\mathrm{c}}$ & $73,95 \pm 6,1$ &, 000 \\
\hline Renda N (\%) & & & &, 000 \\
\hline$<1$ salário mínimo & $22(17,7)$ & $1(0,9)$ & N/A & \\
\hline 1 - 2 salários mínimos & $86(69,4)$ & $27(24,8)$ & N/A & \\
\hline 3 - 5 salários mínimos & $13(10,5)$ & $50(45,9)$ & N/A & \\
\hline > 5 salários mínimos & $3(2,4)$ & $31(28,4)$ & N/A & \\
\hline Classe ocupacional N (\%) & & & &, 000 \\
\hline Trabalho não manual & $5(4,0)$ & $12(11,0)$ & N/A & \\
\hline Manual especializado & $1(0,8)$ & $46(42,2)$ & N/A & \\
\hline Manual semi-especializado & $24(19,4)$ & $44(40,4)$ & N/A & \\
\hline Doméstico & $22(17,7)$ & $7(6,4)$ & N/A & \\
\hline Agricultores & $72(58,1)$ & $0(0,0)$ & & \\
\hline IMC $\left(\mathrm{kg} / \mathrm{m}^{2}\right)$ Média \pm DP & $26,27 \pm 4,6^{\mathrm{a}}$ & $28,31 \pm 4,2$ & $27,33 \pm 4,5$ &, 005 \\
\hline MEEM Média \pm DP & $22,55 \pm 4,5^{\mathrm{a}, \mathrm{b}}$ & $27,06 \pm 2,2^{\mathrm{c}}$ & $27,79 \pm 2,3$ &, 000 \\
\hline Anos de estudo Média \pm DP & $2,49 \pm 3,2^{a, b}$ & $8,85 \pm 4,7^{c}$ & $14,00 \pm 2,8$ &, 000 \\
\hline
\end{tabular}


Os três grupos foram homogêneos em relação ao sexo. Os participantes de London (IDH-muito alto) eram em média mais velhos do que os participantes de ambas as regiões brasileiras, e os participantes de Coari (IDH-baixo) eram em média mais velhos do que os participantes de Ribeirão Preto (IDH-alto).

O registro sobre renda e classe ocupacional foram apresentados apenas para as duas regiões brasileiras, sendo possível observar relevantes desigualdades. Os idosos do grupo IDH-baixo relataram rendas significantemente mais baixas quando comparados aos idosos do grupo IDH-alto. Do mesmo modo, enquanto no grupo IDH-baixo os idosos se concentraram nas ocupações de agricultura e trabalho doméstico, os idosos do grupo IDH-alto relataram ocupações em cargos de trabalhos manuais especializados, semiespecializado e não manuais com maiores exigências intelectuais.

O grupo IDH-baixo apresentou menor IMC comparado apenas com o grupo IDHalto. O estado cognitivo geral (MEEM) foi significativamente maior no grupo IDH-muito alto em comparação com os grupos IDH-baixo e IHD-alto. Indivíduos do grupo IDH-alto apresentaram, em média, maiores escores no MEEM quando comparados aos participantes do grupo IDH-baixo. Os anos de estudo foram significativamente maiores no grupo IDH-muito alto em comparação com os dois grupos das regiões brasileiras, IDH-alto e IDH-baixo. Entre os indivíduos do grupo IDH-alto, os anos de estudo foram significativamente maiores quando comparados aos indivíduos do grupo IDH-baixo.

Foram observadas também diferenças significativas nas características de saúde e função física entre os três grupos. Essas informações são resumidamente apresentadas na tabela 4 . 
Tabela 4 - Características de saúde e função física dos três grupos

\begin{tabular}{lrrrr}
\hline \hline Variáveis & IDH-Baixo & IDH-Alto & IDH-Muito alto & Valor de \\
& $\mathrm{n}=124$ & $\mathrm{n}=109$ & $\mathrm{n}=140$ & \multicolumn{1}{c}{$\mathrm{p}^{*}$} \\
\hline Medicamentos N Média \pm DP & $1,1 \pm 1,4^{\mathrm{a}, \mathrm{b}}$ & $2,66 \pm 2,1^{\mathrm{c}}$ & $7,63 \pm 4,7$ & $\mathbf{, 0 0 0}$ \\
História de tabagismo N (\%) & $85(68,5)^{\mathrm{a}, \mathrm{b}}$ & $37(33,9)$ & $53(37,9)$ & $\mathbf{, 0 0 0}$ \\
Hipertensão N (\%) & $58(46,8)$ & $56(51,4)$ & $72(51,4)$ &, 701 \\
Diabetes Mellitus N (\%) & $20(16,1)$ & $19(17,4)$ & $23(16,4)$ &, 962 \\
Acidente vascular cerebral N (\%) & $12(9,4)$ & $3(2,8)$ & $7(5,0)$ &, 069 \\
Doença pulmonar N (\%) & $4(3,2)$ & $4(3,7)$ & $11(7,9)$ &, 168 \\
Osteoporose N (\%) & $15(12,1)$ & $9(8,3)$ & $20(14,3)$ &, 340 \\
Osteoartrites N (\%) & $54(43,5)^{\mathrm{a}}$ & $27(24,8)^{\mathrm{c}}$ & $52(37,1)$ & $\mathbf{, 0 1 0}$ \\
Quedas nos últimos 6 meses N (\%) & $18(14,5)$ & $23(21,1)$ & $40(28,6)$ & $\mathbf{, 0 2 0}$ \\
Número de quedas Média \pm DP & $0,23 \pm 0,6^{\mathrm{b}}$ & $0,27 \pm 0,5$ & $0,45 \pm 0,9$ & $\mathbf{, 0 3 6}$ \\
Medo de cair N (\%) & $84(67,7)^{\mathrm{a}, \mathrm{b}}$ & $40(36,7)^{\mathrm{c}}$ & $15(10,7)$ & $\mathbf{, 0 0 0}$ \\
SPPB Média \pm DP & $10,53 \pm 1,2^{\mathrm{b}}$ & $10,59 \pm 1,1^{\mathrm{c}}$ & $9,32 \pm 2,2$ & $\mathbf{, 0 0 0}$ \\
\hline \hline
\end{tabular}

N, número absoluto; DP, desvio padrão; SPPB, Short Physical Performance Battery;

a, diferença significativa entre IDH-baixo e IDH-alto; $b$, diferença significativa entre IDH-baixo e IDHmuito alto; c, diferença significativa entre IDH-alto e IDH-muito alto;

*, Teste ANOVA one-way para variáveis contínuas e qui-quadrado para variáveis categóricas

Os indivíduos do grupo IDH-muito alto tomavam mais medicamentos em comparação com ambos os grupos IDH-baixo e IHD-alto, enquanto que os indivíduos do grupo IDH-alto tomavam, em média, mais medicamentos do que os indivíduos do grupo IDH-baixo. Indivíduos do grupo IDH-baixo apresentaram, em média, maior histórico de tabagismo em comparação com os grupos IDH-alto e IDH-muito alto. Não houve diferenças entre os grupos no número de comorbidades, exceto para osteoartrites, a qual foi encontrada maior relato entre os indivíduos do grupo IDH-alto em comparação com os grupos IDH-baixo e IDH-muito alto.

O número de participantes que caíram nos últimos 6 meses, bem como o número de quedas nos últimos 6 meses foi estatisticamente maior no grupo IDH-muito alto comparado ao grupo IDH-baixo. Curiosamente, o número de participantes que relataram 
medo de cair no grupo IDH-baixo foi maior quando comparado aos participantes do grupo IDH-alto e IDH-muito alto. O grupo IDH-alto apresentou maior porcentagem de indivíduos que relataram medo de cair em comparação ao grupo IDH-muito alto. O grupo IDH-muito alto apresentou, em média menor escore do SPPB (função de membros inferiores) em comparação com os dois grupos das regiões brasileiras, IDH-alto e IDHbaixo.

\subsection{Desempenho da marcha nos grupos por IDH}

O teste Wilks-Lambda revelou diferenças entre os grupos por IDH no modelo não ajustado $\left(\lambda=0,71 ; \mathrm{F}_{10,732}=13,4 ; \mathrm{p}=<, 001\right)$. A análise univarada revelou que velocidade da marcha, cadência, tempo da passada e comprimento do passo diferiram significativamente entre os grupos. Quando a análise foi ajustada por sexo, idade, altura, peso, quantidade de medicamentos, MEEM, número de quedas e SPPB (ajustamento 1) as diferenças no padrão da marcha permaneceram estatisticamente significativas $(\lambda=$ 0,$\left.76 ; \mathrm{F}_{10,672}=9,5 ; \mathrm{p}=<, 001\right)$, e todas as variáveis da marcha apresentaram efeito principal entre os grupos. No modelo de ajuste total (ajustamento1 + anos de estudo), as diferenças no padrão da marcha permaneceram estatisticamente significante $(\lambda=0,78$; $\left.\mathrm{F}_{10,668}=8,9 ; \mathrm{p}=<, 001\right)$. $\mathrm{O}$ efeito principal entre os grupos permaneceu estatisticamente significativo para todas as cinco variáveis analisadas. Comparações pareadas ajustadas por correções de Bonferroni mostraram que o grupo IDH-baixo apresentou menor velocidade de marcha, menor cadência, maior tempo da passada e menor comprimento do passo do que os grupos IDH-alto e IDH-muito alto. Menor largura da passada foi encontrada entre os indivíduos do grupo IDH-baixo, porém apenas quando comparado ao 
grupo IDH-alto. Não foram observadas nenhuma diferença no desempenho da marcha entre os grupos IDH-alto e IDH-muito alto. Os dados são apresentados na tabela 5.

\subsection{Variabilidade da marcha nos grupos por IDH}

$\mathrm{Na}$ análise não ajustada das flutuações passo a passo da marcha (isto é, variabilidade), efeito principal entre os grupos foi encontrado para a variabilidade do comprimento do passo $\left(\mathrm{F}_{2,365}=38,2 ; \mathrm{p}=<, 001\right)$. Quando se adicionou as covariáveis de confusão do modelo 1 de ajustamento, o efeito principal entre os grupos foi mantido $\left(\mathrm{F}_{2}\right.$, $337=4,6 ; p=, 010)$. Da mesma forma, o efeito principal entre os grupos permaneceu até mesmo quando o modelo 2 de ajustamento (modelo $1+$ anos de estudo) foi aplicado na análise $\left(\mathrm{F}_{2,335}=3,2 ; \mathrm{p}=, 041\right)$. As comparações entre pares ajustadas por Bonferroni mostraram que os idosos do grupo IDH-muito alto apresentaram maior variabilidade do comprimento do passo do que os idosos dos grupos IDH-alto e IDH baixo. Entre os idosos das duas regiões brasileiras (IDH-alto e IDAH-baixo) não foram observadas diferenças na variabilidade do comprimento do passo.

$\mathrm{Na}$ análise da variabilidade do tempo da passada nenhum efeito principal foi observado entre os grupos, não sendo encontrada assim diferenças significativas entre os idosos dos três grupos. A tabela 6 apresenta a descrição dos dados da variabilidade, bem como os resultados da análise univariada. 
Tabela 5 - Desempenho da marcha habitual dos grupos por IDH

\begin{tabular}{|c|c|c|c|c|c|c|}
\hline \multirow{2}{*}{ Variáveis } & \multirow{2}{*}{$\begin{array}{c}\text { IDH-baixo } \\
n=124 \\
\text { Média } \pm \text { DP }\end{array}$} & \multirow{2}{*}{$\begin{array}{c}\text { IDH-alto } \\
\mathrm{n}=109 \\
\text { Média } \pm \mathrm{DP}\end{array}$} & \multirow{2}{*}{$\begin{array}{l}\text { IDH-muito alto } \\
n=140 \\
\text { Média } \pm \text { DP }\end{array}$} & \multicolumn{3}{|c|}{ Efeito principal entre os grupos (valor de p) } \\
\hline & & & & Não ajustado & Modelo 1 & Modelo 2 \\
\hline $\begin{array}{l}\text { Velocidade } \\
(\mathrm{cm} / \mathrm{s})\end{array}$ & $94.74 \pm 18.3^{\mathrm{a}, \mathrm{b}}$ & $117.93 \pm 20.4$ & $110.2 \pm 20.7$ & $<.001$ & $<.001$ & $<.001$ \\
\hline $\begin{array}{l}\text { Cadência } \\
\text { (passos/min) }\end{array}$ & $104.49 \pm 10.0^{\mathrm{a}, \mathrm{b}}$ & $114.36 \pm 9.6$ & $106.34 \pm 9.2$ & $<.001$ & $<.001$ & $<.001$ \\
\hline $\begin{array}{l}\text { Tempo da passada } \\
\text { (millisec) }\end{array}$ & $1156 \pm 0.1^{\mathrm{a}, \mathrm{b}}$ & $1046 \pm 0.1$ & $1134 \pm 0.0$ & $<.001$ & $<.001$ & $<.001$ \\
\hline $\begin{array}{l}\text { Comprimento do passo } \\
(\mathrm{cm})\end{array}$ & $54.02 \pm 7.4^{\mathrm{a}, \mathrm{b}}$ & $61.82 \pm 8.2$ & $61.70 \pm 9.5$ & $<.001$ & $<.001$ & $<.001$ \\
\hline $\begin{array}{l}\text { Largura da passada } \\
(\mathrm{cm})\end{array}$ & $7.98 \pm 2.8^{\mathrm{a}}$ & $8.70 \pm 2.4$ & $8.03 \pm 3.3$ & .117 & .001 & .001 \\
\hline
\end{tabular}

Modelo 1: ajuste por sexo, idade, altura, peso, quantidade de medicamentos, MEEM, número de quedas, SPPB; Modelo 2: ajustes do modelo 1 + anos de estudo a, diferença significativa entre os grupos IDH-baixo e IDH-alto; b, diferença significativa entre os grupos IDH-baixo e IDH-muito alto; 
Tabela 6 - Variabilidade da marcha dos grupos por IDH

\begin{tabular}{|c|c|c|c|c|c|c|}
\hline \multirow[t]{2}{*}{ Variabilidade (COV\%) } & \multirow{2}{*}{$\begin{array}{c}\text { IDH-baixo } \\
n=124 \\
\text { Média } \pm \text { DP }\end{array}$} & \multirow{2}{*}{$\begin{array}{c}\begin{array}{c}\text { IDH-alto } \\
\mathrm{n}=109\end{array} \\
\text { Média } \pm \mathrm{DP}\end{array}$} & \multirow{2}{*}{$\begin{array}{c}\begin{array}{c}\text { IDH-muito } \\
\text { alto } \\
\mathrm{n}=140\end{array} \\
\text { Média } \pm \mathrm{DP}\end{array}$} & \multicolumn{3}{|c|}{$\begin{array}{l}\text { Efeito principal entre os grupos } \\
\text { (valor de } \mathrm{p})\end{array}$} \\
\hline & & & & $\begin{array}{c}\text { Não } \\
\text { ajustado }\end{array}$ & $\begin{array}{c}\text { Modelo } \\
1 \\
\end{array}$ & $\begin{array}{c}\text { Modelo } \\
2 \\
\end{array}$ \\
\hline $\begin{array}{l}\text { Variabilidade do tempo } \\
\text { da passada }\end{array}$ & $2.00 \pm 0.9$ & $2.21 \pm 0.7$ & $2.33 \pm 1.3$ & .067 & .283 & .293 \\
\hline $\begin{array}{l}\text { Variabilidade do } \\
\text { comprimento do passo }\end{array}$ & $3.05 \pm 1.4^{\mathrm{a}}$ & $3.22 \pm 0.8^{\mathrm{b}}$ & $4.72 \pm 2.2$ & .000 & .010 & .041 \\
\hline
\end{tabular}

Modelo 1: ajuste por sexo, idade, altura, peso, quantidade de medicamentos, MEEM, número de quedas, SPPB; Modelo 2: ajustes do modelo $1+$ anos de estudo

a, diferença significativa entre os grupos IDH-baixo e IDH- muito alto; $b$, diferença significativa entre os grupos IDH-alto e IDH-muito alto;

\subsection{Custo da dupla-tarefa na marcha nos grupos por IDH}

As projeções gráficas do desempenho da marcha na condição de dupla-tarefa para velocidade, comprimento do passo e da variabilidade do comprimento do passo são apresentadas na figura 5 .

O teste ANOVA one-way mostrou efeito principal entre os grupos no modelo não ajustado para o custo da dupla-tarefa na marcha para todas as variáveis, exceto largura do passo. Quando a análise foi ajustada no modelo 1, o efeito principal entre os grupos permaneceu significativo para velocidade $\left(\mathrm{F}_{2,340}=3,4 ; \mathrm{p}=, 033\right)$, comprimento do passo $\left(\mathrm{F}_{2,340}=4,3 ; \mathrm{p}=, 014\right)$ e variabilidade do comprimento do passo $\left(\mathrm{F}_{2,335}=5,8 ; \mathrm{p}=, 003\right)$. No modelo 2 (ajustes do modelo1 + anos de estudo), o efeito principal entre os grupos permaneceu significativo para as mesmas variáveis: velocidade $\left(\mathrm{F}_{2}, 338=2,9 ; \mathrm{p}=, 050\right)$, comprimento do passo $\left(\mathrm{F}_{2}, 338=4,3 ; \mathrm{p}=, 015\right)$ e variabilidade do comprimento do passo $\left(\mathrm{F}_{2,338}=4,7 ; \mathrm{p}=, 010\right)$. Comparações pareadas ajustadas por correções de Bonferroni mostraram que os indivíduos do grupo IDH-muito alto apresentaram menor custo da 
dupla tarefa na marcha para velocidade e comprimento do passo e para variabilidade do comprimento do passo em comparação com ambos os grupos IDH-baixo e IDH-alto. Não foi encontrado diferença estatística entre os grupos IDH-baixo e IDH-alto para o custo da dupla-tarefa.

Os dados das análises do custo da dupla-tarefa na marcha nos três grupos são apresentados na tabela 7 .
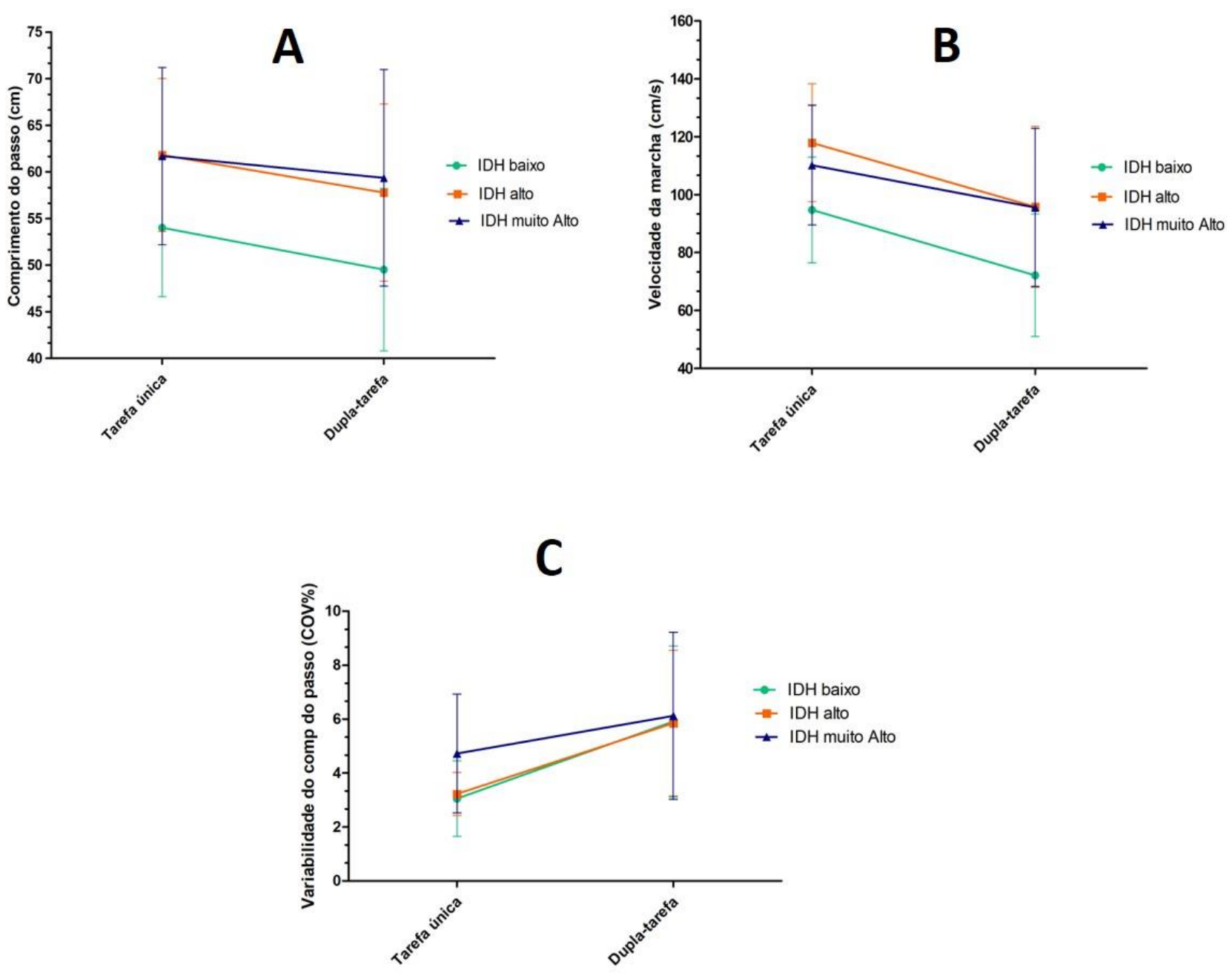

Figura 5 - Representação gráfica do desempenho da marcha dos grupos na caminhada habitual (tarefa única) e em condição de dupla-tarefa. A, comprimento do passo; B, velocidade da marcha; e C, variabilidade do comprimento do passo 
Tabela 7 - Dados do desempenho da marcha na condição de dupla-tarefa e o custo da dupla-tarefa na marcha entre os grupos por IDH

\begin{tabular}{|c|c|c|c|c|c|c|c|}
\hline \multirow{2}{*}{ Variáveis } & & \multirow{2}{*}{$\begin{array}{c}\begin{array}{c}\text { IDH-baixo } \\
\mathrm{n}=124\end{array} \\
\text { Média } \pm \mathrm{DP}\end{array}$} & \multirow{2}{*}{$\begin{array}{c}\begin{array}{c}\text { IDH-alto } \\
\mathrm{n}=109\end{array} \\
\text { Média } \pm \mathrm{DP}\end{array}$} & \multirow{2}{*}{$\begin{array}{c}\text { IDH-muito alto } \\
\mathrm{n}=140\end{array}$} & \multicolumn{3}{|c|}{$\begin{array}{l}\text { Efeito principal entre os grupos (valor } \\
\text { de p) }\end{array}$} \\
\hline & & & & & $\begin{array}{c}\text { Não } \\
\text { ajustado }\end{array}$ & Modelo 1 & Modelo 2 \\
\hline \multirow{2}{*}{$\begin{array}{l}\text { Velocidade } \\
(\mathrm{cm} / \mathrm{s})\end{array}$} & Dupla-tarefa & $72,16 \pm 21,2$ & $95,79 \pm 27,8$ & $95,61 \pm 27,3$ & & & \\
\hline & Custo da dupla-tarefa & $-24,25 \pm 14,6^{\mathrm{a}, \mathrm{b}}$ & $-19,46 \pm 14,7$ & $-13,98 \pm 15,1$ & $<, 001$ &, 033 &, 050 \\
\hline \multirow[t]{2}{*}{$\begin{array}{l}\text { Cadência } \\
\text { (passos/min) }\end{array}$} & Dupla-tarefa & $86,59 \pm 18,1$ & $98,44 \pm 18,0$ & $95,44 \pm 16,4$ & & & \\
\hline & Custo da dupla-tarefa & $-17,50 \pm 13,1$ & $-14,05 \pm 31,0$ & $-10,45 \pm 12,0$ & $<, 001$ & ,293 & ,413 \\
\hline \multirow[t]{2}{*}{$\begin{array}{l}\text { Tempo da passada } \\
\text { (millisec) }\end{array}$} & Dupla-tarefa & $1459 \pm 0,3$ & $1261 \pm 0,3$ & $1298 \pm 0,2$ & & & \\
\hline & Custo da dupla-tarefa & $24,32 \pm 21.5$ & $16.30 \pm 16.9$ & $13.58 \pm 16.6$ & $<.001$ & .543 & .484 \\
\hline \multirow{2}{*}{$\begin{array}{l}\text { Comprimento do } \\
\text { passo } \\
(\mathrm{cm})\end{array}$} & Dupla-tarefa & $49,52 \pm 8,7$ & $57,78 \pm 9,5$ & $59,37 \pm 11,6$ & & & \\
\hline & Custo da dupla-tarefa & $-8,76 \pm 8,3^{a, b}$ & $-6,69 \pm 7,3$ & $-4,13 \pm 8,5$ & $<, 001$ & ,014 &, 015 \\
\hline \multirow{2}{*}{$\begin{array}{l}\text { Largura da passada } \\
(\mathrm{cm})\end{array}$} & Dupla-tarefa & $8,42 \pm 3,5$ & $8,95 \pm 2,9$ & $8,43 \pm 3,9$ & & & \\
\hline & Custo da dupla-tarefa & $4,99 \pm 22,7$ & $3,20 \pm 21,1$ & $2,52 \pm 51,5$ & ,927 &, 881 & ,928 \\
\hline \multirow{2}{*}{$\begin{array}{l}\text { Variabilidade do } \\
\text { tempo da passada } \\
\text { (COV\%) }\end{array}$} & Dupla-tarefa & $4,87 \pm 3,4$ & $4,07 \pm 2,4$ & $4,19 \pm 3,3$ & & & \\
\hline & Custo da dupla-tarefa & $139,55 \pm 132,4$ & $94,53 \pm 119,2$ & $86,44 \pm 133,3$ &, 003 &, 747 &, 922 \\
\hline $\begin{array}{l}\text { Variabilidade do } \\
\text { comprimento do } \\
\text { passo } \\
(\mathrm{COV} \%)\end{array}$ & $\begin{array}{l}\text { Dupla-tarefa } \\
\text { Custo da dupla-tarefa }\end{array}$ & $\begin{array}{c}5,91 \pm 2,8 \\
113,16 \pm 101,9^{a, b}\end{array}$ & $\begin{array}{c}5,85 \pm 2,7 \\
92,18 \pm 84,4^{\mathrm{c}}\end{array}$ & $\begin{array}{c}6,12 \pm 3,1 \\
43,11 \pm 74,7\end{array}$ &, 000 & ,003 & ,010 \\
\hline
\end{tabular}

Modelo 1: ajuste por sexo, idade, altura, peso, quantidade de medicamentos, MEEM, número de quedas, SPPB; Modelo 2: ajustes do modelo 1 + anos de estudo a, diferença significativa entre os grupos IDH-baixo e IDH-alto; b, diferença significativa entre os grupos IDH-baixo e IDH-muito alto; c, diferença significativa entre os grupos IDH-alto e IDH-muito alto 


\section{Discussão}




\section{DISCUSSÃO}

Este estudo avaliou o desempenho da marcha e o custo da marcha na dupla-tarefa de idosos de regiões com diferentes IDH's no continente americano. Pelo conhecimento da revisão sistemática de literatura realizada até o momento da escrita desta tese, esse é o primeiro estudo que buscou comparar o desempenho da marcha de indivíduos idosos expostos a diferentes IDH's em um desenho transversal multi-país.

Os resultados mostraram evidências robustas de que idosos de uma região com baixo IDH podem apresentar pior desempenho da marcha, identificado por menor velocidade, menor cadência, maior tempo da passada, menor comprimento do passo e menor largura da passada comparados aos indivíduos que passaram sua vida vivendo em regiões com IDH alto ou muito alto. Esse pior desempenho da macha foi mantido até mesmo quando as variáveis de confusão, incluindo os anos de estudo, foram ajustados ao modelo estatístico. Esses resultados confirmaram a primeira hipótese deste estudo. Por outro lado, curiosamente a análise da variabilidade da marcha demonstrou que os idosos do grupo IDH-muito alto apresentaram uma maior flutuação dos passos identificada pelo comprimento do passo comparado aos idosos brasileiros dos dois grupos, IDH-baixo e IDH-alto.

Foi observado um maior custo da marcha na dupla-tarefa para velocidade, comprimento do passo e variabilidade do comprimento do passo entre idosos da região com baixo IDH comparados aos idosos que viviam nas regiões com alto e muito alto IDH. Essa diferença permaneceu até mesmo quando se ajustou o modelo estatístico à vários fatores de confusão, confirmando parcialmente a segunda hipótese. Além disso, essas diferenças no custo da marcha na dupla-tarefa para a velocidade da marcha foram 
fortemente influenciadas pela regulação do comprimento do passo, mas não pelo tempo da passada. É importante ressaltar também que as diferenças estatísticas entre esses grupos foram profundamente atenuadas, embora não tenham desparecido, após o ajuste por anos de educação.

Nesse estudo, o grupo IDH-baixo apresentou o pior desempenho da marcha, incluindo velocidade mais lenta, cadência mais lenta, maior tempo da passada, menor comprimento do passo e menor largura da passada. Embora poucos estudos tenham avaliado a relação entre determinantes socioeconômicos e outras variáveis espaçotemporais da marcha além da velocidade, existem evidências na literatura demonstrando que a cadência e o comprimento da passada podem ser afetados por componentes individuais das dimensões do IDH. Por exemplo, um estudo (Brown et al., 2014) encontrou que a capacidade de caminhar a uma cadência $\geq 100$ passos/min podem reduzir em $21 \%$ a mortalidade por todas as causas. Outro estudo (Woo et al., 1999) avaliou o comprimento da passada de 2032 idosos, demonstrando que o menor comprimento da passada estava significativamente associado ao aumento do risco de mortalidade, dependência funcional e institucionalização. É importante destacar que a velocidade é altamente correlacionada com as sub variáveis da marcha, incluindo cadência e o comprimento do passo, e, portanto, ela (velocidade da marcha) pode ser responsável por grande parte das alterações nessas variáveis.

Em relação à análise da variabilidade da marcha, a maior flutuação do comprimento do passo entre os idosos do grupo IDH-muito alto pode explicar o maior relato de histórico e número de quedas nos últimos seis meses encontrados nesse grupo. A variabilidade da marcha quantifica a magnitude da flutuação dos passos, e o aumento 
dessas flutuações pode indicar instabilidade, e consequentemente predispor os idosos a maior chance de cair (Hausdorff, Rios, \& Edelberg, 2001; Paterson, Hill, \& Lythgo, 2011). De fato, a variabilidade da marcha tem sido considerada um preditor independente de múltiplas quedas e incapacidades funcionais entre os idosos que vivem na comunidade (Callisaya et al., 2011; Paterson et al., 2011). Além disso, os resultados do SPPB complementam essas informações. Embora a média no desempenho do SPPB para os três grupos tenha permanecido acima do limiar de incapacidade considerado pelo seu escore (abaixo de 7 pontos sugere probabilidade de incapacidade), os idosos do grupo IDHbaixo apresentaram melhor desempenho nesse teste $($ escore $=10,53)$ em comparação com os idosos do grupo IDH-muito alto (escore $=9,32$ ). É possível sugerir uma hipótese explicativa para esses resultados. Coari é uma cidade localizada no interior do estado do Amazonas, e como a maioria das cidades dessa região, apresenta características peculiares como dificuldade de acesso e locomoção intermunicipais (deslocamento são possíveis principalmente pelos rios, através de barcos e muitas vezes por pequenas canoas, chamadas de rabetas) e estrutura urbana precária. Como as cidades do Amazonas são cercadas e interconectadas pelos rios Negro e Solimões, a maioria da população idosa que reside no interior do estado, vive ou já viveu em algum momento da sua vida em comunidades ao longo da margem dos rios, as chamadas "comunidades ribeirinhas". Essa exposição a fatores de riscos externos característicos dessa região vivenciadas por décadas pelos idosos poderiam levá-los à possíveis adaptações orgânicas e funcionais às situações de desequilíbrio.

Estudos recentes (Freire Junior et al., 2018; Maia Ribeiro et al., 2013) sugerem que condições ambientais e atividades cotidianas desses idosos que residem no interior do 
Amazonas poderiam influenciar positivamente no equilíbrio e no desempenho funcional. Assim, o estilo de vida e as condições ambientais provavelmente contribuem para a manutenção da força e função dos membros inferiores, bem como um nível mais alto de atividade física (Maia Ribeiro et al., 2013). Por outro lado, é possível que, devido a iniquidades socioeconômicas e eventos adversos característicos de regiões com baixo IDH, essa influência no equilíbrio e no desempenho funcional não reflita necessariamente no melhor estado geral de saúde dos idosos. Essa hipótese, apesar de razoável para ser considerada, é necessário estudos complementares prospectivos futuros para entender melhor esse fenômeno. Assim, de acordo com os resultados desta tese, a variabilidade da marcha estaria mais relacionada com os eventos de quedas e estabilidade postural, enquanto as variáveis espaço-temporais da marcha habitual, bem como o paradigma da dupla-tarefa poderiam explicar melhor as iniquidades socioeconômicas entre as regiões com diferentes IDH's.

Estudos prévios já debatem sobre o uso de diferentes variáveis da marcha na identificação de diferentes desfechos específicos. Por exemplo, a velocidade de marcha pode refletir eventos relacionados à pior estado de saúde (Abellan Van Kan et al., 2009), declínio da função cognitiva (Callisaya et al., 2015), mortalidade (White et al., 2013), enquanto outros estudos têm demonstrado que a variabilidade da marcha pode ser um melhor preditor para quedas (Callisaya et al., 2011; Paterson et al., 2011). Por outro lado, entender como as variáveis da marcha são associadas a esses fenômenos tem sido um desafio (Hollman, McDade, \& Petersen, 2011).

Considerando o desempenho da marcha encontrado no presente estudo, a possível razão para as diferenças observadas entre os grupos poderia ser atribuída a insultos 
sofridos nas funções orgânicas durante o curso de vida. Determinantes socioeconômicos como menor escolaridade e menor renda ( $\varnothing$ vrum, Gustavsen, \& Rickertsen, 2014) podem afetar potencialmente o estilo de vida dos indivíduos, com consequências importantes para os diferentes sistemas orgânicos. Diversas condições de saúde podem ser influenciadas por adversidades sociais, e estudos anteriores tem demonstrado alguns desfechos de saúde, como por exemplo fragilidade (Alvarado et al., 2008; Gruenewald et al., 2009) e sarcopenia (Sayer \& Cooper, 2006), como consequências dessa exposição a longo prazo a condições socioeconômicas desfavoráveis. Nessa mesma direção, apoiando os resultados deste estudo, a revisão sistemática desenvolvida como parte do material desta tese e publicada recentemente (Freire Júnior, Pieruccini-Faria, \& Montero-Odasso, 2018), encontrou evidências robustas de que iniquidades relacionadas aos determinantes socioeconômicos que compõem as dimensões do IDH (educação, renda e variáveis relacionadas à expectativa de vida) estão associadas ao baixo desempenho da marcha no final da vida. Além disso, dimensões mais baixas do IDH estavam associadas a uma velocidade de marcha mais lenta, passos mais curtos e maiores flutuações da passada (i.e., variabilidade) entre os idosos. Esses resultados juntos, corroboram com as suposições desta tese de que o desempenho da marcha em idosos pode ser fortemente prejudicado por exposições a longo prazo nas regiões com baixo IDH, mas não em regiões com alto ou muito IDH.

É importante notar, no entanto, que quando os modelos estatísticos foram ajustados por vários fatores de confusão, incluindo anos de estudo, as diferenças entre os grupos foram atenuadas no custo da marcha na dupla-tarefa. Isto sugere que poucos anos de estudo podem ter um impacto deletério no desempenho da marcha no final da vida. 
Embora não tenha sido possível controlar a influência da renda mensal nas diferenças estatísticas devido a limitações metodológicas, sabe-se que a educação desempenha um papel fundamental em outros aspectos socioeconômicos (Brunello et al., 2016; Hahn \& Truman, 2015). Espera-se que indivíduos com maiores níveis de educação tomem melhores decisões sobre estilos de vida (p.ex., tabagismo, serviços médicos, atividades físicas, nutrição), os quais têm implicações positivas para a saúde na velhice (Busch et al., 2015). Como já destacado anteriormente nesta tese, o efeito protetor a longo prazo da educação sobre a integridade orgânica pode ser observado também na velocidade da marcha devido à sua relação robusta com vários eventos adversos e comorbidades (Manuel Montero-Odasso et al., 2005), incluindo a integridade neurológica (Srikanth et al., 2010).

As diferenças no desempenho da marcha relacionadas à educação, encontradas neste estudo, podem ser explicadas por dois fatores principais considerando as discussões na literatura (Lenehan, Summers, Saunders, Summers, \& Vickers, 2015; Welmer et al., 2013) e também na revisão sistemática desenvolvida (Freire Júnior et al., 2018): dano periférico/físico e a reserva cognitiva (capacidade central). Indivíduos com menos anos de estudo podem ocupar empregos que exigem mais esforços físicos extenuantes do que intelectuais. As ocupações manuais, como carregar cargas pesadas, realizar trabalhos repetitivos, ou mesmo realizar atividades de agricultura, são mais propensas a serem ocupadas por indivíduos com níveis educacionais mais baixos, e a exposição a esse tipo de ocupação por muitos anos pode ter consequências negativas para a integridade física. Neste estudo, é improvável que a função física tenha contribuído para as diferenças de desempenho da marcha, pois embora os idosos do grupo IDH-baixo tenham apresentado 
desempenho no SPPB estatisticamente melhor do que o grupo IDH-muito alto (tabela 2), isso não foi refletido na marcha.

Em relação aos níveis de escolaridade, existe evidência robusta (Tucker \& Stern, 2011) corroborando com a ideia de que a educação tem um impacto positivo na cognição em níveis neurais, o que sugere que indivíduos que alcançaram maior nível educacional acumulam reserva cognitiva no final da vida. A reserva cognitiva, por sua vez, se traduz na capacidade de usar os recursos cerebrais disponíveis para atingir objetivos externos que é análogo à cognição de ordem superior, incluindo funções executivas (Tucker \& Stern, 2011). A solução de problemas e a estimativa de perigos, como parte das funções executivas, são os domínios cognitivos mais comumente associados à disfunção da marcha, e seu declínio ao longo do tempo tem sido associado à deterioração do desempenho da marcha, incluindo lentidão e comprimento de passos mais curtos, independentemente do comprometimento cognitivo basal (Cohen, Verghese, \& Zwerling, 2016; Manuel Montero-Odasso et al., 2012). Portanto, o alto custo da marcha na duplatarefa encontrado no grupo IDH-baixo sustenta a noção de que a natureza dos problemas da marcha entre os grupos experimentais deste estudo está associada à redução das capacidades centrais, e não das capacidades periféricas/físicas.

Uma importante limitação deste estudo é a falta de informações sobre renda do grupo IDH-muito alto, o que impede de afirmar que a educação é o principal determinante das diferenças no desempenho da marcha para pessoas expostas a ambientes com diferentes IDH's. Assim, as conclusões sobre a influência negativa de aspectos socioeconômicos, relacionados ao baixo IDH, sobre um pior desempenho da marcha devem ser tomadas com cautela. 


\section{Conclusão}




\section{CONCLUSÃO}

Em conclusão, indivíduos que vivem em regiões com baixo IDH apresentam pior desempenho da marcha em comparação com indivíduos que vivem em regiões com IDH alto ou muito alto. Anos de educação são um potencial mediador de deficiências da marcha na velhice, por limitação da capacidade de processamento central dos idosos, o que pode afetar o desempenho da marcha e as habilidades de multitarefa. Este estudo contribui para o campo da gerontologia, demonstrando a importância dos fatores socioeconômicos para o curso de mobilidade e independência dos idosos. No campo da saúde pública, a ideia da marcha como um marcador complementar possibilita conhecer o impacto dos aspectos sociais individuais relacionados ao IDH no estado de saúde da população. Esse conhecimento é relevante para se entender melhor a simbiose entre um indivíduo e o ambiente no qual ele viveu ao longo dos anos. 


\section{Referências}




\section{REFERÊNCIAS}

Abellan Van Kan, G., Rolland, Y., Andrieu, S., Bauer, J., Beauchet, O., Bonnefoy, M., ... Vellas, B. (2009). Gait speed at usual pace as a predictor of adverse outcomes in community-dwelling older people an International Academy on Nutrition and Aging (IANA) task force. Journal of Nutrition, Health and Aging, 13(10), 881-889. https://doi.org/10.1007/s12603-009-0246-z

Alvarado, B. E., Zunzunegui, M.-V., Béland, F., \& Bamvita, J.-M. (2008). Life course social and health conditions linked to frailty in Latin American older men and women. The Journals of Gerontology. Series A, Biological Sciences and Medical Sciences, 63(12), 1399-1406. Retrieved from http://www.ncbi.nlm.nih.gov/pubmed/19126855

Arnau, A., Espaulella, J., Méndez, T., Serrarols, M., Canudas, J., Formiga, F., \& Ferrer, M. (2016). Lower limb function and 10-year survival in population aged 75 years and older. Family Practice, 33(1), 10-16. https://doi.org/10.1093/fampra/cmv088

Avlund, K., Damsgaard, M. T., \& Osler, M. (2004). Social position and functional decline among non-disabled old men and women. European Journal of Public Health, 14(2), 212-216. Retrieved from http://www.ncbi.nlm.nih.gov/pubmed/15230514

Bertolucci, P. H., Brucki, S. M., Campacci, S. R., \& Juliano, Y. (1994). O Mini-Exame do Estado Mental em uma popula????o geral. Impacto da escolaridade. Arquivos de Neuro-Psiquiatria, 52(1), 1-7. https://doi.org/10.1590/S0004-282X1994000100001

Bez, J. P. de O., \& Neri, A. L. (2014). [Gait speed, grip strength and self-rated health 
among the elderly: data from the FIBRA Campinas network, São Paulo, Brazil]. Ciência \& Saúde Coletiva, 19(8), 3343-3353. https://doi.org/10.1590/141381232014198.09592013

Brown, J. C., Harhay, M. O., \& Harhay, M. N. (2014). Walking cadence and mortality among community-dwelling older adults. Journal of General Internal Medicine, 29(9), 1263-1269. https://doi.org/10.1007/s11606-014-2926-6

Brown, P. J., Roose, S. P., Zhang, J., Wall, M., Rutherford, B. R., Ayonayon, H. N., ... Yaffe, K. (2016). Inflammation, Depression, and Slow Gait: A High Mortality Phenotype in Later Life. Journals of Gerontology - Series A Biological Sciences and Medical Sciences, 71(2), 221-227. https://doi.org/10.1093/gerona/glv156

Brunello, G., Fort, M., Schneeweis, N., \& Winter-Ebmer, R. (2016). The Causal Effect of Education on Health: What is the Role of Health Behaviors? Health Economics, 25(3), 314-336. https://doi.org/10.1002/hec.3141

Brunner, E., Shipley, M., Spencer, V., Kivimaki, M., Chandola, T., Gimeno, D., ... Marmot, M. (2009). Social inequality in walking speed in early old age in the Whitehall II study. J Gerontol A Biol Sci Med Sci, 64(10), 1082-1089. https://doi.org/glp078 [pii]ไr10.1093/gerona/glp078 [doi]

Busch, T. de A., Duarte, Y. A., Pires Nunes, D., Lebrão, M. L., Satya Naslavsky, M., dos Santos Rodrigues, A., \& Amaro, E. (2015). Factors associated with lower gait speed among the elderly living in a developing country: a cross-sectional population-based study. BMC Geriatrics, 15(1), 35. https://doi.org/10.1186/s12877-015-0031-2

Callisaya, M. L., Blizzard, C. L., Wood, A. G., Thrift, A. G., Wardill, T., \& Srikanth, V. K. (2015). Longitudinal Relationships Between Cognitive Decline and Gait 
Slowing: The Tasmanian Study of Cognition and Gait. The Journals of Gerontology Series A: Biological Sciences and Medical Sciences, 70(10), 1226-1232. https://doi.org/10.1093/gerona/glv066

Callisaya, M. L., Blizzard, L., Schmidt, M. D., Martin, K. L., McGinley, J. L., Sanders, L. M., \& Srikanth, V. K. (2011). Gait, gait variability and the risk of multiple incident falls in older people: a population-based study. Age and Ageing, 40(4), 481-487. https://doi.org/10.1093/ageing/afr055

Census. (2016). Statistics canada - Technical Report. Retrieved September 13, 2018, from https://www12.statcan.gc.ca/census-recensement/index-eng.cfm?HPA=1

Cesari, M., Kritchevsky, S. B., Newman, A. B., Simonsick, E. M., Harris, T. B., Penninx, B. W., ... Pahor, M. (2009). Added value of physical performance measures in predicting adverse health-related events: results from the Health, Aging And Body Composition Study. J Am Geriatr.Soc., 57(1532-5415 (Electronic)), 251-259.

Cesari, M., Onder, G., Zamboni, V., Manini, T., Shorr, R. I., Russo, A., ... Landi, F. (2008). Physical function and self-rated health status as predictors of mortality: results from longitudinal analysis in the ilSIRENTE study. BMC Geriatrics, 8, 34 . https://doi.org/10.1186/1471-2318-8-34

Cesari, M., Pahor, M., Marzetti, E., Zamboni, V., Colloca, G., Tosato, M., ... Markides, K. (2009). Self-assessed health status, walking speed and mortality in older Mexican-Americans. Gerontology, 55(2), 194-201. https://doi.org/10.1159/000174824

Cohen, J. A., Verghese, J., \& Zwerling, J. L. (2016). Cognition and gait in older people. Maturitas, 93, 73-77. https://doi.org/10.1016/j.maturitas.2016.05.005 
Cooke, M., Guimond, E., \& McWhirter, J. (2008). The changing well-being of older adult Registered Indians: an analysis using the registered Indian Human Development Index. Canadian Journal on Aging, 27(4), 385-397 13p. https://doi.org/10.3138/cja.27.4.385

Coppin, A. K., Ferrucci, L., Lauretani, F., Phillips, C., Chang, M., Bandinelli, S., \& Guralnik, J. M. (2006). Low Socioeconomic Status and Disability in Old Age: Evidence From the InChianti Study for the Mediating Role of Physiological Impairments. The Journals of Gerontology Series A: Biological Sciences and Medical Sciences, 61(1), 86-91. https://doi.org/61/1/86 [pii]

Costa-Font, J., \& Hern??ndez-Quevedo, C. (2012). Measuring inequalities in health: What do we know? What do we need to know? Health Policy. https://doi.org/10.1016/j.healthpol.2012.04.007

Dumith, S. C., Hallal, P. C., Reis, R. S., \& Kohl, H. W. (2011). Worldwide prevalence of physical inactivity and its association with human development index in 76 countries. Preventive Medicine, 53(1-2), 24-28. https://doi.org/10.1016/j.ypmed.2011.02.017

Dumurgier, J., Elbaz, A., Ducimetière, P., Tavernier, B., Alpérovitch, A., \& Tzourio, C. (2009). Slow walking speed and cardiovascular death in well functioning older adults: prospective cohort study. BMJ (Clinical Research Ed.), 339, b4460. https://doi.org/10.1136/bmj.b4460

Freire, A. N., Guerra, R. O., Alvarado, B., Guralnik, J. M., \& Zunzunegui, M. V. (2012). Validity and Reliability of the Short Physical Performance Battery in Two Diverse Older Adult Populations in Quebec and Brazil. Journal of Aging and Health, 24(5), 
863-878. https://doi.org/10.1177/0898264312438551

Freire Junior, R. C., Fernandes, T. G., Borges, G. F., Guerra, R. O., \& de Abreu, D. C. C. (2018). Factors associated with low levels of physical activity among elderly residents in a small urban area in the interior of the Brazilian Amazon. Archives of Gerontology and Geriatrics, 75. https://doi.org/10.1016/j.archger.2017.11.007

Freire Júnior, R. C., Pieruccini-Faria, F., \& Montero-Odasso, M. (2018). Are Human Development Index dimensions associated with gait performance in older adults? A systematic review. Experimental Gerontology. https://doi.org/10.1016/j.exger.2017.12.001

Fritz, S., \& Lusardi, M. (2009). Walking speed: the sixth vital sign. Journal of Geriatric Physical Therapy, 32(2), 1-5. https://doi.org/10.1519/00139143-200932020-00002

Gerstorf, D., Ram, N., Goebel, J., Schupp, J., Lindenberger, U., \& Wagner, G. G. (2010). Where people live and die makes a difference: Individual and geographic disparities in well-being progression at the end of life. Psychology and Aging, 25(3), 661-676. https://doi.org/10.1037/a0019574

Gomes, G. de C., Teixeira-Salmela, L. F., Fonseca, B. E., Freitas, F. A. S. de, Fonseca, M. L. M., Pacheco, B. D., ... Caramelli, P. (2015). Age and education influence the performance of elderly women on the dual-task Timed Up and Go test. Arquivos de Neuro-Psiquiatria, 73(3), 187-193. https://doi.org/10.1590/0004-282X20140233

Gruenewald, T. L., Seeman, T. E., Karlamangla, A. S., \& Sarkisian, C. A. (2009). Allostatic Load and Frailty in Older Adults. Journal of the American Geriatrics Society, 57(9), 1525-1531. https://doi.org/10.1111/j.1532-5415.2009.02389.x Guralnik, J. M., Simonsick, E. M., Ferrucci, L., Glynn, R. J., Berkman, L. F., Blazer, D. 
G., ... Wallace, R. B. (1994). A Short Physical Performance Battery Assessing Lower Extremity Function: Association With Self-Reported Disability and Prediction of Mortality and Nursing Home Admission. Journal of Gerontology, 49(2), M85-M94. https://doi.org/10.1093/geronj/49.2.M85

Gutierrez-Misis, A., Sanchez-Santos, M. T., Banegas, J. R., Castell, M. V, GonzalezMontalvo, J. I., \& Otero, A. (2015). Walking speed and high blood pressure mortality risk in a Spanish elderly population. J Hum Hypertens, 29(9), 566-572. https://doi.org/10.1038/jhh.2015.32

Hahn, R. A., \& Truman, B. I. (2015). Education Improves Public Health and Promotes Health Equity. International Journal of Health Services : Planning, Administration, Evaluation, 45(4), 657-678. https://doi.org/10.1177/0020731415585986

Hall, C. D., Echt, K. V, Wolf, S. L., \& Rogers, W. A. (2011). Cognitive and motor mechanisms underlying older adults' ability to divide attention while walking. Physical Therapy, 91(7), 1039-1050. https://doi.org/10.2522/ptj.20100114

Hardy, S. E., Perera, S., Roumani, Y. F., Chandler, J. M., \& Studenski, S. A. (2007). Improvement in usual gait speed predicts better survival in older adults. Journal of the American Geriatrics Society, 55(11), 1727-1734. https://doi.org/10.1111/j.15325415.2007.01413.x

Hausdorff, J. M., Rios, D. A., \& Edelberg, H. K. (2001). Gait variability and fall risk in community-living older adults: a 1-year prospective study. Archives of Physical Medicine and Rehabilitation, 82(8), 1050-1056. https://doi.org/10.1053/apmr.2001.24893

Hollman, J. H., McDade, E. M., \& Petersen, R. C. (2011). Normative spatiotemporal gait 
parameters in older adults. Gait \& Posture, 34(1), 111-118.

https://doi.org/10.1016/j.gaitpost.2011.03.024

Idland, G., Engedal, K., \& Bergland, A. (2013). Physical performance and 13.5-year mortality in elderly women. Scand J Public Health, 41(1), 102-108. https://doi.org/10.1177/1403494812466460

Instituto Brasileiro de Geografia e Estatística. IBGE. (2011). Banco de dados: cidades@ . Retrieved October 9, 2017, from http://www.ibge.gov.br/cidadesat/topwindow.htm?1

Jancova-Vseteckova, J., Bobak, M., Kubinova, R., Capkova, N., Peasey, A., Marmot, M. G., \& Pikhart, H. (2015). Social patterning in grip strength, chair rise, and walk speed in an aging population: The Czech HAPIEE study. Journal of Aging and Physical Activity, 23(2), 264-271. https://doi.org/10.1123/japa.2013-0142

Kuh, D., Ben-Shlomo, Y., Lynch, J., Hallqvist, J., \& Power, C. (2003). Life course epidemiology. Journal of Epidemiology and Community Health, 57(10), 778-783. https://doi.org/10.1136/JECH.57.10.778

Lenehan, M. E., Summers, M. J., Saunders, N. L., Summers, J. J., \& Vickers, J. C. (2015). Relationship between education and age-related cognitive decline: a review of recent research. Psychogeriatrics, 15(2), 154-162. https://doi.org/10.1111/psyg.12083

Lord, S., Howe, T., Greenland, J., Simpson, L., \& Rochester, L. (2011). Gait variability in older adults: a structured review of testing protocol and clinimetric properties. Gait \& Posture, 34(4), 443-450. https://doi.org/10.1016/j.gaitpost.2011.07.010 Maia Ribeiro, E. A., Ribeiro, E. E., Viegas, K., Teixeira, F., Dos Santos Montagner, G. F. 
F., Mota, K. M., ... De Paz, J. A. (2013). Functional, balance and health determinants of falls in a free living community Amazon riparian elderly. Archives of Gerontology and Geriatrics, 56(2), 350-357.

https://doi.org/10.1016/j.archger.2012.08.015

Medina Gonzalez, P. (2016). Linear variability of gait according to socioeconomic status in elderly. Colombia Medica (Cali, Colombia), 47(2), 94-99.

Moher, D., Liberati, A., Tetzlaff, J., \& Altman, D. G. (2014). Preferred Reporting Items for Systematic Reviews and Meta-Analyses : Annals of Internal Medicine, 151(2), 264-269. https://doi.org/10.1371/journal.pmed1000097

Montero-Odasso, M., Muir, S. W., Hall, M., Doherty, T. J., Kloseck, M., Beauchet, O., \& Speechley, M. (2011). Gait Variability Is Associated With Frailty in Communitydwelling Older Adults. The Journals of Gerontology Series A: Biological Sciences and Medical Sciences, 66A(5), 568-576. https://doi.org/10.1093/gerona/glr007

Montero-Odasso, M., Muir, S. W., \& Speechley, M. (2012). Dual-task complexity affects gait in people with mild cognitive impairment: The interplay between gait variability, dual tasking, and risk of falls. Archives of Physical Medicine and Rehabilitation, 93(2), 293-299. https://doi.org/10.1016/j.apmr.2011.08.026

Montero-Odasso, M., Oteng-Amoako, A., Speechley, M., Gopaul, K., Beauchet, O., Annweiler, C., \& Muir-Hunter, S. W. (2014). The motor signature of mild cognitive impairment: Results from the gait and brain study. Journals of Gerontology - Series A Biological Sciences and Medical Sciences, 69(11), 1415-1421. https://doi.org/10.1093/gerona/glu155

Montero-Odasso, M., Schapira, M., Soriano, E. R., Varela, M., Kaplan, R., Camera, L. a, 
\& Mayorga, L. M. (2005). Gait velocity as a single predictor of adverse events in healthy seniors aged 75 years and older. The Journals of Gerontology. Series A, Biological Sciences and Medical Sciences, 60(10), 1304-1309. https://doi.org/10.1093/gerona/60.10.1304

National Heart, Blood and Lung Institute [NIH]. Quality Assessment Tool for Observational Cohort and Cross-Sectional Studies. (2014).

Nofuji, Y., Shinkai, S., Taniguchi, Y., Amano, H., Nishi, M., Murayama, H., ... Suzuki, T. (2016). Associations of Walking Speed, Grip Strength, and Standing Balance With Total and Cause-Specific Mortality in a General Population of Japanese Elders. Journal of the American Medical Directors Association, 17(2), 184.e1184.e7. https://doi.org/10.1016/j.jamda.2015.11.003

Øvrum, A., Gustavsen, G. W., \& Rickertsen, K. (2014). Age and socioeconomic inequalities in health: Examining the role of lifestyle choices. Advances in Life Course Research, 19, 1-13. https://doi.org/10.1016/J.ALCR.2013.10.002

Parihar, R., Mahoney, J. R., \& Verghese, J. (2013). Relationship of Gait and Cognition in the Elderly. Current Translational Geriatrics and Experimental Gerontology Reports, 2(3), 167-173. https://doi.org/10.1007/s13670-013-0052-7

Paterson, K., Hill, K., \& Lythgo, N. (2011). Stride dynamics, gait variability and prospective falls risk in active community dwelling older women. Gait \& Posture, 33(2), 251-255. https://doi.org/10.1016/j.gaitpost.2010.11.014

Perera, S., Studenski, S., Chandler, J. M., \& Guralnik, J. M. (2005). Magnitude and patterns of decline in health and function in 1 year affect subsequent 5-year survival. J Gerontol A Biol Sci Med Sci, 60(7), 894-900. 
https://doi.org/10.1093/gerona/60.7.894

Plouvier, S., Carton, M., Cyr, D., Sabia, S., Leclerc, A., Zins, M., \& Descatha, A. (2016). Socioeconomic disparities in gait speed and associated characteristics in early old age. BMC Musculoskeletal Disorders, 17(1), 178. https://doi.org/10.1186/s12891016-1033-8

Quiben, M. U., \& Hazuda, H. P. (2015). Factors Contributing to 50-ft Walking Speed and Observed Ethnic Differences in Older Community-Dwelling Mexican Americans and European Americans. Physical Therapy, 95(6), 871-883.

https://doi.org/10.2522/ptj.20140152

Richter, M., \& Blane, D. (2013). The life course: challenges and opportunities for public health research. International Journal of Public Health, 58(1), 1-2. https://doi.org/10.1007/s00038-012-0436-Z

Rolland, Y., Lauwers-Cances, V., Cesari, M., Vellas, B., Pahor, M., \& Grandjean, H. (2006). Physical performance measures as predictors of mortality in a cohort of community-dwelling older French women. Eur J Epidemiol, 21(2), 113-122. https://doi.org/10.1007/s10654-005-5458-x

Rosa, N. M. de B., de Queiroz, B. Z., Pereira, D. S., di Sabatino Santos, M. L. A., Oliveira, D. M. G., Narciso, F. M. e S., \& Pereira, L. S. M. (2011). Interleukin-6 plasma levels and socioeconomic status in Brazilian elderly community-dwelling women. Archives of Gerontology and Geriatrics, 53(2), 196-199. https://doi.org/10.1016/j.archger.2010.10.022

Rosano, C., Newman, A. B., Katz, R., Hirsch, C. H., \& Kuller, L. H. (2008). Association between lower digit symbol substitution test score and slower gait and greater risk of 
mortality and of developing incident disability in well-functioning older adults. Journal of the American Geriatrics Society, 56(9), 1618-1625.

https://doi.org/10.1111/j.1532-5415.2008.01856.x

Sabia, S., Dumurgier, J., Tavernier, B., Head, J., Tzourio, C., \& Elbaz, A. (2014). Change in fast Walking speed preceding death: Results from a prospective longitudinal cohort study. Journals of Gerontology - Series A Biological Sciences and Medical Sciences, 69 A(3), 354-362. https://doi.org/10.1093/gerona/glt114

Sayer, A. A., \& Cooper, C. (2006). Aging, sarcopenia and the life-course. Reviews in Clinical Gerontology, 16(04), 265-274.

https://doi.org/10.1017/S0959259807002225

Soares, G. P., Klein, C. H., Silva, N. A. de S. e, \& Oliveira, G. M. M. de. (2016). Progression of Mortality due to Diseases of the Circulatory System and Human Development Index in Rio de Janeiro Municipalities. Arquivos Brasileiros de Cardiologia. https://doi.org/10.5935/abc.20160141

Sousa, A. C. P. D. A., Guerra, R. O., Tu, M. T., Phillips, S. P., Guralnik, J. M., \& Zunzunegui, M. V. (2014). Lifecourse adversity and physical performance across countries among men and women aged 65-74. PLoS ONE, 9(8), e102299. https://doi.org/10.1371/journal.pone.0102299

Srikanth, V., Sanders, L., Callisaya, M., Martin, K., \& Phan, T. (2010). Brain aging and gait. Aging Health. https://doi.org/10.2217/ahe.09.79

Studenski, S., Perera, S., Patel, K., Rosano, C., Faulkner, K., Inzitari, M., ... Guralnik, J. (2011). Gait speed and survival in older adults. JAMA : The Journal of the American Medical Association, 305(1), 50-58. https://doi.org/10.1001/jama.2010.1923 
Tabue-Teguo, M., Le Goff, M., Avila-Funes, J. A., Frison, E., Helmer, C., F??art, C., ... Dartigues, J. F. (2015). Walking and psychomotor speed in the elderly: Concordance, correlates and prediction of death. Journal of Nutrition, Health and Aging, 19(4), 468-473. https://doi.org/10.1007/s12603-014-0560-y

Taekema, D. G., Gussekloo, J., Westendorp, R. G., de Craen, A. J., \& Maier, A. B. (2012). Predicting survival in oldest old people. Am J Med, 125(12), 1188-1194 e1. https://doi.org/10.1016/j.amjmed.2012.01.034

Thorpe, R. J., Koster, A., Kritchevsky, S. B., Newman, A. B., Harris, T., Ayonayon, H. N., ... Simonsick, E. M. (2011). Race, socioeconomic resources, and late-life mobility and decline: Findings from the health, aging, and body composition study. Journals of Gerontology - Series A Biological Sciences and Medical Sciences, 66 A(10), 1114-1123. https://doi.org/10.1093/gerona/glr102

Toots, A., Rosendahl, E., Lundin-Olsson, L., Nordstrom, P., Gustafson, Y., \& Littbrand, H. (2013). Usual gait speed independently predicts mortality in very old people: a population-based study. J Am Med Dir Assoc, 14(7), 529 e1-6. https://doi.org/10.1016/j.jamda.2013.04.006

Tu, M. T., Zunzunegui, M.-V., Guerra, R., Alvarado, B., \& Guralnik, J. M. (2013). Cortisol profile and depressive symptoms in older adults residing in Brazil and in Canada. Aging Clinical and Experimental Research, 25(5), 527-537. https://doi.org/10.1007/s40520-013-0111-0

Tucker, A. M., \& Stern, Y. (2011). Cognitive reserve in aging. Current Alzheimer Research, 8(4), 354-360. https://doi.org/10.2174/1567211212225912050

Uguccioni, J. (2016). The Human Development Index in Canada: Ranking the Provinces 
and Territories Internationally, 2000-2014. Centre for the Study of Living Standards, 2016-14. Retrieved from http://www.csls.ca/reports/csls2016-14.pdf

United Nations Development Programme. (2013). The Human Development Atlas in Brazil. Retrieved October 17, 2017, from http://atlasbrasil.org.br/2013/en/

United Nations Development Programme. (2016). Technical notes - HDI. Retrieved from http://hdr.undp.org/sites/default/files/hdr2016_technical_notes_0.pdf

United Nations Development Programme. (2018). Human Development Indices and Indicators 2018 Statistical Update. Retrieved from http://www.hdr.undp.org/sites/default/files/2018_human_development_statistical_u pdate.pdf

United Nations Development Programme - UNDP. (2016). Retrieved from http://hdr.undp.org/en/content/human-development-index-hdi

Weber, D. (2016). Differences in physical aging measured by walking speed: evidence from the English Longitudinal Study of Ageing. BMC Geriatrics, 16, 31. https://doi.org/10.1186/s12877-016-0201-x

Weidung, B., Bostr??m, G., Toots, A., Nordstr??m, P., Carlberg, B., Gustafson, Y., \& Littbrand, H. (2015). Blood pressure, gait speed, and mortality in very old individuals: A population-based cohort study. Journal of the American Medical Directors Association, 16(3), 208-214. https://doi.org/10.1016/j.jamda.2014.09.004

Welmer, A.-K., Kareholt, I., Rydwik, E., Angleman, S., \& Wang, H.-X. (2013).

Education-related differences in physical performance after age 60: a cross-sectional study assessing variation by age, gender and occupation. Bmc Public Health, 13, 641. https://doi.org/10.1186/1471-2458-13-641 
White, D. K., Neogi, T., Nevitt, M. C., Peloquin, C. E., Zhu, Y., Boudreau, R. M., ... Zhang, Y. (2013). Trajectories of gait speed predict mortality in well-functioning older adults: the Health, Aging and Body Composition study. The Journals of Gerontology. Series A, Biological Sciences and Medical Sciences, 68(4), 456-464. https://doi.org/10.1093/gerona/gls197

Woo, J., Ho, S. C., \& Yu, A. L. (1999). Walking speed and stride length predicts 36 months dependency, mortality, and institutionalization in Chinese aged 70 and older. Journal of the American Geriatrics Society, 47(10), 1257-1260.

Woolford, M. H., Weller, C., \& Ibrahim, J. E. (2017). Unexplained Absences and Risk of Death and Injury Among Nursing Home Residents: A Systematic Review. Journal of the American Medical Directors Association. https://doi.org/10.1016/j.jamda.2017.01.007

Zaninotto, P., Sacker, A., \& Head, J. (2013). Relationship between wealth and age trajectories of walking speed among older adults: evidence from the English Longitudinal Study of Ageing. The Journals of Gerontology. Series A, Biological Sciences and Medical Sciences, 68(12), 1525-1531.

https://doi.org/10.1093/gerona/glt058 
Apêndices 


\section{APÊNDICE 1- Termo de Consentimento Livre e Esclarecido}

\section{TERMO DE CONSENTIMENTO LIVRE E ESCLARECIDO}

Convidamos o (a) Sr (a) para participar da Pesquisa: A Influência do contexto sociocultural e demográfico no controle postural e marcha de idosos residentes em municípios brasileiros com diferentes índices de desenvolvimento humano", sob a responsabilidade do pesquisador Msc. Renato Campos Freire Júnior.

Sua participação é voluntária e se dará por meio de repostas a uma entrevista com um conjunto de perguntas, após essa entrevista, e caso seja selecionado o $\mathrm{Sr}$ (a) será convidado a participar da segunda fase, a qual constará de avaliações específicas de saúde em laboratórios do Instituto de Saúde e Biotecnologia (ISB-Coari) da Universidade Federal do Amazonas (UFAM) em dias previamente agendados e no Laboratório de Avaliação e Reabilitação do Equilíbrio - LARE do Departamento de Fisioterapia da Faculdade de Medicina de Ribeirão Preto - FMRP/USP.

Os principais riscos decorrentes de sua participação na pesquisa estão na segunda fase. A execução dos testes que envolvem esforço físico pode suscitar sensação de fadiga ou respostas fisiológicas indesejadas; caso isso aconteça os testes serão interrompidos e o(a) $\operatorname{Sr}(a)$ receberá devido atendimento. Se você aceitar participar, estará contribuindo para um melhor conhecimento da saúde dos idosos da região e que pode servir como base para o planejamento de políticas públicas voltadas a esta população.

Se depois de consentir em sua participação o(a) $\operatorname{Sr}(a)$ desistir de continuar participando, tem o direito e a liberdade de desistir em qualquer fase da pesquisa, independente do motivo e sem nenhum prejuízo a sua pessoa. $\mathrm{O}(\mathrm{a}) \operatorname{Sr}(a)$ não terá nenhuma despesa e também não receberá nenhuma remuneração. Os resultados da pesquisa serão analisados e publicados, mas sua identidade não será divulgada, sendo guardada em sigilo.

Para qualquer outra informação, o(a) $\mathrm{Sr}(\mathrm{a})$ poderá entrar em contato com o pesquisador no endereço em Coari: Instituto de Saúde e Biotecnologia da Universidade Federal do Amazonas-UFAM na estrada Coarí-Mamiá, no 305, Espírito Santo, CoariAmazonas- CEP: 69460-000, pelo telefone (97) 3561-2363. Caso o(a) Sr(a) resida em Ribeirão Preto poderá entrar em contato com os responsáveis pela pesquisa no endereço: Faculdade de Medicina de Ribeirão Preto-USP, Av. Bandeirantes, 3900, CEP 
14049-900, Curso de Fisioterapia, Tel:(16)3602-4585 ou ainda poderá entrar em contato com o Comitê de Ética em Pesquisa - CEP/UFAM, na Rua Teresina, 495, Adrianópolis, Manaus-AM, telefone (92) 3305-5130.

Consentimento Pós-Informação

$\mathrm{Eu}$, fui informado sobre o que o pesquisador quer fazer e porque precisa da minha colaboração, e entendi a explicação. Por isso, eu concordo em participar do projeto, sabendo que não vou ganhar nada e que posso sair quando quiser. Este documento é emitido em duas vias que serão ambas assinadas por mim e pelo pesquisador, ficando uma via com cada um de nós.

Assinatura do participante

Assinatura do Pesquisador Responsável

Data:

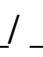

assinar)

Impressão do dedo polegar (caso não saiba 


\section{APÊNDICE 2 - Termos de pesquisa para revisão sistemática}

\begin{tabular}{|c|c|c|}
\hline CONCEPT & MeSH TERMS & KEYWORDS \\
\hline \multirow{10}{*}{ Human Development Index } & Income distribution [MeSH] & \\
\hline & OR Education $[\mathrm{MeSH}] \mathrm{OR}$ & \\
\hline & Life expectancy [MeSH] & \\
\hline & OR Mortality [MeSH] OR & Human development index \\
\hline & Survival analysis [MeSH] & OR HDI OR \\
\hline & OR Socioeconomic factors & Socioeconomic disparities \\
\hline & [MeSH] OR Cultural & health OR Social class \\
\hline & characteristics $[\mathrm{MeSH}] \mathrm{OR}$ & \\
\hline & Ethnology [MeSH] OR & \\
\hline & Social class $[\mathrm{MeSH}]$ & \\
\hline Elderly & $\begin{array}{c}\text { Aged }[\mathrm{MeSH}] \text { OR Aging } \\
{[\mathrm{MeSH}]}\end{array}$ & Older adults OR elderly \\
\hline \multirow{3}{*}{ Gait } & Gait [MeSH] OR Walking & \multirow{3}{*}{$\begin{array}{c}\text { Gait OR Physical } \\
\text { performance OR dual task }\end{array}$} \\
\hline & $\begin{array}{l}\text { [MeSH] OR locomotion } \\
\text { [MeSH] OR “Dual-task } \\
\text { performance (Test)" }\end{array}$ & \\
\hline & {$[\mathrm{MeSH}]$} & \\
\hline \multirow{5}{*}{ Study Design } & Prospective studies [MeSH] & \\
\hline & OR Cross-sectional studies & Observational study OR \\
\hline & [MeSH] OR Observational & Longitudinal study OR \\
\hline & Study $[\mathrm{MeSH}] \mathrm{OR}$ & Cross-sectional study \\
\hline & Longitunal study [MeSH] & \\
\hline
\end{tabular}




\section{APÊNDICE 3 - Estratégias de pesquisa para PubMed e EMBASE}

USING PUBMED DATABASE

1. Gait/ OR Walking/ OR Locomotion/

2. (Gait OR Physical performance OR dual task).ti,ab

3. Strategy 1 OR 2

4. Aged/ OR Aging/

5. (older adults OR elderly).ti,ab

6. Strategy 4 OR 5

7. (Human Development Index OR HDI OR Socioeconomic disparities health).ti.ab

8. Income distribution/ OR Education/ OR "Life expectancy (epidemiology)"/ OR

Mortality/ OR Survival analysis/ OR "Socioeconomic factors (epidemiology)"/ OR

Cultural characteristics/ OR Ethnology/ OR Social class/

9. Strategy 7 OR 8

10. Prospective studies/ OR Cross-sectional studies/

11. (Observational study).pt

12. (Longitudinal study OR cross sectional study).ti,ab

13. Strategy 10 OR 11 OR 12

14. Strategy 3 AND 6 AND 9 AND 13 
USING EMBASE DATABASE

1. Income/ OR Education/ OR Life expectancy/ OR Mortality/ OR Survival analysis/

OR Cultural factors/ OR Ethnology/

2. Socioeconomic.mp OR Socioeconomics/

3. Social class.mp OR Social class/

4. Human development index.mp

5. Strategy 1 OR 2 OR 3 OR 4

6. Aged/

7. Aging/ ep, et

8. Older adults.mp

9. Strategy 6 OR 7 OR 8

10. Gait.mp OR Gait/

11. Walking/ OR Locomotion

13. Physical performance.mp

14. Strategy 10 OR 11 OR 12 OR 13

15. Prospective study/

16. Cross-sectional study.mp OR Cross-sectional/

17. Observational study.mp OR Observational study/

18. Longitudinal study.mp OR Longitudinal study/

19. Strategy 15 OR 16 OR 17 OR 18

20. Strategy 5 AND 9 AND 14 AND 19 


\section{APÊNDICE 4 - Questionário Geral}

\section{QUESTIONÁRIO GERAL - IDENTIFICAÇÃO DE CONDIÇÕES SÓCIOECONÔMICAS, CULTURAIS, SAÚDE EM GERAL E HISTÓRIA DE QUEDAS}

\section{IDENTIFICAÇÃO}

Setor censitário: $\mathrm{N}^{\mathrm{o}}$ domicílio: $\mathrm{N}^{\mathrm{o}}$ questionário:

Entrevistador:

Data das visitas: $1^{\text {a }}$ )

Nome do entrevistado:

Endereço completo:

Ponto de referência do domicílio:

Telefones para contato/nome do contato:

UBS:

1. Entrevistado: 1. Idoso 2. Informante (especificar?

2. Data de nascimento do idoso:

3. Sexo: 1. Masculino 2. Feminino

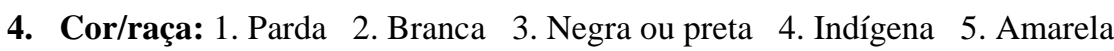

5. Quantos anos de estudo o(a) $\operatorname{Sr}(\mathbf{a})$ tem?

6. Sabe ler e escrever: 1 . Sim 2 . Não

7. Escolaridade:

1. Curso de alfabetização 2. Primário 3. Ginásio

4. Primeiro grau 5. Segundo grau (científico, técnico, normal) 6. Superior

8. Estado civil:

1. Casado(a) 2. Solteiro(a) 3. Separado(a)/divorciado(a)

$$
\text { 4. Viúvo(a) 5. Amasiado(a) }
$$

9. Naturalidade:

10. Ocupação/trabalho (atual):

11. Profissão Pregressa:

12. Religião: 1. Católico(a) 2. Evangélico(a) 3. Espírita $\quad$ 4. outras

13. Tipo de casa: 1 . Alvenaria 2 . Madeira

14. O senhor(a) já morou em comunidade ribeirinha (interior)?

1. Sim 2. Não (pule a questão 15)

15. Quanto tempo morou em comunidade ribeirinha? (anos)

16. Cuidador é uma pessoa que fica lhe ajudando nas suas atividades diárias, como tomar banho, vestirse, alimentar-se ou ajudar a tomar seus remédios, pagar contas, entre outras. $\mathrm{O}$ (a) $\operatorname{Sr}(a)$ tem cuidador?

1. Sim 2. Não (pule questão 18)

17. Quem é seu cuidador principal?

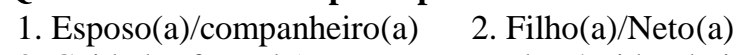

3. Cuidador formal (pessoa contratada p/cuidar do idoso) 4. Outros

5. Sem cuidador fixo

18. Com quem o senhor mora?

1. Só 2. Com o cônjuge 3. Com filhos 4. Com netos

5. Com outros de sua geração (irmã(o), cunhada(o), amigo(a))

6 . Somente com o cuidador profissional

19. Quantas pessoas moram na casa?

20. Qual a renda familiar mensal:
1. $<1$ salário
2. 1 a 2 salários
3. 3 a 5 salários
4. > 5 salários 
21. Quantas pessoas dependem dessa renda, incluindo o(a) $\operatorname{Sr}(a)$ ?

22. O Sr(a). considera ter dinheiro suficiente para suas necessidades diárias?

$$
\begin{array}{ll}
\text { 1. Sim 2. Não } & 0
\end{array}
$$

\section{SAÚDE E HÁBITOS DE VIDA}

23. Em geral, o(a) $\operatorname{Sr}(a)$. diria que sua saúde é:
1. Muito boa
2. Boa
3. Regular
4. Ruim
5. Muito ruim

24. Em comparação com a saúde de outras pessoas que o(a) $\operatorname{Sr}(a)$ conhece da sua idade, o(a) $\operatorname{Sr}(a)$ diria que sua saúde é:
1. Muito pior
2. Pior 3. Igual
4. Melhor 5. Muito melhor

25. O(a) Sr.(a) fuma ou fumou cigarros?

1. Não/nunca (pule para questão 31)

2. Fumou e parou (responde questões 26 a 28 e pula para a 31)

3. Fuma atualmente (pula para a questão 29)

26. Por quantos anos o(a) $\operatorname{Sr}($ a) fumou?

27. Quantos cigarros o(a) $\mathrm{Sr}$ (a) fumava por dia?

28. Há quantos anos o(a) $\operatorname{Sr}$ (a) parou de fumar?

29. Há quantos anos o(a) $\mathrm{Sr}$ (a) fuma?

30. Quantos cigarros o(a) $\operatorname{Sr}($ a) fuma por dia?

31. Com que frequiência o(a) $\operatorname{Sr}(a)$ toma bebidas alcoólicas?
0. Nunca (pule para questão 34 )
1. Mensalmente ou menos
2. De 2 a 4 vezes por mês
3. De 2 a 3 vezes por semana
4. 4 ou mais vezes por semana

32. Nas ocasiões em que bebe, quantas doses o(a) senhor(a) consome normalmente ao beber?
0 . 1 ou 2
1. 3 ou 4
2. 5 ou 6
3. 7,8 ou 9
4. 10 ou mais

33. Com que frequência o(a) senhor(a) toma "cinco ou mais doses" de uma vez?

0 . Nunca

1. Menos de uma vez por semana

2. Mensalmente3. Semanalmente 4. Todos ou quase todos os dias

Algum médico ou profissional de saúde já disse que o(a) $\operatorname{Sr}(a)$ tem alguma das condições abaixo

relacionados? (marque a(s) questão(ões) caso positiva(s))

34. Hipertensão arterial

35. Diabetes

36. Doença no coração (Qual?

37. Derrame ou AVC

38. Doença sexualmente transmissível

39. Doença pulmonar (Qual?

40. Câncer (Qual?

41. Osteoporose

42. Artrite, reumatismo ou artrose

43. Depressão

44. Demência

45. Úlcera gástrica

46. Outras condições ou deficiências

\section{MEDICAMENTOS}

47. $\mathrm{O}$ (a) $\mathrm{Sr}$ (a) está tomando algum medicamento?

1. Sim (preencher o quadro abaixo)

2. Não (pule o quadro abaixo)

\begin{tabular}{|l|l|l|l|}
\hline Motivo terapêutico & Nome genérico/comercial & Dose diária & Data início \\
\hline
\end{tabular}




\begin{tabular}{|l|l|l|l|}
\hline & & & \\
\hline & & & \\
\hline
\end{tabular}

48. Acontece com o $\mathrm{Sr}$ (a) de perder um pouco de urina e se molhar acidentalmente; seja porque não deu tempo de chegar ao banheiro, ou quando está dormindo; ou quando tosse ou espirra, ou faz força?

$\begin{array}{lll}\text { 1. Sim } & \text { 2. Não } \quad \text { 3ão sabe }\end{array}$

\section{SERVIÇOS DE SAÚDE}

49. Nos últimos seis meses, o (a) $\operatorname{Sr}(a)$ precisou se consultar com médico ou outro profissional da saúde? 1. Sim 2. Não

50. Qual o principal motivo pelo qual o (a) $\operatorname{Sr}($ a) procurou esse atendimento?

1. Acidente ou lesão

2. Doença

3. Para fazer consulta de rotina (ou Check-up)

4. Sintomas inespecíficos

5. Outros

51. Onde procurou esse atendimento?

1. Posto de saúde

2. Consultório particular

3. Ambulatório de hospital

4. Pronto- socorro ou emergência

5. Atendimento domiciliar

6. Outro

52. $\mathrm{O}$ (a) $\mathrm{Sr}$ (a) conseguiu ser atendido(a)?
1. Sim
2. Não

53. Qual o motivo?

54. Nos últimos 30 dias, o(a) $\mathrm{Sr}$ (a) recebeu a visita do agente comunitário de saúde do posto, sem contar o agente que faz a vistoria da dengue?
1. Sim
2. Não

\section{FADIGA}

55. Com que frequência na última semana o(a) Sr.(a) sentiu que tudo que fez exigiu um grande esforço?

1. Sempre

2. Na maioria das vezes

3. Poucas vezes

4. Nunca/raramente

56. Com que frequência na última semana o(a) Sr.(a) sentiu que não pôde fazer nada devido a cansaço?

1. Sempre

2. Na maioria das vezes

3. Poucas vezes

4. Nunca/raramente

\section{ALTERAÇÕES DO PESO}

57. Considerando os últimos 12 meses, o(a) $\operatorname{Sr}(a)$ ganhou peso?

$$
\begin{array}{lll}
\text { 1. Sim 2. Não } & \text { 3. Não sabe }
\end{array}
$$

58. Quantos quilos ganhou, aproximadamente?

59. Considerando os últimos 12 meses, o(a) $\operatorname{Sr}$ (a) perdeu peso involuntariamente?
1. Sim
2. Não
3. Não sabe

60. Quantos quilos perdeu, aproximadamente?

61. Teve perda de apetite? 

1. $\mathrm{Sim}$
2. Não
3. Não sabe

\section{ATIVIDADES DO DIA A DIA}

62. Qual o seu principal meio de locomoção?

1. a pé 2. motocicleta 3. Automóvel 4. Canoa, catraia ou barco 5. Transporte coletivo 6. Outro (

63. Com que frequência utiliza "transporte coletivo/moto-táxi" como meio de transporte?

1. Nunca

2. Poucas vezes 3. Quase todo dia 4. 1 ou mais vezes por dia

64. Onde o $\operatorname{Sr}($ a) dorme?

1. Em cama 2. Em rede 3. No chão 4. Outros

65. Participa de alguma atividade social?

1. Nenhuma

2. Igreja

3. Clube de idosos

4. Associação

5. Trabalho

6. Outras (Qual?

66. Com que frequência frequenta estes grupos?

1. Raramente

2. 1 vez por mês

3. 1 vez por semana

4. Mais de 2 vezes por semana

5. Quase todo dia

\section{HISTÓRIA DE QUEDAS}

67. Você já caiu no chão ou costuma cair (últimos 6 meses)?

$$
\text { 1. Sim 2. Não (responda as questões } 70 \text { e 71) }
$$

68. Local da queda

1. ambiente doméstico

2. ambiente externo

69. Período do dia em que ocorreu a última queda?

$$
\begin{array}{lll}
\text { 1. manhã } & \text { 2. Tarde } & \text { 3. noite }
\end{array}
$$

70. Apresenta "quase quedas"?

$$
\text { 1. sim 2. não }
$$

71. Ao realizar as atividades do dia a dia você tem medo de cair?
1. não tenho medo
2. Tenho pouco medo
3. Tenho medo moderado
4. Tenho muito medo

72. Quantas quedas você teve nos últimos 6 meses?

1. 1 Queda

2. 2 a 3 quedas

3. Mais de 3 quedas

73. Na última queda, o(a) $\operatorname{Sr}(a)$ precisou de ajuda para se levantar?
1. Sim
2. Não

74. Na última queda, o(a) $\operatorname{Sr}(a)$ demorou mais de 15 a 20 minutos para levantar-se?

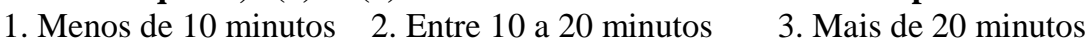

75. $\mathrm{O}(\mathrm{a}) \mathrm{Sr}(\mathrm{a})$ deixou de fazer alguma de suas atividades habituais por causa da última queda?
1. Sim
2. Não 
Anexos 


\section{ANEXO I - Aprovação do Comitê de Ética e Pesquisa}

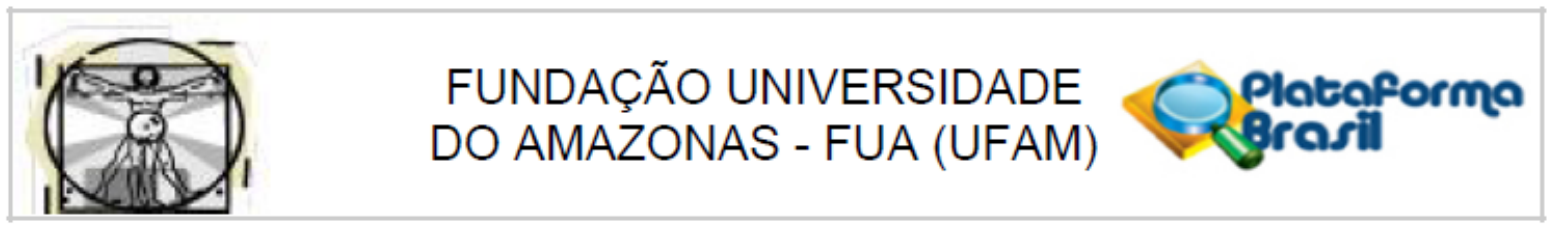

\section{PARECER CONSUBSTANCIADO DO CEP}

\section{DADOS DO PROJETO DE PESQUISA}

Título da Pesquisa: A influência do contexto sociocultural e demográfico no controle postural e marcha de idosos residentes no interior de dois estados brasileiros: Coari - AM e Ribeirão Preto $\mathrm{SP}$

Pesquisador: Renato Campos Freire Júnior

Área Temática:

Versão: 2

CAAE: 21609213.7.0000.5020

Instituição Proponente: Universidade Federal do Amazonas - UFAM

Patrocinador Principal: Financiamento Próprio

\section{DADOS DO PARECER}

Número do Parecer: 511.058

Data da Relatoria: 15/01/2014

\section{Apresentação do Projeto:}

Trata-se de um projeto de Doutorado.Nos idosos, em virtude das alterações fisiológicas do envelhecimento e até mesmo de sua maior predisposição a déficits funcionais, podem ser observados problemas na velocidade de resposta às informações sensoriais e nos recursos de atenção para a manutenção da estabilidade postural. Por isso, as tarefas que demandam atenção e que são realizadas simultaneamente a uma tarefa de equilibrio mostram efeitos deletérios sobre o controle postural em adultos mais velhos. Contudo, o processo de envelhecimento pode apresentar variações em sua concepção e vivência conforme a cultura, classe social, histórias de vida pessoais, condições educacionais, estilos de vida, gêneros, entre outros. Assim o presente estudo tem como objetivo

avaliar a influencia do contexto sócio-cultural e demográfico no controle postural e marcha entre idosos residentes no interior do Amazonas e no interior de São Paulo.

\section{Objetivo da Pesquisa:}

Objetivo Primário:

Avaliar a influencia do contexto sócio-cultural e demográfico no controle postural e marcha entre idosos residentes no interior do Amazonas e no interior de São Paulo

Objetivo Secundário: 


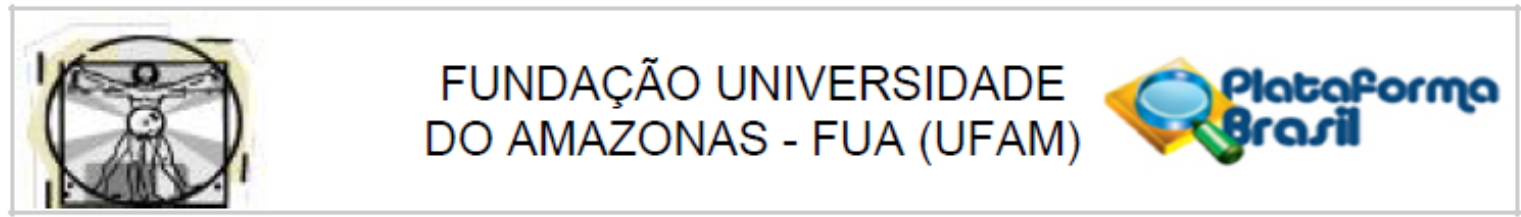

Continuação do Parecer: 511.058

- Identificar o perfil sócio-cultural e demográfico dos idosos das duas regiões estudadas;

- Conhecer o histórico de quedas e o medo de cair entre os idosos de Coari- AM e Ribeirão Preto - SP;

- Identificar e comparar fatores ambientais para queda no domicílio dos idosos residentes em Coari-AM e Ribeirão Preto-SP;

- Avaliar a marcha em 3 situações diferentes: marcha habitual, marcha associada a uma tarefa cognitiva e marcha associada a uma tarefa motora;

- Avaliar o nível de atividade física habitual dos idosos das duas regiões;

- Avaliar o controle postural dos idosos por meio da Short Physical Permormance Battery SPPB(GURALNIK, 1994);

- Avaliar força muscular de preensão palmar e de membro inferior

\section{Avaliação dos Riscos e Benefícios:}

Riscos e benefícios : adequados conforme a resolução 466/12

\section{Comentários e Considerações sobre a Pesquisa:}

A população a ser estudada será de indivíduos que possuam 60 anos ou mais no momento da coleta dos dados, residentes no município de Coari- AM e residentes no município de Ribeirão Preto-SP.¿A população a ser estudada será de indivíduos que possuam 60 anos ou mais no momento da coleta dos dados, residentes no município de Coari-AM e residentes no município de Ribeirão Preto-SP.

Os idosos voluntários residentes em Coari e em Ribeirão Preto serão selecionados por meio de convites em visitas domiciliares a partir dos setores censitários urbanos dos municípios, e distribuídas as visitas pelo mapa das duas cidades, segundo o Instituto Brasileiro de Geografia e Estatística (IBGE, 2010). ¿

\section{Considerações sobre os Termos de apresentação obrigatória:}

1-Folha de rosto: assinada pelo pesquisador e pelo diretor do ISB - Coari

2-Cronograma: adequado

3-Orçamento: adequado

4-TCLE: em forma de convite, com os devidos endereços do pesquisador em ambas as cidades inseridos.

5-Carta de Anuência: emitida pela coordenadora do Laboratório de de Avaliação e Reabilitação do Equilíbrio (LARE) da Faculdade de Medicina de Ribeirão Preto (FMRP)

Endereço: Rua Teresina, 4950

Bairro: Adrianópolis

UF: AM Município:

MANAUS CEP: $69.057-070$

Telefone: (92)3305-5130 Fax: (92)3305-5130 E-mail: cep@ufam.edu.br 


\section{FUNDAÇÃO UNIVERSIDADE DO AMAZONAS - FUA (UFAM)}

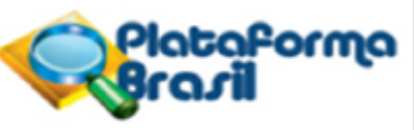

Continuação do Parecer: 511.058

6-Instrumentos de Coleta de dados: anexados

7- Termo de Anuência: o pesquisador esclareceu que o processo de seleção da amostra será em contato na residência dos idosos, seguindo o censo do IBGE 2010

\section{Recomendações:}

As alterações devem ser sempre retificadas no texto inserido na plataforma Brasil.

Conclusōes ou Pendências e Lista de Inadequações:

O pesquisador atendeu as pendências do parecer anterior e o projeto encontra-se em consonância com a resolução 466/12 do CNS.

Portanto, somos de parecer favorável pela aprovação.

Situação do Parecer:

Aprovado

Necessita Apreciação da CONEP:

Não

Considerações Finais a critério do CEP:

MANAUS, 15 de Janeiro de 2014

Assinador por:

MARIA EMILIA DE OLIVEIRA PEREIRA ABBUD

(Coordenador)

Endereço: Rua Teresina, 4950

Bairro: Adrianópolis

UF: AM

Município: MANAUS

CEP: $\quad 69.057-070$

Telefone: (92)3305-5130

Fax: $(92) 3305-5130$

E-mail: cep@ufam.edu.br 


\section{AVALIAÇÃo DO EQUILÍBRIO}

\section{Versão Brasileira da Short Physical Performance Battery- SPPB}

\section{1- Testes de equilíbrio:}

A) Posição com os pés juntos

A.1) Pontuação:

Manteve por 10 segundos

Não manteve por 10 segundos

Não tentou

Se pontuar 0 , encerre os Testes de equilíbrio e marque o motivo no quadro 1.

Tempo de exercução quando for menor que $10 \mathrm{seg}$ : segundos

B) Posição em pé com um pé parcialmente à frente

B.1) Pontuação

Manteve por 10 segundos

Não manteve por 10 segundos

Não tentou

Se pontuar 0, encerre os Testes de equilíbrio e marque o motivo no quadro 1. Tempo de execução quando for menor que 10 seg: segundos

C) Posição em pé com um pé à frente

C.1) Pontuação

Manteve por 10 segundos $\quad$ (2) pontos

Não manteve de 3 a 9,99 segundos (1) ponto

Manteve por menos de 3 segundo (0) ponto

Não tentou

(0) ponto

Se pontuar 0 , encerre os Testes de equilíbrio e marque o motivo no quadro 1. Tempo de execução quando for menor que $10 \mathrm{seg}$ : segundos

D) Pontuação total nos testes de equilíbrio: (soma dos pontos)

Quadro 1

Se o paciente não realizou o teste ou falhou, marque o motivo:

1) Tentou mas não conseguiu

2) O paciente não consegue manter-se na posição sem ajuda

3) Não tentou, o avaliador sentiu-se inseguro

4) Não tentou, o paciente sentiu-se inseguro

5) $O$ paciente não conseguiu entender as intruções.

6) Outros (Especifique): 
7) O paciente recusou participação.

\section{2) Teste de Velocidade de Marcha}

A) Primeira tentativa

Tempo da primeira tentativa

A. Tempo para 3 ou 4 metros: ___ ___ segundos

B. Se o paciente não realizou o teste ou falhou, marque o motivo:

1) Tentou, mas não conseguiu.

2) O paciente não consegue caminhar sem ajuda de outra pessoa.

3) Não tentou, o avaliador julgou inseguro.

4) Não tentou, o paciente sentiu-se inseguro.

5) O paciente não conseguiu entender as instruções.

6) Outros (Especifique):

7) O paciente recusou participação

C. Apoios para a primeira caminhada:

Nenhum ( ) bengala ( ) outro ( )

D. Se o paciente não conseguiu realizar a caminhada pontue:

( ) 0 ponto, e prossiga para o Teste de levantar da cadeira.

B) Segunda tentativa

Tempo da segunda tentativa

A. Tempo para 3 ou 4 metros: ___ ___ segundos

B. Se o paciente não realizou o teste ou falhou, marque o motivo:

1) Tentou, mas não conseguiu.

2) O paciente não consegue caminhar sem ajuda de outra pessoa.

3) Não tentou, o avaliador julgou inseguro.

4) Não tentou, o paciente sentiu-se inseguro.

5) O paciente não conseguiu entender as instruções.

6) Outros (Especifique):

7) O paciente recusou participação

C. Apoios para a primeira caminhada:

Nenhum ( ) bengala ( ) outro ( )

D. Se o paciente não conseguiu realizar a caminhada pontue:

( ) 0 ponto

PONTUAÇÃO DO TESTE DE VELOCIDADE DE MARCHA 
Extensão do teste de marcha: Quatro metros ( ) ou Três metros ( )

Qual foi o tempo mais rápido dentre as duas caminhadas?

Marque o menor dos dois tempos: segundos e utilize para pontuar.

( Se somente uma caminhada foi realizada, marque esse tempo) _______ segundos

Se o paciente não conseguiu realizar a caminhada: (0) ponto

Pontuação da caminhada de 3 metros:

Se o tempo for maior que 6,52 segundos: (1) ponto

Se o tempo for de 4,66 a 6,52 segundos: (2) pontos

Se o tempo for de 3,62 a 4,65 segundos: (3) pontos

Se o tempo for menor que 3,62 segundos: (4) pontos

Pontuação para a caminhada de 4 metros:

Se o tempo for maior que 8,70 segundos: (1) ponto

Se o tempo for de 6,21 a 8,70 segundos: (2) pontos

Se o tempo for de 4,82 a 6,20 segundos: (3) pontos

Se o tempo for menor que 4,82 segundos: (4) pontos

\section{3) Teste de levantar-se da cadeira}

3.1. Pré-teste: levantar-se da cadeira uma vez

Resultado do Pré-teste: levantar-se da cadeira uma vez

A. Levantou-se sem ajuda e com segurança:

Sim ( ) Não ( )

.O paciente levantou-se sem usar os braços

( ) Vá para o teste de levantar-se da cadeira 5 vezes.

.O paciente usou os braços para levantar-se

( ) Encerre o teste e pontue 0

.Teste não completado ou não realizado

( ) Encerre o teste e pontue 0

B. Se o paciente não realizou o teste ou falhou, marque o motivo:

1) Tentou, mas não conseguiu.

2) O paciente não consegue levantar-se da cadeira sem ajuda.

3) Não tentou, o avaliador julgou inseguro.

4) Não tentou, o paciente sentiu-se inseguro.

5) O paciente não conseguiu entender as instruções.

6) Outros (Especifique):

7) O paciente recusou participação

3.2. Teste de levantar-se da cadeira 5 vezes

Resultado do teste de levantar-se da cadeira cinco vezes

A.Levantou-se as cinco vezes com segurança: Sim () Não ()

B.Levantou-se as cinco vezes com êxito, registre o tempo: _______segundos 
C.Se o paciente não realizou o teste ou falhou, marque o motivo:

1) Tentou, mas não conseguiu.

2) O paciente não consegue levantar-se da cadeira sem ajuda.

3) Não tentou, o avaliador julgou inseguro.

4) Não tentou, o paciente sentiu-se inseguro.

5) O paciente não conseguiu entender as instruções.

6) Outros (Especifique):

7) O paciente recusou participação

\section{PONTUAÇÃO DO TESTE DE LEVANTAR-SE DA CADEIRA}

O participante não conseguiu levantar-se as 5 vezes, ou completou o teste em tempo maior que 60 segundos: (0) ponto

Se o tempo do teste for de 16,70 segundos ou mais: (1) ponto

Se o tempo do teste 13,70 a 16,69 segundos: (2) pontos

Se o tempo do teste for de 11,20 a 13,69 segundos: (3) pontos

Se o tempo do teste for de 11,19 segundos ou menos: (4) pontos

\section{PONTUAÇÃO COMPLETA PARA A VERSÃO BRASILEIRA DA SHORT PHYSICAL PERFORMANCE BATTERY-SPPB}

1. Pontuação total do teste de equilíbrio: pontos

2. Pontuação do teste de velocidade de marcha: pontos

3. Potuação do teste de levanter-se da cadeira: pontos

4. Pontuação total:___ pontos (some os pontos acima)

\section{CLASSIFICACÃ̃O}

\begin{tabular}{|l|l|}
\hline 0 a 3 pontos & Incapacidade ou desempenho ruim \\
\hline 4 a 6 pontos & Baixo desempenho \\
\hline 7 a 9 pontos & Moderado desempenho \\
\hline 10 a 12 pontos & Bom desempenho \\
\hline
\end{tabular}

